\title{
DOCUMENTATION OF UCODE, \\ A Computer Code for \\ Universal Inverse Modeling
}

\section{U.S. GEOLOGICAL SURVEY}

WATER-RESOURCES INVESTIGATIONS REPORT 98-4080

\section{UNIVERSAL -- USE WITH ANY MODEL}

Finite-Difference Models

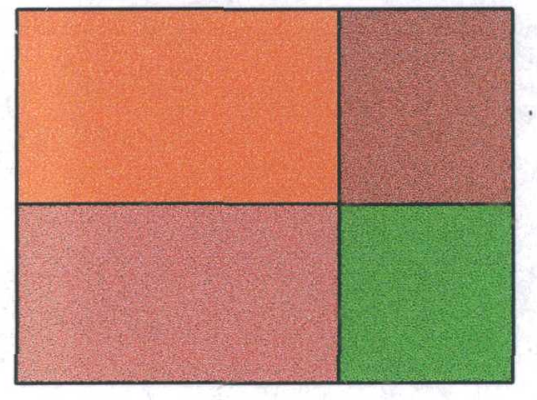

Finite-Element Models
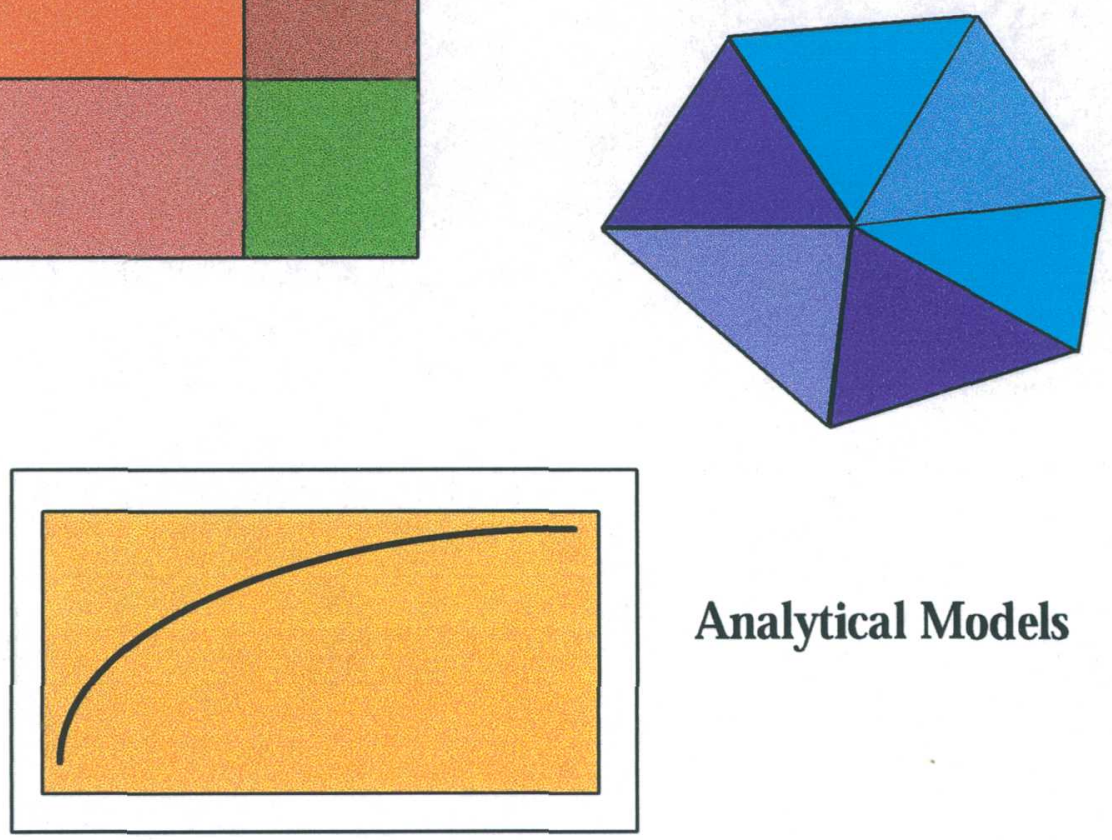

Analytical Models 


\section{DOCUMENTATION OF UCODE,}

\section{A Computer Code for}

Universal Inverse Modeling

By Eileen P. Poeter ${ }^{1}$ and Mary C. Hill ${ }^{2}$

1. International Ground Water Modeling Center of the Colorado School of Mines

2. U.S. Geological Survey

\section{U.S. GEOLOGICAL SURVEY}

WATER-RESOURCES INVESTIGATIONS REPORT 98-4080

Prepared in cooperation with the

U.S. Army Corps of Engineers Waterways Experiment Station and the International Ground Water Modeling Center of the Colorado School of Mines

Denver, Colorado

1998 


\section{U.S. DEPARTMENT OF THE INTERIOR \\ BRUCE BABBITT, Secretary \\ U.S. GEOLOGICAL SURVEY \\ Thomas J. Casadevall, Acting Director}

The use of trade, product industry, or firm names is for descriptive purposes only and does not imply endorsement by the U.S. Government.

For additional information write to:

Regional Research Hydrologist

U.S. Geological Survey

Box 25046, Mail Stop 413

Denver Federal Center

Denver, CO 50225-0046
Copies of this report can be

can be purchased from:

U.S. Geological Survey

Branch of Information Services

Box 25286

Denver, CO 50225-0425 


\section{PREFACE}

The computer code described in this report is designed to allow inverse modeling, posed as a parameter estimation problem, using existing application models. Although designed using ground-water models, the code can be used in conjunction with other application models that use ASCII or text only input, produce ASCII or text only output, and can be executed in batch mode. The performance of UCODE has been tested in a variety of applications. Future applications, however, might reveal errors that were not detected in the test simulations. Users are requested to notify the originating office of any errors found in the report or the computer program. Updates might occasionally be made to both the report and to UCODE. Users can check for updates on the Internet at URL http://water.usgs.gov/software/ground_water.html/. 


\section{CONTENTS}

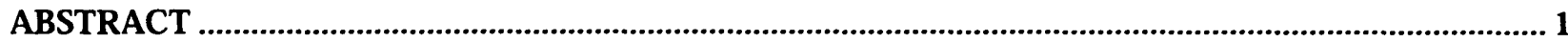

INTRODUCTION

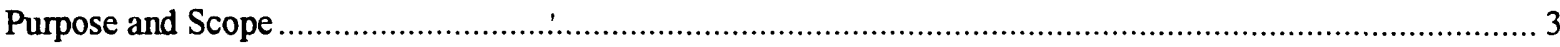

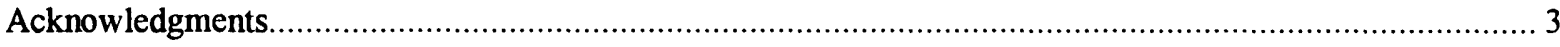

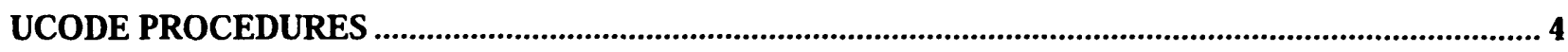

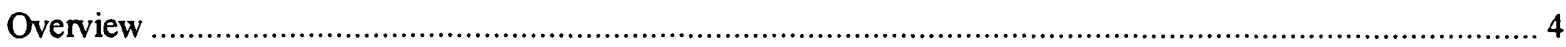

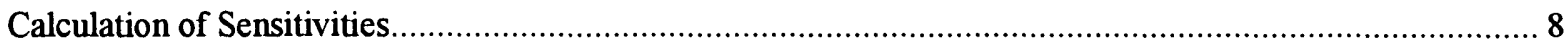

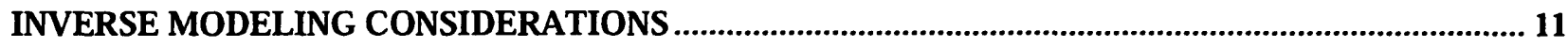

Guidelines for Effective Model Calibration and Analysis using Nonlinear Regression............................. 11

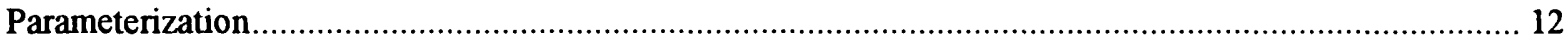

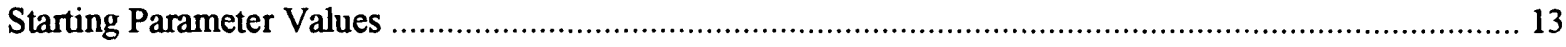

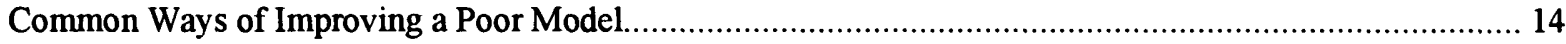

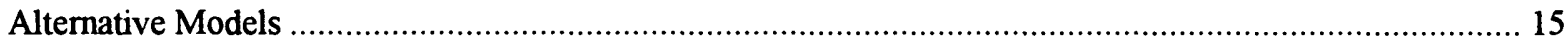

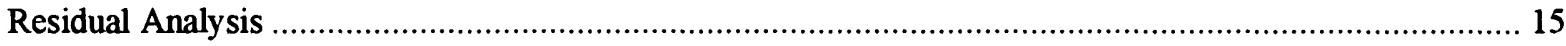

Predictions and Differences and Their Linear Confidence and Prediction Intervals ............................... 15

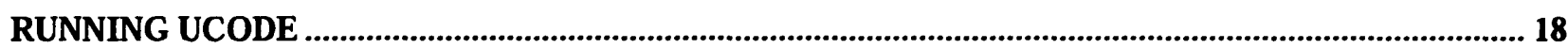

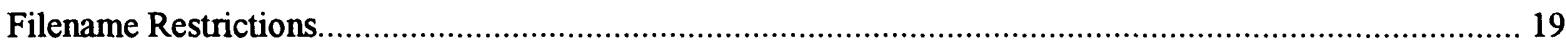

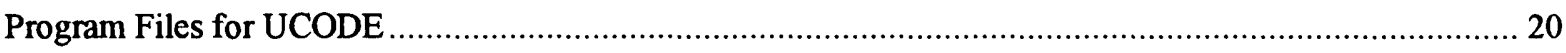

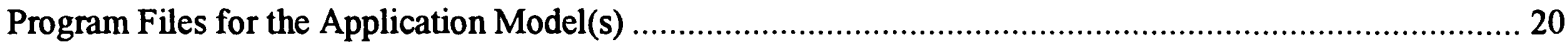

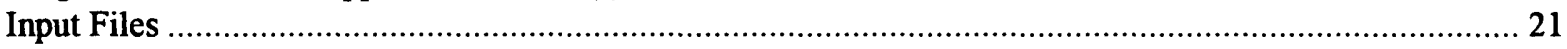

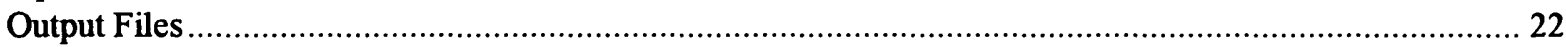

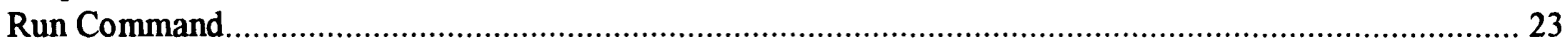

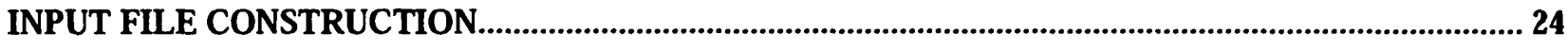

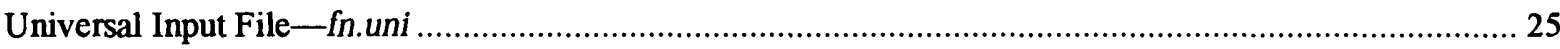

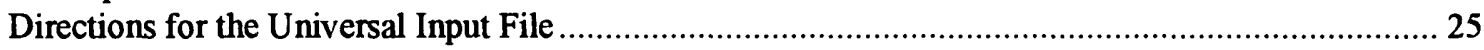

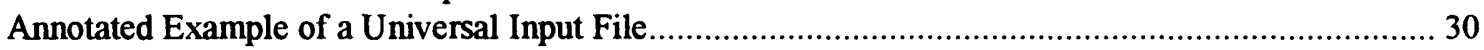

Prepare File—fn.pre, Template, and Function ( $f n . f n c)$ Files ..................................................... 30

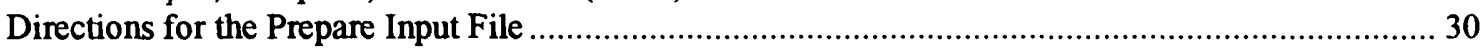

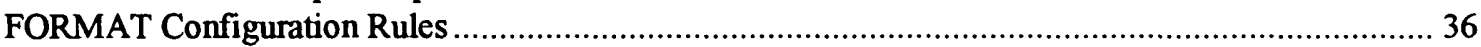

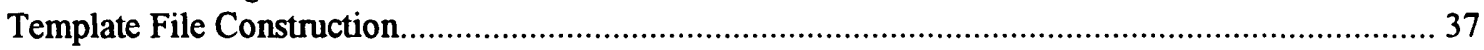

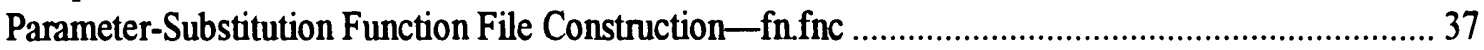

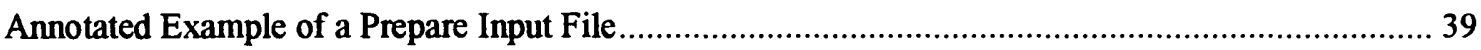

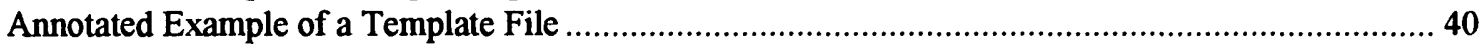

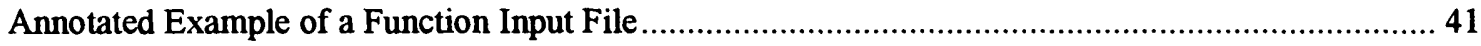

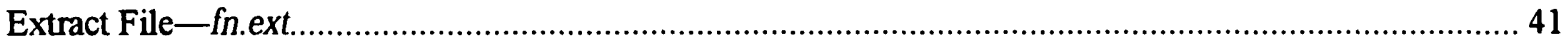

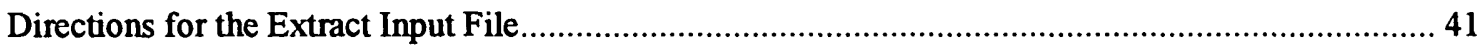

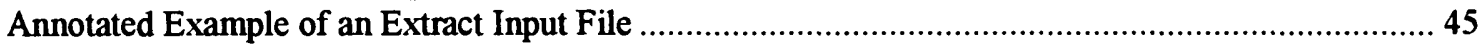

Input Files for Predictions and Differences and Linear Confidence and Prediction Intervals...................... 47

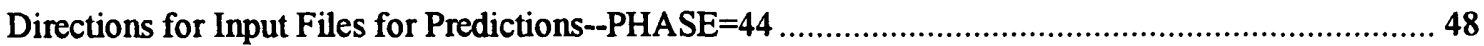

Directions for Input Files for Differences-PHASE=45 ......................................................... 49

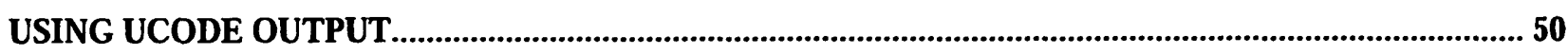

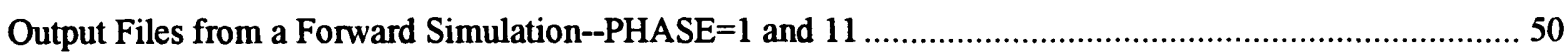

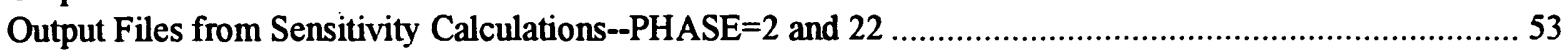

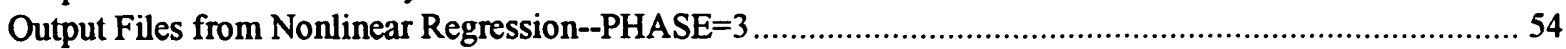




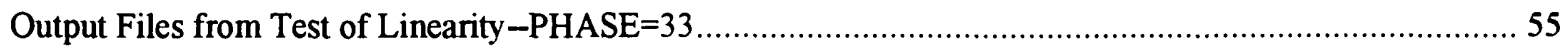

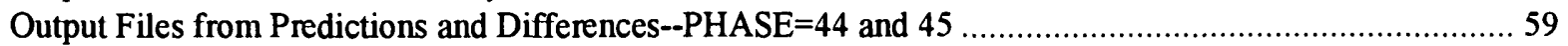

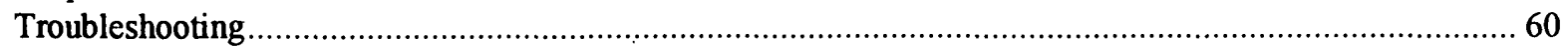

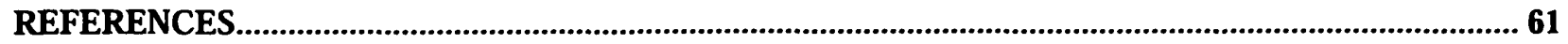

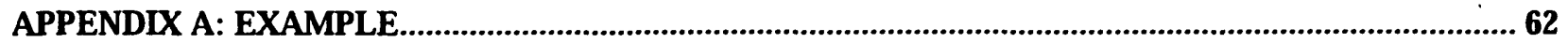

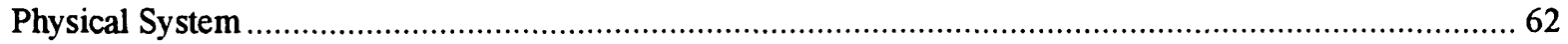

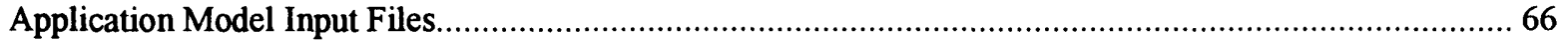

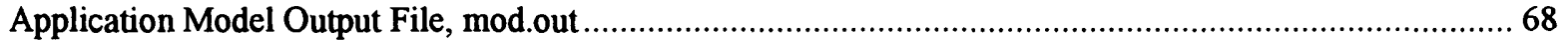

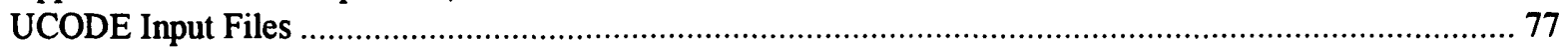

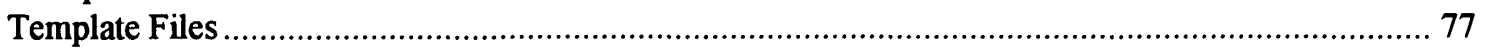

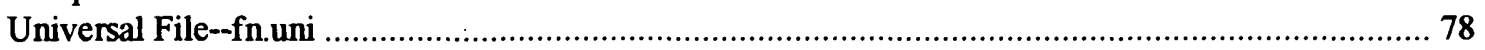

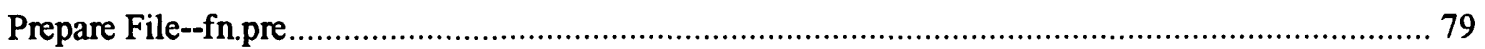

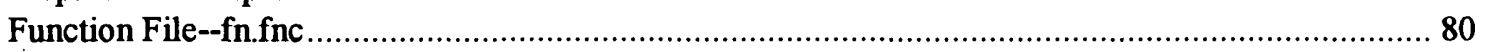

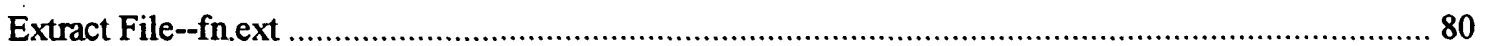

Input Files for Predictions and Their Confidence and Prediction Intervals--fn.u44 and fn.e45 ........... 81

Input Files for Differences and Their Confidence and Prediction Intervals--fn.u45 and fn.e45 .......... 83

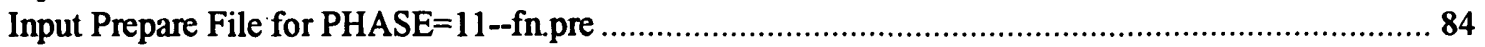

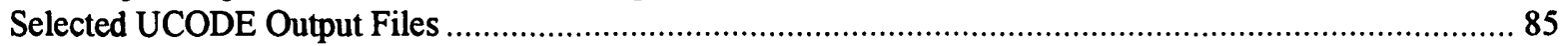

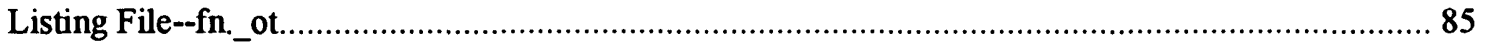

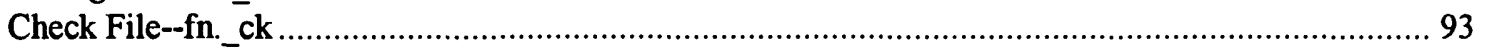

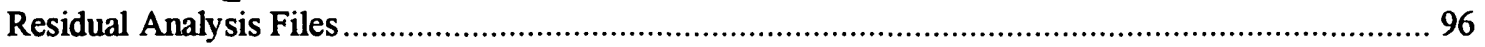

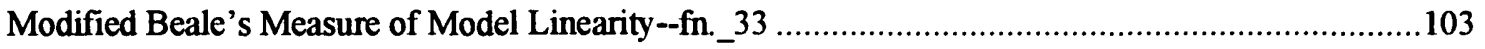

Output File for Predictions and Their Linear Confidence and Prediction Intervals-fn._44...............105

Output File for Differences and Their Linear Confidence and Prediction Intervals--fn._45...............108

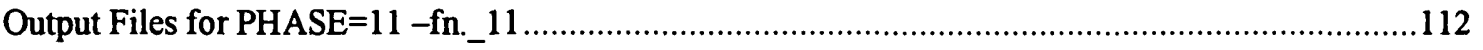

APPENDIX B: DISTRIBUTION, COMPILING, PORTABILITY, AND SPACE ISSUES...........................113

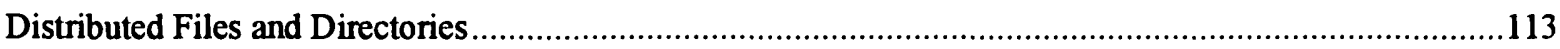

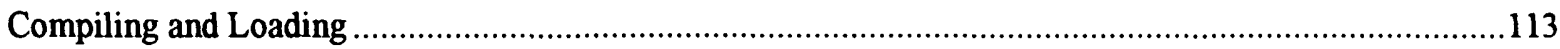

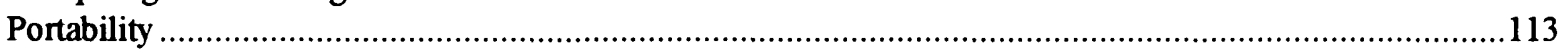

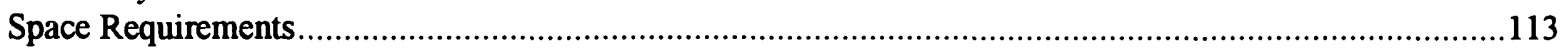

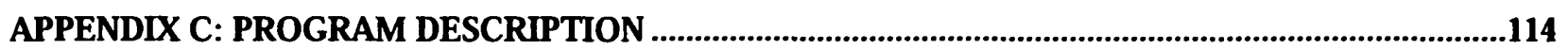

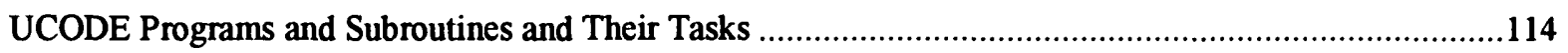

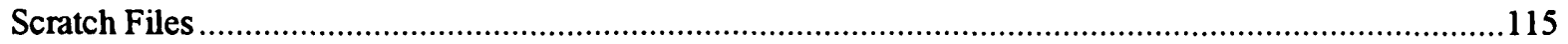

\section{FIGURES}

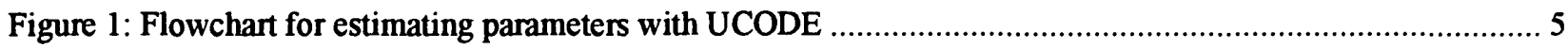

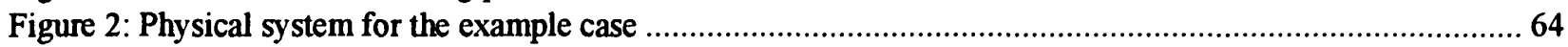

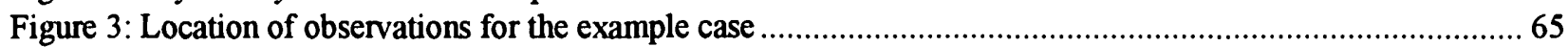

\section{TABLES}

Table 1: Guidelines for effective model calibration (from Hill, 1998) .......................................................... 12

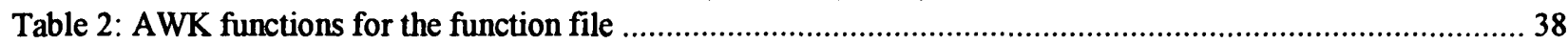

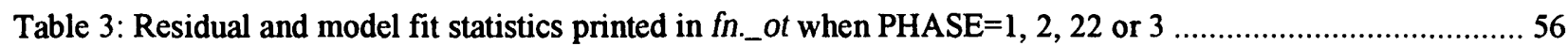

Table 4: Parameter statistics printed in fn._ot when PHASE=2, 22, and 3 .................................................... 57

Table 5: Files created by UCODE that contain data sets for graphical residual analysis ..................................... 58

Table 6: Regression performance measures printed in fn._ot when PHASE $=3$.................................................5 


\title{
DOCUMENTATION OF UCODE,
}

\section{A Computer Code for Universal Inverse Modeling}

\author{
By Eileen P. Poeter and Mary C. Hill
}

\begin{abstract}
This report documents the computer program UCODE, which performs inverse modeling, posed as a parameter-estimation problem, using nonlinear regression. Any application model or set of models can be used; the only requirement is that they have numerical (ASCII or text only) input and output files and that the numbers in these files have sufficient significant digits. Application models can include pre-processors and post-processors as well as models related to the processes of interest (physical, chemical, and so on), making UCODE extremely powerful. An estimated parameter can be a quantity that appears in the input files of the application model(s), or that can be used in conjunction with user-defined functions to calculate a quantity that appears in the input files. Observations to be matched in the regression can be any quantity for which a simulated equivalent value can be produced, and simulated equivalent values are calculated using values that appear in the application model output files and a set of additive and multiplicative functions. Prior, or direct, information on estimated parameters also can be included in the regression. The nonlinear regression problem is solved by minimizing a weighted leastsquares objective function with respect to the parameter values using a modified Gauss-Newton method. Sensitivities needed for the method are calculated approximately by forward or central differences, and problems and solutions related to this approximation are discussed. Statistics are calculated and printed for use in (1) diagnosing inadequate data and identifying parameters that probably cannot be estimated; (2) evaluating estimated parameter values; (3) evaluating the model representation of the actual processes; and (4) quantifying the likely uncertainty of model simulated values. UCODE is intended for use on any computer operating system: it consists of
\end{abstract}


algorithms programmed in perl, a freeware language designed for text manipulation, and Fortran90, which efficiently performs numerical calculations.

\section{INTRODUCTION}

Despite their apparent utility, inverse models are used much less than would be expected calibrations conducted using only trial-and-error methods are much more commonly used in practice. This is partly because of difficulties inherent in inverse modeling, which are related to the mathematics used to represent the processes, the complexity of the simulated systems, and the sparsity of data in most situations; and partly due to a lack of effective, versatile inverse models. Recent work has clearly demonstrated that inverse modeling, though an imperfect tool, provides capabilities that help modelers take greater advantage of the insight available from their models and data. Expanded use of this technology requires tools with different capabilities than those that exist in currently available inverse models. UCODE has two attributes that are not jointly available in other inverse models: (1) the ability to work with any mathematically based model or pre- or post-processor with ASCII or text only input and output files, and (2) the inclusion of more informative statistics.

UCODE is designed to allow inversion using existing algorithms (called application models in this work) that use numerical (ASCII or text only) input, produce numerical output, and can be executed in batch mode. Specifically, the code was developed to: (1) manipulate application model input files and read values from application model output files; (2) compare user-provided observations with equivalent simulated values derived from the values read from the application model output files using a weighted least-squares objective function; (3) use a modified Gauss-Newton method to adjust the value of user selected input parameters in an iterative procedure to minimize the value of the weighted least-squares objective function; (4) report the estimated parameter values; and (5) calculate and print statistics to be used to (a) diagnose inadequate data or identify parameters that probably cannot be estimated, (b) evaluate estimated parameter values, (c) evaluate how accurately the model represents the actual processes, and (d) quantify the uncertainty of model simulated values.

Application models executed by UCODE can include pre-processors and post-processors as well as models related to the processes of interest (physical, chemical, and so on), making 
UCODE extremely powerful. In general, graphical user interfaces cannot be used directly with UCODE, but can be adapted with relatively little effort.

\section{Purpose and Scope}

This report documents how to use UCODE, a universal inverse code. Because UCODE can be used with application models from any discipline, readers of this report may come from many backgrounds. Different fields tend to have their own problems related to inverse modeling and their own literature addressing these problems. The reader is encouraged to become familiar with these resources.

This report begins with an overview of how UCODE solves the nonlinear regression problem, and how the sensitivities needed for the regression are calculated. The nonlinear regression theory used in UCODE and guidelines for its use in model calibration are described by Hill (1994, 1998), as derived largely from Cooley and Naff (1990), and basic ideas from those works are presented briefly. The remainder of the report describes, in detail, how to run UCODE, construct input files, and use the UCODE output files. Appendix A includes selected application model and UCODE input and output files for a simple problem. Appendices B and C include information about the distributed code and a description of the code, respectively. Source files for UCODE are available at the Internet address listed in the beginning of this report. The expertise of the authors is in the simulation of ground-water systems, so examples in this report come from this field. The program, however, has nearly unlimited applicability.

Users of UCODE need to be familiar with the application model(s). In addition, although this report is written at an elementary level, some knowledge about basic statistics and the application of nonlinear regression is assumed. For example, it is assumed that the reader is familiar with the terms "standard deviation, variance, correlation, sensitivity, optimal parameter values, and residual analysis". Readers who are unfamiliar with these terms need to review a basic । statistics book. Useful references and applications are cited in Hill (1998), including the illustrative example described by Poeter and Hill (1997).

\section{Acknowledgments}

The authors would like to gratefully acknowledge the following people. Richard Yager of the U.S. Geological Survey introduced the authors to the idea of a universal inverse code many 
years ago. David Boldt of the U.S. Geological Survey suggested using the programming language perl and provided the authors with some preliminary perl code and continued advice on perl programming. Larry Allen of the Colorado School of Mines provided some programming assistance.

\section{UCODE PROCEDURES}

This section presents an overview of the procedures used in UCODE. An important part of those procedures is the method for calculating sensitivities, and this is discussed in detail.

\section{Overview}

A flowchart of UCODE is presented in figure 1. This section describes the steps listed in the flowchart and introduces the most commonly used UCODE input files. The input files introduced are the universal, prepare, and extract files (one of each is needed for each UCODE run), the function file (optional, one may be used for each UCODE run), and template files (one or more are used for each UCODE run). The application model(s) executed by UCODE can include only one process/simulation model, a sequence of such models, or any combination of preprocessors, process/simulation models, and post-processors. Each application model needs to be set up to run in batch mode.

UCODE initializes a problem by reading the following information: (1) solution control information, commands needed to execute the application model(s), and observations from the universal file; (2) instructions from the prepare file, template files and, perhaps, a function file, which are used to create application model input files with starting or updated parameter values; and (3) instructions from the extract file for calculating simulated equivalents for each observation from numbers extracted from the application model output files. This information is stored for later use. 


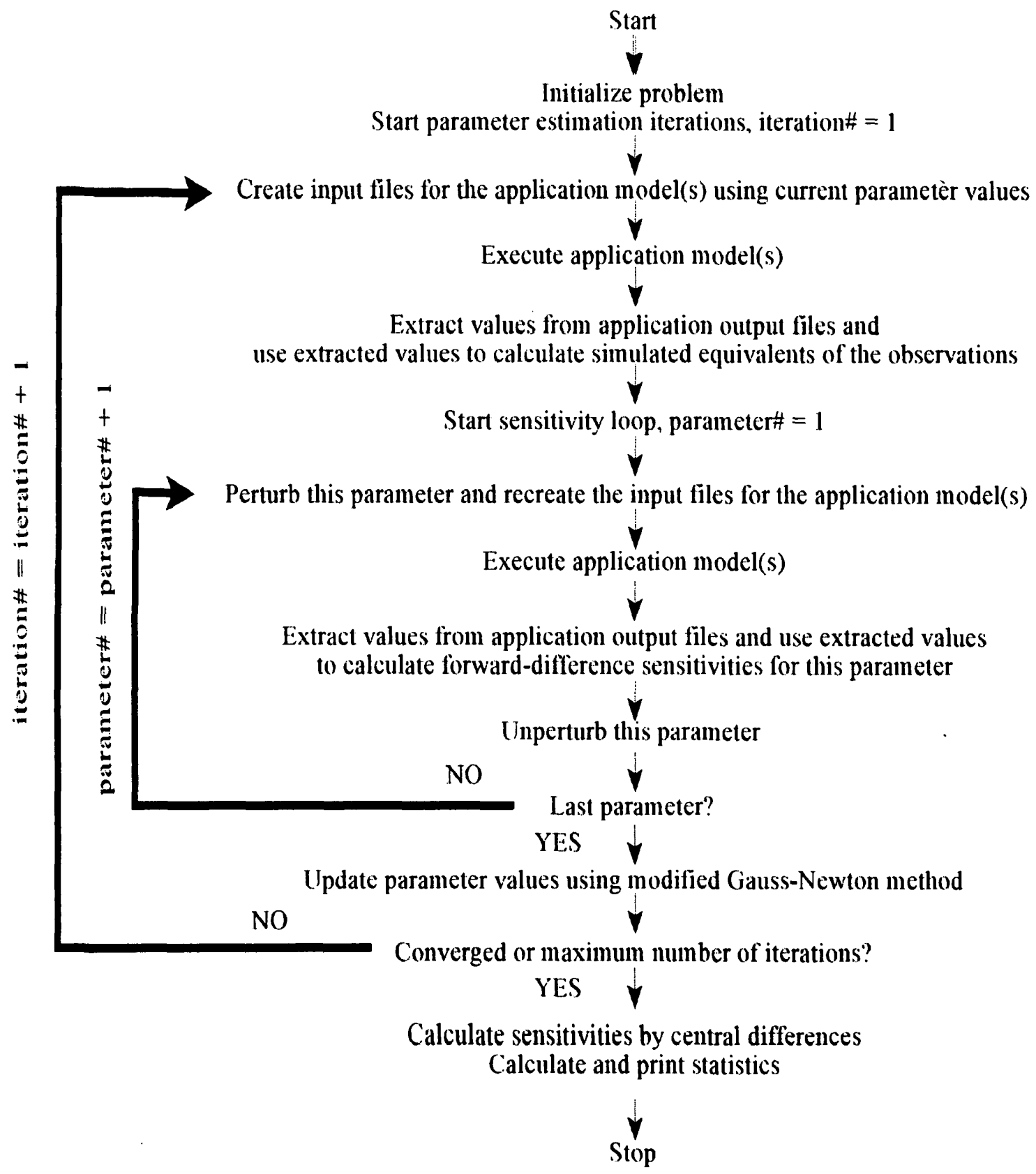

Figure 1: Flowchart for estimating parameters with UCODE 
Parameter-estimation iterations are needed to solve the nonlinear regression problems for which UCODE is designed. In UCODE, parameter-estimation iterations begin by substituting the starting parameter values into the template files using instructions from the prepare file to create application model input files. UCODE then performs one execution of the application model(s) based on commands provided by the user. Next, for each observation, UCODE extracts one or more values from the application model output and, using instructions from the extract file, calculates an equivalent simulated value to be compared to the observation. Equivalent simulated values are referred to simply as simulated values in the remainder of this section. Examples of calculating simulated values from extracted values are described below. The simulated values calculated at this step of each parameter-estimation iteration are called unperturbed simulated values because they are calculated using the starting or updated parameter estimates. The unperturbed simulated values are subtracted from the observations, and these differences are called residuals. The residuals are weighted, squared, and summed to produce the sum-ofsquared-weighted residuals objective function, which is used by the regression to measure model fit of the observations (Hill, 1998, eq. 1).

To calculate sensitivities of the simulated values to the parameters, the application model(s) are executed once again for each parameter, and each time the value of one parameter is slightly different (perturbed) than its unperturbed value. The differences between perturbed simulated values and the unperturbed simulated values are used to calculate forward-difference sensitivities, as described below. Alternatively, the application model(s) can be executed yet again for each parameter (not shown in fig. 1) and sensitivities can be calculated using more accurate central differences, but this added accuracy is rarely needed to perform parameter-estimation iterations.

Once the residuals and the sensitivities are calculated, they are used in a computer program which is specified by name in the universal file and performs a single parameterestimation iteration. UCODE is distributed with the nonlinear regression code MRDRIVE, which updates the parameter values using one iteration of the modified Gauss-Newton method as described by Hill (1998). The last step of each parameter-estimation iteration involves comparing two quantities against convergence criteria: (1) the changes in the parameter values and (2) the change in the sum-of-squared-weighted residuals. If the changes are too large and the maximum 
number of parameter-estimation iterations has not been reached, the next parameter-estimation iteration is executed. If the changes are small enough, parameter estimation converges. If convergence is achieved because the changes in the parameter values are small ( 1 above), the parameter values are assumed to be the optimal parameter values - that is, the values that produce the best possible match between the simulated and observed values, as measured using the weighted least-squares objective function. If convergence is achieved because the changes in the objective function are small, it is less likely that the estimated parameters are optimal and further analysis generally is needed.

If parameter estimation does not converge and the maximum number of iterations has not been reached, the updated parameter values are substituted into the template files, and the next parameter-estimation iteration is performed.

When parameter estimation converges or the maximum number of iterations has been reached, sensitivities are calculated using the more accurate central-difference method. The additional accuracy is needed to achieve a sufficiently accurate parameter variance-covariance matrix (Hill, 1998, eq. 26), from which a number of useful statistics are calculated. If parameterestimation converged, the final parameter values are considered to be optimized.

Once a model is calibrated, it can be used to make predictions for management or other purposes. UCODE can calculate linear confidence and prediction intervals that approximate the likely uncertainty in predictions simulated using the application models and optimized parameter values.

UCODE allows substantial flexibility in the values that are to be used as simulated equivalents of the observations or that are to be simulated as predictions because such values can be calculated from more than one of the values extracted from the application model output file(s). A situation in which this would be needed is when an observation is located at a point in space that is not represented by a printed value in the simulation output, but rather falls between the locations of a number of printed values. In this situation, UCODE can be instructed to interpolate the printed values to obtain a simulated value to compare with the observation. Alternatively, an observation may be the equivalent of the sum of many values or portions of values printed by the application code(s). In UCODE, these values or appropriate portions of them can be summed to obtain an equivalent simulated value. 


\section{Calculation of Sensitivities}

One sensitivity equals the derivative of a simulated value, $y^{\prime}$, associated with an observation, $y$, with respect to one parameter, $b$. That is, $\partial y^{\prime} / \partial b$. One sensitivity is calculated for each observation with respect to each parameter. Sensitivities serve two functions in inverse modeling. First, they are useful indicators of both the importance of the observation to the estimation of the different parameters and the importance of each parameter to the simulated values. Second, they are needed by the modified Gauss-Newton method to determine parameter values that produce the best fit, as measured by a weighted least-squares objective function. For additional discussion about sensitivities and their utility, see Hill (1998, eq. 8-13 and Guideline 3).

In UCODE, sensitivities are calculated approximately using either a forward- or centraldifference approximation. For forward differences, each sensitivity (one for each observation with respect to each parameter) is calculated as:

$$
\frac{\Delta y^{\prime}}{\Delta b}=\frac{y^{\prime}(b+\Delta b)-y^{\prime}(\mathbf{b})}{(b+\Delta b)-(b)}
$$

where:

$\Delta y^{\prime}=$ the change in the simulated value caused by the parameter value change, $\Delta b$;

b = a vector (can be thought of as a list), of the values of the estimated parameters;

$\Delta \mathbf{b}=\mathbf{a}$ vector in which all values are zero except for one which corresponds to the parameter for which sensitivities are being calculated;

$\Delta b=$ the nonzero value in $\Delta \mathbf{b}$, which is called the perturbation for this parameter; and $y^{\prime}(b)$ and $y^{\prime}(b+\Delta b)$ indicate that the value of the simulated value, $y^{\prime}$, is calculated using the parameter values represented by $\mathbf{b}$ or $(\mathbf{b}+\Delta \mathbf{b})$.

The derivative is said to be "evaluated for the parameter values in b", which is important because for nonlinear problems, the sensitivities are different depending on the values in $\mathbf{b}$.

The size of the perturbation, $\Delta b$, is calculated as a user-specified factor (PERTURBATION of the prepare file; see below) times the unperturbed parameter value. To calculate backward instead of forward differences, specify a negative factor. If the unperturbedparameter value equals zero during the regression, the perturbation is calculated using the starting parameter value. If the starting parameter value equals zero, a value of 1.0 is used to calculate $\Delta b$, so that $\triangle \mathrm{b}=$ PERTURBATION in that circumstance. Calculating the sensitivities for each 
parameter using either forward or backward differences requires that the application model be run once for the unperturbed parameters and an additional time for each parameter being estimated. The flowchart of figure 1 includes the steps by which forward-difference sensitivities are calculated.

Central-difference sensitivities are more accurate than forward-difference sensitivities, but require runs of the application model(s) in which the perturbed parameter is both increased and decreased, thus increasing execution time by about a factor of two. The central-difference sensitivities are calculated as:

$$
\frac{\Delta_{2} \mathrm{y}^{\prime}}{\Delta_{2} \mathrm{~b}}=\frac{\mathrm{y}^{\prime}(\mathbf{b}+\Delta \mathbf{b})-\mathrm{y}^{\prime}(\mathbf{b}-\Delta \mathbf{b})}{(\mathbf{b}+\Delta \mathbf{b})-(\mathbf{b}-\Delta \mathbf{b})}
$$

where $\Delta_{2}$ is used to denote the central-difference. Again, the derivative is said to be "evaluated for the parameter values in $\mathbf{b}$ ". The added accuracy of the central-difference approximation always is needed when the variance-covariance matrix is calculated. It rarely is needed for the regression if the suggestions described below are followed, but UCODE allows central-difference sensitivities to be used in the regression if the variable DIFFERENCING $=2$ in the universal file, as described below.

The accuracy of the approximate sensitivities calculated by UCODE depends on the number of accurate significant figures included in the extracted simulated values and the magnitude of the simulated values. For example, using the problem in Appendix A, UCODE was executed using the partial double-precision application model MODFLOW96 (Harbaugh and McDonald, 1996) with the preconditioned conjugate-gradient (PCG2) solver (Hill, 1990) with HCLOSE $=1 \times 10^{-5}$ and RCLOSE $=1 \times 10^{-5}$. For this problem, with hydraulic heads typically in the 100 's, this is expected to produce values that are accurate to about seven significant digits. A print format with six significant figures (the maximum provided by MODFLOW96) was used to print heads. The parameter values substituted into the template files typically had four significant digits. Sensitivities calculated by UCODE with PERTURBATION $=0.01$, or one percent of the parameter value, were compared with the more accurate sensitivity-equation sensitivities calculated by MODFLOWP (Hill, 1992) using the PCG2 solver with HCLOSE $=$ RCLOSE $=$ $1 \times 10^{-5}$. For this situation, even the more accurate central-difference sensitivities differed in the third significant digit for three of the six estimated parameters, which can produce important 
differences in calculated parameter correlation coefficients in some circumstances ( 0 . Osterby, Aarhus University, Denmark and M.C. Hill, U.S Geological Survey, written commun., 1997). This indicates that the number of significant figures used for both the simulated values and the parameter substitution needs to be carefully considered. The simulated values and parameter values of equations 1 and 2 need to have sufficient precision to maintain a reasonable number of significant digits after the subtraction. Use of more than 6 or 7 significant digits, however, needs to be considered carefully. Depending on how single and double precision variables are used in the application model and the accuracy of the computer, the additional figures may be meaningless and would not improve the accuracy of the perturbation sensitivities.

Some situations provide opportunities for improving the accuracy of the simulation. In ground-water flow problems, for example, one such situation occurs when the simulated hydraulic heads are in the 100 's or 1000 's. Often a simple change in datum results in simulated values being consistently in the 10 's, which allows more of the available significant figures to be used to improve the accuracy of the solution. For example, the accuracy of the problem in Appendix A would improve by increasing the datum by $100 \mathrm{~m}$. To accomplish this, $100 \mathrm{~m}$ would need to be subtracted from the hydraulic-head observations, the river elevation, and the elevation of the bottom of the top layer. In transport simulations, similar improvements may be attainable by scaling the concentrations.

For nonlinear parameters, the accuracy of the sensitivities also depends on the size of the parameter perturbations. Determining the appropriate size can be problematic. Theoretically, the perturbation sensitivities approach the exact sensitivities as the perturbation size decreases. However, perturbations that are too small can result in negligible differences in the extracted values or differences that are obscured by round-off error. A perturbation that is too large, however, can yield inaccurate sensitivities for nonlinear parameters. The user needs to be aware of the potential difficulties and may need to experiment with different perturbation values.

Even in nonlinear problems, some parameters can be linear. For example, in ground-water problems, recharge is a linear parameter if the forward problem is linear (the system is confined and all boundary conditions are linear). For linear parameters, perturbations generally can be large, and inaccurate sensitivities result only when the perturbation is so small that the numerators of equations 1 and 2 are dominated by round-off error. 
A value of zero is calculated and printed for the sensitivity by UCODE if the extracted values for the perturbed and unperturbed parameters are identical given the number of significant figures printed in the output. If many of the other sensitivities related to this parameter are nonzero, the zero value may simply indicate that the observation is not very important to estimation of the parameter involved, and this is correctly represented by the zero sensitivity value. In such a situation, no corrective action is needed. If all of the sensitivities for a parameter are zero, a problem clearly exists, and corrective action is needed. If many sensitivities for a parameter are zero, corrective action may or may not be needed. Five possible corrective actions are: (1) smaller solver convergence criteria can be specified in the application codes to improve the accuracy of the simulated values, but also will increase execution time; (2) the extracted values can be printed with more significant figures in the application model output file if the values are calculated with sufficient accuracy; (3) the datum of the problem can be changed or a normalization can be applied, as discussed above; (4) the perturbation for the parameter can be increased (this may require use of more significant digits to represent the parameter in the template files); and (5) the methods for coping with insensitive parameters discussed below can be employed. If available, the first three options are preferable because the fourth option will produce less accurate sensitivities and the fifth may require a less detailed parameterization.

\section{INVERSE MODELING CONSIDERATIONS}

Calibration of models of complex systems is commonly hampered by problems of parameter insensitivity and extreme correlation caused by data that are insufficient to estimate the defined parameters. A lengthy discussion of the utility and limitations of using nonlinear regression methods in the calibration and analysis of complex models is beyond the scope of this report, but is considered by Hill (1998). The discussions of this report in this section and in the section "Using UCODE Output" briefly present a few key issues and provide suggestions and warnings where they will be most readily available to users of UCODE.

\section{Guidelines for Effective Model Calibration and Analysis using Nonlinear Regression}

There are many opinions about how nonlinear regression can best be applied to the calibration of complex models, and there is not a single set of ideas that is applicable to all 
situations. It is useful, however, to consider one complete set of guidelines that incorporates many of the methods and statistics available in nonlinear regression, such as those suggested and explained by Hill (1998) and listed in table 1. This approach has been used successfully even with exceptionally complex systems; see D'Agnese and others (1998, in press). Table 1 is presented to introduce and remind the reader of the guidelines, but the brief statements could be misleading. Those who wish to use these guidelines are encouraged to read the complete discussion.

Table 1: Guidelines for effective model calibration (from Hill, 1998)

1. Apply the principle of parsimony (start very simple; build complexity slowly)

2. Use a broad range of information to constrain the problem

3. Maintain a well-posed, comprehensive regression problem

4. Include many kinds of data as observations in the regression

5. Use prior information carefully

6. Assign weights which reflect measurement errors

7. Encourage convergence by making the model more accurate

8. Evaluate model fit

9. Evaluate optimized parameters

10. Test alternative models

11. Evaluate potential new data

12. Evaluate the potential for additional estimated parameters

13. Use confidence and prediction intervals to indicate parameter and prediction uncertainty

14. Formally reconsider model calibration from the perspective of the desired predictions

\section{Parameterization}

Parameterization is the process of identifying the aspects of the simulated system that are to be represented by estimated parameters. Most data sets only support the estimation of relatively few parameters. In most circumstances, it is useful to begin with simple models and incorporate complexity as warranted by the complexity of the system and the inability of the model to match observed values (Guideline 1 of table 1).

To obtain an accurate model and a tractable calibration problem, data not used directly as observations in the regression need to be incorporated into model construction (Guideline 2 of 
table 1). For example, in ground-water systems, it is important to respect and use the known hydrogeology, and it is unacceptable to add features to the model to attain model fit if they contradict known hydrogeologic characteristics.

During calibration it may not be possible to estimate all parameters of interest using the available observations. In such circumstances, consider the suggestions of the section "Common Ways of Improving a Poor Model".

\section{Starting Parameter Values}

Nonlinear regression begins with starting parameter values. There are three aspects of these starting values that are important.

1. In UCODE, depending on the option chosen, the starting parameter values are used to calculate residuals, scaled and composite scaled sensitivities, and parameter correlation coefficients. These statistics are important to diagnosing potential problems with the model and the regression and to determining ways of addressing these problems. In most circumstances, it is useful to evaluate these statistics regularly as the model changes during the calibration process. The statistics printed by UCODE are discussed in the section "Using UCODE Output" and in Hill (1998). The latter also includes a discussion of how model nonlinearity effects the analysis.

2. It is sometimes advantageous to change the starting parameter values. As calibration proceeds, parameter values that produce a better model fit than the original starting parameter values are estimated by regression. Using the estimated parameter values to update the original starting parameter values used by UCODE in subsequent regression runs can reduce execution time because, commonly, fewer regression iterations are required when the starting parameter values produce a closer model fit.

3. The starting parameter values can be used to test for the uniqueness of optimized parameter values; that is, the values at which the regression converges. This is accomplished by initiating the regression with different sets of starting values. If the resulting parameter estimates differ from each other by values that are small relative to their calculated standard deviations, the optimization is likely to be unique. If this is not the case, the optimal parameter values are not unique. Lack of uniqueness can be caused by a number of factors. If caused by local minima, 
it may be possible to examine the objective function value achieved by the different sets of parameter estimates and identify a global minimum as the set of estimated parameter values that produces the smallest objective-function value. If non-uniqueness is caused by extreme parameter correlation, the objective-function value for each optimized set of parameters is likely to be similar and at least one pair of parameters will have a correlation coefficient very close to 1.0 or -1.0 . This is demonstrated clearly by the simple test case presented by Poeter and Hill (1997).

\section{Common Ways of Improving a Poor Model}

Problems such as insensitivity and extreme correlation of parameters and poor model fit are common in model calibration. Possible ways of addressing these problems are as follows, listed in order of how often the suggestion is most appropriate in practice.

1. Reconsider the model construction. Regression difficulties and poor model fit can help reveal misconceptions used to construct the model.

2. Modify the defined parameters by adding, omitting, and(or) combining parameters to be estimated. See section "Parameterization" above.

3. Carefully eliminate observations or prior information based on evidence that they are likely to be biased. Do not omit observations just because the model does not fit them well.

4. Adjust weights either for groups of observations and prior information, or perhaps individually. Small changes in the weighting rarely affect regression results, so, in most circumstances, time-consuming repeated runs using slightly different weights should be avoided.

A useful approach is to continually strive to identify and correct inaccuracies in the model construction or the use of observations. Use the model fit and calculated parameter sensitivities and correlation coefficients to facilitate this process. Nearly always, nonlinear regression will converge as the problems are resolved. This is the 'Achieve convergence through improved model accuracy' approach described in Hill (1998). Additional potential difficulties and resolutions also are discussed in Hill (1998). 


\section{Alternative Models}

The sparse data sets available for the development of most models often support equally feasible alternative conceptual models, and it is important to evaluate all such models. Equally feasible conceptual models are those that reasonably represent known conditions and yield an acceptable fit to the data with reasonable optimal parameter values, as determined using regression. All such models need to be used to make predictions and to determine the associated confidence in those predictions. If the various models produce a range of predictions that are different enough to make the appropriate management decision or scientific conclusion unclear, statistics of the regression can be used to help identify data that are most likely to differentiate the models, and thus help to eliminate those that are not representative of the system.

\section{Residual Analysis}

Analysis of the residuals (observed minus simulated values) is crucial to judging whether a model is likely to represent a system accurately. A complete analysis of residuals includes consideration of summary statistics and consideration of graphs and maps of weighted and unweighted residuals (see section "Graphical Analysis of Model Fit and Related Statistics" and Guideline 8 of Hill, 1998). In the graphical analyses, some departure from ideal patterns may be attributed to the limited number of data and the fitting of the regression. The effect of these contributions can be evaluated by generating random data sets that have the same number of data and characteristics consistent with the fitting of the regression. Such random data sets are generated by UCODE using a slightly modified version of the computer program RESANP (Hill, 1994; Cooley and Naff, 1990).

\section{Predictions and Differences and Their Linear Confidence and Prediction Intervals}

Predictions are calculated by UCODE using the calibrated application model(s). In these simulations, the estimated parameter values are used and the predictions are defined using UCODE input files in the same manner that observations were defined for model calibration.

UCODE includes some sophisticated methods of calculating and evaluating predictions of interest. First, UCODE allows differences to be calculated by subtracting values produced by what is called a base simulation from values produced by what is called a predictive simulation. That is: 
(value from predictive simulation) - (value from base simulation) $=$ difference Commonly, but not always, the base simulation represents conditions related to the calibration. For a steady-state calibration model, the base case commonly is equivalent to the calibration conditions; for a transient calibration the base case commonly is equivalent to the conditions at the end of the calibration period. In a ground-water example, values of interest might be hydraulic heads at the same location before and after additional pumpage is imposed on the system. In this circumstance, the predictive simulation includes the additional pumpage, and the base simulation does not. The difference would be the drawdown resulting from the pumpage. The use of differences is discussed further by Hill (1994).

UCODE can be used to calculate 95-percent linear confidence and prediction intervals on both predictions and differences, using equations 11 though 17 and a slightly modified version of computer program YCINT presented by Hill (1994). This is accomplished in UCODE using central-difference sensitivities (eq. 2). Linear confidence and prediction intervals indicate the uncertainty with which the predictions or differences are determined using the calibrated application model(s). In this context, confidence and prediction intervals can be defined as follows:

Confidence intervals represent the uncertainty in the simulated values that is a propagation of the uncertainty in the estimated parameter values. For the purpose of calculating the confidence interval, the uncertainty in the estimated parameter values is expressed by the optimal parameter variance-covariance matrix (Hill, 1998, eq. 28). The validity of the confidence intervals depends on the calibrated application model(s) accurately representing the true system, the model being linear, and the weighted residuals being normally distributed.

Prediction intervals include the uncertainty in the estimated parameter values as described for confidence intervals, but also include the effects of the measurement error that is likely to be incurred if the predicted quantity were to be measured. Prediction intervals need to be used when a measured value is to be compared to the calculated interval.

From these definitions, it is obvious that a single prediction can have an associated confidence interval or prediction interval, depending on whether or not the effects of measurement error are to be included. The idea of prediction interval is distinct from the predictions, but the similarity of the terms can cause confusion. The terms need to be used carefully. 
There are several ways to calculate the confidence and prediction intervals, depending on how many predictions and differences are to be considered together. The calculations differ only in the critical values used (Hill, 1994, eq. 11-17), which are statistics from standard probability distributions. The probability distributions of concern are the Student-t, Bonferroni-t, and Fdistributions. Tables of the statistics from these distributions were programmed into UCODE, so that the appropriate critical value is determined by the program, based on information provided by the user. Two types of intervals are considered: individual and simultaneous, and there are three ways of calculating simultaneous intervals. UCODE calculates all of the intervals and prints three of them after eliminating one as being less accurate than its alternative. Of the three intervals printed, the user needs to choose the appropriate interval for a given application. The intervals and selection criteria are described in the following paragraphs.

Individual intervals apply when only one prediction or difference is of concern. There is only one method of calculating individual linear confidence and prediction intervals (Hill, 1994, eq. 11 and 15), and it is exact if the model is linear and accurate, and the residuals are normally distributed.

Simultaneous intervals apply when the number of predictions and differences of concern exceeds one, or when the interval is calculated on a quantity which is not precisely defined, such as the largest value wherever it occurs within the model.

If a finite number of predictions and differences are of concern, and the number is represented by $\mathrm{k}$, the approximate Bonferroni and Scheffe $\mathrm{d}=\mathrm{k}$ (or, if $\mathrm{k}$ is greater than the number of parameters, $n p$, then Scheffe $d=n p$ ) simultaneous intervals apply. Both methods tend to produce intervals that are larger than exact intervals would be for a linear, accurate model with normally distributed residuals. In any circumstance, therefore, the smaller of the two intervals needs to be used, and UCODE only prints the smaller of the two intervals. A potential problem occurs when a combination of predictions and differences are included in the $\mathrm{k}$ values, and the total number of values of concern is finite. The confidence and prediction intervals on the predictions are calculated using a critical value determined using the number of predictions; the confidence and prediction intervals on differences are calculated using a critical value determined using the number of differences. This problem can be resolved by defining enough predictions or 
differences to make the number used to determine the critical values the desired number, and then ignoring results that are not of interest.

If the number of predictions and differences of concern cannot be exactly defined, simultaneous linear confidence and prediction intervals using the approximate Scheffe $d=n p$ method apply. Scheffe $d=n p$ intervals tend to be larger than exact linear intervals would be for a linear, accurate model calculated for the same circumstances.

While linear confidence and prediction intervals can be useful indicators of the uncertainty with which the prediction or difference has been determined, as tested by Christensen and Cooley (in press), the intervals also can be misleading if interpreted and presented without understanding and correctly representing their underlying assumptions. In particular, the significance level of the intervals is nominally 5 percent ( 1.0 minus 0.95 for 95 -percent intervals), but depends on the model being linear for parameter values near the optimized parameter values, and on the model accurately representing the system. Model linearity can be tested with UCODE, which uses a slightly modified version of BEALEP (Hill, 1994; Cooley and Naff, 1990); model accuracy is evaluated by analyzing model fit as mentioned above in the section "Residual Analysis". The proper use, and potential inaccuracies, of using linear confidence and prediction intervals for nonlinear problems is discussed by Hill (1994 and 1998) and Christensen and Cooley (in press).

Another common problem occurs when the predictions and differences of interest include types of quantities not included in the observations used to calibrate the model, or the calibration conditions differ dramatically from the calibration conditions. In such a circumstance, confidence and prediction intervals may be useful, but generally do not accurately indicate prediction uncertainty and need to be used with caution.

\section{RUNNING UCODE}

This section (1) contains information on filename restrictions that need to be respected for UCODE to perform correctly, (2) provides a complete list of the filenames UCODE uses with brief explanations; and (3) describes the command used to run UCODE. Additional information on the input and output files is presented in subsequent sections. 
The PHASE of the UCODE execution is mentioned below in describing the input and output files. PHASE is a variable fully defined later in the instructions for input file fn.uni (see below), and governs the input files needed and the output files produced.

\section{Filename Restrictions}

The filenames involved in UCODE include the names of the program files, batch files used to run the application models, files used by the application model, UCODE input and output files, and temporary files used by UCODE. Names of the UCODE program files and input and output files need to conform to the restrictions described below. Names of the batch files and files used by the application model are unrestricted.

Most UCODE input and output files are named with a user-defined prefix (referred to as fn) specified in the UCODE command line (see the section "Run Command"). For the required universal, prepare, and extract input files, and the optional function file, all of which are presented below, UCODE requires the suffixes uni, pre, ext, and fnc respectively. For example, fn.uni is the universal input file, where $f n$ is replaced by the user-defined prefix. Italicized filenames are used to refer to these generic filenames in this report to remind the reader that the $f n$ is replaced. For case-sensitive operating systems, fn needs to be the same case as is used on the UCODE command line, and the suffix needs to be lower case.

Output filename suffixes are specified by UCODE, and always start with an underscore (for example, fn._ot) to make them readily identifiable. In most circumstances, the UCODE output files are written over in subsequent runs of UCODE. To preserve output files, the prefix of the subsequent run can be changed, or files can be moved to another directory or renamed.

One set of UCODE input and output files have no naming restriction. These are the template files and the application model input files the template files are used to create. Names for both types of files are specified in the UCODE prepare input file (see below). For convenience, template files are referred to as *.tpl in this report. Typically, there are many template files for a single run of UCODE, so that the * would be replaced by many names.

There are 18 temporary files produced by UCODE named u9_zscr.1 through u9_zscr.16, and u9_zscr.44 and u9_zscr.45, as listed in Appendix C. At the end of execution, UCODE deletes all files that start with "u9_zscr.". Care needs to be taken to ensure that no other files 
with these names are located in the directory in which UCODE is executed. The files are given their unusual names in hopes of avoiding naming conflicts.

\section{Program Files for UCODE}

The UCODE program consists of two files that most modelers will execute: a perl file and a Fortran executable file. Two additional files are needed to interpret the perl file and another two are needed for execution of the Fortran executable file, as compiled. These files are briefly described here, and are binary files except as noted.

ucode

An ASCII file that contains the perl portion of the inversion code. The perl language does not require that executables be created.

Executable

of mrdrive The compiled and loaded Fortran90 inversion algorithm executed by UCODE. The Fortran files also are distributed with UCODE, and are described in Appendix C. If another inversion algorithm is used, its name needs to be specified in input file fn.uni (see below).

Executable

of perl A freeware program that interprets the ucode file to execute its commands. For distribution

on a $P C$

per1100.dll Windows file needed for executing perl on a PC under windows.

Copies of the perl executable and accessory files as required for some operating systems can be retrieved from http://www.perl.com/perl/ and are available for most operating systems (UNIX, DOS, SUNOS, and so on). Additional details regarding distribution and compiling of UCODE are given in a "readme" file on the distribution sites and Appendix B. A more detailed description of the first two program files is presented in Appendix C.

\section{Program Files for the Application Model(s)}

Application model program files need to be accessible for UCODE execution. They can be located in another directory, and can be referenced directly or through a batch file. A batch file is needed if variables are defined on or following application model command lines. 


\section{Input Files}

The input files needed to run UCODE are listed here. Directions for constructing all but the application model input files are included in the following section "Input File Construction" and examples are presented there and in Appendix A. fn in the filenames is replaced by the userdefined prefix specified in the UCODE run command. The filenames are italicized to remind the reader of this substitution. The first three files, fn.uni, fn,pre, and fn.ext have strict naming requirements as discussed above, as does an optional fourth file, fn.fnc.

Universal file (Note naming restrictions discussed above)

fn.uni Contains control parameters for the regression and printing, and observation information.

Prepare file (Note naming restrictions discussed above)

fn.pre Specifies whether a function file fn.fnc is used to define parameters. Names the template files and the application model input files that the template files are used to create with the defined parameters. Provides the starting parameter values, reasonable minimum and maximum values of the parameters, perturbation size, and formatting information for substituting parameter values into template files.

Defines prior information on the parameters.

Extract file (Note naming restrictions discussed above)

fn.ext Names the application model output files, describes how to extract values from the output, and defines how to use the extracted information to calculate simulated equivalents of the observations.

Function file (Note naming restrictions discussed above)

fn.fnc Optional file that is read only if indicated in the prepare file. Allows functions of the parameter values to be used as input to the application model.

Template files (any filenames can be used, but *.tpl is used in this report) 
*.tpl Copies of application model input files, edited such that search strings replace values derived from the defined parameters. The prepare file describes how the search strings are to be replaced with numbers to create input files for the application model.

fn.u44, fn.p44, fn.f44, and fn.e44;

fn.u45, fn.p45, fn.f45, and fn.e45 Additional input files needed when PHASE $=44$ or 45 (see directions for the universal file below). Rudimentary versions of these files with comments to guide their completion are created by UCODE, with the prefix, "temp" as discussed below in the section 'Input Files Needed for Predictions and Their Linear Confidence and Prediction Intervals'.

Input files for the application model(s) that are not produced by UCODE using the template files.

\section{Output Files}

The following is a complete list of the UCODE output files with brief descriptions, and is provided to help the user classify UCODE output files. Additional information about file content, suggestions for using the output, and examples are provided in the section "Using UCODE Output" and Appendix A. fn represents the user-specified filename prefix (see section "Run Command" below). As noted above, the UCODE output files commonly are written over in subsequent runs of UCODE. To preserve output files, change the prefix for different runs, move the files to another directory, or rename the files.

fn._ot The main UCODE output file. Contains some of the diagnostic and inferential statistics described by (Hill, 1998). Content depends on the value of PHASE as specified in the universal file.

fn._ck Reports the extraction commands from the fn.ext file, the value extracted from the application model output file using each extraction command, and the simulated values that are calculated from extracted value(s). Also reports the name and value of the observation listed in the fn.uni file to which the regression will compare the 
simulated value. Use this file to find and correct errors in the fn.ext and fn.uni input files.

fn._st A restart file containing parameter values from each parameter-estimation iteration. Only generated for $\mathrm{PHASE}=3$. Use this file to obtain intermediate parameter values for restarting the regression.

$f n . \_o s, f n . \_w w, f n . \_w s, f n . \_r, f n . \_w, f n . \_n m, f n . \_r p, f n . \_r d, f n . \_r g \quad$ Files containing data for the graphical analyses of model fit described by Hill (1998). These data can be used to produce $x-y$ graphs, maps, 3D visualization, and so on. Examples of these files are listed in section "Residual Analysis Files" of Appendix A.

fn._11, fn._33, fn._44, fn._45 Primary output files for PHASE=11, 33, 44, and 45, respectively. fn._lb File created when PHASE=11, contains labels for columns of file fn._11. (Ib stands for label).

fn._tp File created when PHASE=1, but only written during PHASE=33, only used for PHASE $=33,44$ and 45 ; generally not accessed by the user.

fn._b1 File created when PHASE=1, but only written during PHASE=3, and used for 33; generally not accessed by the user.

fn._b2 File created when PHASE=33, generally not accessed by the user.

fn._y1, fn._y2 Files created when PHASE $=44$ and 45 , respectively, but generally not accessed by the user.

Selected application model input files are produced by UCODE using the template files.

\section{Run Command}

The run command needs to be executed in the directory containing the UCODE input files. An example run command is:

\section{perl ucode fn}

where: "perl" is the command necessary to invoke the Perl program on the computer where the code is installed; and "ucode" is the pathname for the UCODE Perl script; and fn is a filename prefix that needs to be replaced using any name that conforms with filename restrictions of the 
operating system being used. The only exception is that spaces are not allowed in $\mathrm{fn}$, even on operating systems that allow spaces in filenames.

\section{INPUT FILE CONSTRUCTION}

The UCODE input files are described in detail in this section. As discussed in the previous section 'Filename Restrictions,' most of these files need to have names of the form $f n$. , where fn is replaced by the prefix defined in the UCODE run command, and the suffix * is specified for different types of files. For example, the universal file suffix needs to be uni, and the universal file is referred to as fn.uni in this report. Italicized names are used to remind the reader that the fn prefix is replaced by the user-defined prefix from the run command.

The following sections describe the universal, prepare, template, function, and extract input files in detail and provide annotated examples of each file. Four characteristics are shared by all but the template files, so are listed here and briefly mentioned again below.

free format Each line of the input files is read using free-format, but the number of variables specified for each line needs to be adhered to strictly.

blank lines Blank lines are permitted anywhere in all files, except for fn.uni in which no blank lines are permitted.

\# Comments are included in all of the files by inserting the symbol \#, after which all characters are ignored by UCODE. In the universal and extract files, comments can be inserted as the first character of a line or to the right of input data after one or more blank spaces. In the prepare file, comments need to occupy an entire line and the \# needs to be located in the first column.

END The last line of the data input of each file needs to be END or end, starting in the first space. Anything after this line will not be read, which provides a convenient place for notes. On some computers at least one line needs to follow this line; that is, an "enter" or "return" needs to be inserted at the end of the line.

Annotated example files presented in this section illustrate a variety of input options. The files presented generally are not consistent with one another, and simply display possible input file construction. 


\section{Universal Input File-fn.uni}

The universal input file, fn.uni, consists of solution control variables, the name of the inversion model, the command(s) needed to execute the application model(s), variables governing output, and a list of observation information.

\section{Directions for the Universal Input File}

Except for the last part of this input file, which contains the observation information, each line contains only one variable. Comments can be included either by placing a \# sign in the very first column of a line, or by placing a \# sign after one or more blank spaces at the end of a data input line. Blank lines are not permitted before the END line. The data input, in order of appearance, are as follows.

PHASE - Specifies the function UCODE performs. It is useful to begin with PHASE $=1$ and proceed to 2 and(or) 22, and then 3 . Runs with PHASE $=33,44$, and 45 generally are run only using a satisfactorily calibrated model. Phase 11 produces values which can be used to create a sum-of-squared, weighted residuals contour graph, and may never be used in some circumstances. The function of each PHASE is described briefly in the following table.

\begin{tabular}{|c|l|}
\hline PHASE & Function \\
\hline 1 & $\begin{array}{l}\text { Parameter substitution and forward modeling using the starting parameter values } \\
\text { specified in the prepare file. }\end{array}$ \\
\hline 11 & $\begin{array}{l}\text { Substitutes parameters, performs a forward model run, and calculates the sum-of- } \\
\text { squared, weighted residuals objective function for many sets of parameter values. } \\
\text { PHASE=11 produces data sets from which objective-function contour graphs can be } \\
\text { produced. Execution of PHASE=11 requires modification of the search-string lines } \\
\text { of the fn.pre file. }\end{array}$ \\
\hline 2 & Sensitivities at starting parameter values \\
\hline 22 & $\begin{array}{l}\text { Sensitivities and parameter variances, covariances and correlations at starting } \\
\text { parameter values. Execution time for 22 is about twice that of 2 because central } \\
\text { differences, rather than forward differences are calculated. }\end{array}$ \\
\hline 3 & Perform regression. \\
\hline $\begin{array}{l}\text { PHASE=33 and 44 need to be preceded by executing UCODE with PHASE=3 and GRAPH=1 } \\
\text { in the same directory (GRAPH is a variable in fn.uni). }\end{array}$ \\
\hline 33 & $\begin{array}{l}\text { Calculate the modified Beale's measure of model linearity using methods discussed } \\
\text { by Cooley and Naff (1990) and Hill (1994). }\end{array}$ \\
\hline
\end{tabular}


$44 \quad$ Calculate predictions and their linear confidence and prediction intervals. Only PHASE is read from the universal file. ${ }^{1}$

PHASE $=45$ needs to be preceded by executing UCODE with $\mathrm{PHASE}=44$ in the same directory.

45 Calculate differences and their linear confidence and prediction intervals. Only PHASE is read from the universal file. ${ }^{1}$

1. Calculated using a slightly modified version of the computer program YCINT (Hill, 1994).

The following six variables control the sensitivity and regression calculations and define the inversion algorithm.

DIFFERENCING - Controls the method used to calculate sensitivities during the parameterestimation iterations (starting with 1 is recommended):

1 forward differencing is used; and

2 central differencing is used and execution time is likely to double.

TOL When parameter values change less than this fractional amount between regression iterations, parameter estimation converges ( 0.01 is recommended).

SOSR When the sum-of-squared, weighted residuals changes less than this fractional amount over three regression iterations, parameter estimation converges. Ideally, for the final results convergence is achieved by satisfying the TOL criterion so that SOSR can equal 0.0 (in which case SOSR is not used as a convergence criteria). Values of SOSR of 0.01 and even 0.1 can be useful, however, in the early stages of model calibration because it stops the regression when it is not progressing.

NOPT Controls whether quasi-Newton updating will be used when the sum-of-squared, weighted residuals changes less than 0.01 over three regression iterations (using 0 is recommended):

0 no quasi-Newton updating; and

1 apply quasi-Newton update when criterion is met.

NOPT = 1 may facilitate convergence of highly nonlinear problems (Hill, 1998).

MAX-ITER - Maximum number of regression iterations (starting with twice the number of parameters is recommended; it is rare that more iterations will be helpful for problems that do not converge). 
MAX-CHANGE - Maximum fractional change of a parameter value allowed in one regression iteration. For example, if MAX-CHANGE $=2.0$, a parameter value of 1.0 will not be allowed to change by more than 2.0 (MAX-CHANGE times the parameter value). Consequently, the new value will be between -1.0 and 3.0. A parameter value of 2.0 will not be allowed to change more than a value of 4.0 (again, MAXCHANGE times the parameter value), and the new value will be between -2.0 and 6.0). This maximum change is applied to the physical parameter value, not its log transform. Exceptions are discussed in Hill (1998, Appendix B). (MAX$\mathrm{CHANGE}=2.0$ is common, but smaller values may help an oscillating regression to converge.).

INVERSION ALGORITHM - Name of nonlinear regression executable (MRDRIVE, as distributed; generally the path name needs to be specified).

The following lines control the application model(s)

N-APPLICATIONS - Number of application models used.

APPLICATION MODEL EXECUTION COMMANDS - Commands needed to run the application models. Application models can be pre-processor or post-processors. If the application model requires screen input, create a batch file to run the application model. In many situations, the batch file will contain just one line with the application model command followed by < filename, where the file filename contains information that is typically input to the screen. The example in Appendix A illustrates a rather complex connection of files (m.bat, in, ex.fil, and out). The file m.bat runs the application model in batch mode, defining the file in as the standard input and the file out as the standard output using <in and >out, respectively. The file in simply contains the filename ex.fil, which would need to be typed in answer to a query on the screen if the application model were executed directly, as opposed to in batch mode. Specifying the file out results in the diversion of printing from the screen to out, thus allowing messages provided by UCODE concerning the regression to appear on a less cluttered screen.

The following four variables control output, and do not influence the solution. 
SCALE-SENSITIVITIES - Controls the scaling applied to the printed sensitivities. (typically, 1 , 2 , or 3 are used, rarely is the user interested in viewing unscaled sensitivities):

0 No scaling is applied, and unscaled sensitivities are printed.

1 Dimensionless scaled sensitivities are printed. Sensitivities are scaled by the parameter value times the square-root of the weight, resulting in dimensionless numbers. Composite scaled sensitivities also are printed.

2 One-percent scaled sensitivities are printed. Sensitivities are scaled by the parameter value divided by 100 , resulting in numbers with the dimensions of the observations.

3 Both dimensionless and one-percent scaled sensitivities are printed.

PRINT-INTERMEDIATE - Controls whether residuals and sensitivities are printed for intermediate iterations (using 0 is recommended):

0 no printing for intermediate iterations; and

1 printing for intermediate iterations.

GRAPH - When PHASE=3, controls printing of data for graphical evaluation of residuals and creation of input files needed for executing PHASE $=33$ and 44 :

0 do not print post-processing files; and

1 print post-processing files (generally recommended because the files generally are not large and it is convenient to have them available).

NUMBER-RESIDUAL-SETS - The number of sets of residuals that will be produced and written to files $f n . \_r p$, $f n . \_r d$, and $f n . \_r g$ for evaluation of apparent nonrandomness of residuals. All sets used need to be generated in the same run, so if additional sets are desired, execute PHASE=3 again (using final parameter values as starting values to minimize execution time), specifying the total number of desired sets of residuals.

LIST OF OBSERVATIONS - A list of observations follows; one line for each observation. This observation list needs to be coordinated exactly with the extract input file (fn.ext) discussed later, in that the same OBS-NAMEs need to occur in both files. If a mismatch occurs, UCODE prints an error message and stops. It may be convenient, but is not necessary, to put the observations in the same order in the 
two files. To list them in the same order, use the instructions for the extract file to determine an order that considers the extraction effort. Each line in the list of observations includes the following variables.

OBS-NAME OBS-VALUE STATISTIC STAT-FLAG PLOT-SYMBOL The five values need to appear on one line separated by one or more blanks, and need to be in this order. The variables are defined as follows.

OBS-NAME - Observation name including up to 12 non-blank characters. OBSNAME need not occupy 12 spaces, but needs to be followed by a blank space. OBS-VALUE - Observed value.

STATISTIC - Statistic used to calculate the weight for the observation. The statistic can be a variance, standard deviation, or coefficient of variation, depending on the value of STAT-FLAG. The three options are provided so that the user can specify the statistic that is most meaningful in a given situation. For all three options, the statistic is used to calculate the variance, and the weight for the observation is set to one divided by the variance. For further discussion about calculation of weights and suggestions for determining STATISTIC, see Hill (1998, 'Weights for Observations and Prior Information' and Guideline 6).

STAT-FLAG - A flag indicating whether STATISTIC is a variance, standard deviation, or coefficient of variation.

\begin{tabular}{cc} 
STAT-FLAG & STATISTIC \\
\hline 0 & variance \\
1 & standard deviation \\
2 & coefficient of variation \\
\hline
\end{tabular}

PLOT-SYMBOL - Printed in files for graphical analyses to allow control of the symbols used when plotting data. Commonly, different values for PLOT-SYMBOL are used for different types of observations. The utility of this input value depends on the plotting program.

END - Indicates the end of the data input for this file. 


\section{Annotated Example of a Universal Input File}

$$
3
$$

\# phase

\#\# sensitivity and regression control

$1 \quad$ \# differencing: for sensitivity calculations (1 forward, 2 central)

$0.01 \quad$ \# tol, convergence criterion based on changes in estimated parameter values

$0.0 \quad$ \# sosr, convergence criterion based on changes in model fit

$0 \quad$ \# do not apply quasi-Newton updating

$10 \quad$ \# max-iter: maximum \# of iterations

2.0 \# max-change: maximum fractional parameter change

.. Icodelmrdrive \# path and name of inverse code

\#\#\# application models

\begin{tabular}{|c|c|}
\hline $\mathrm{m}^{2}$ & \# number of application models \\
\hline $\mathrm{mt} 3 \mathrm{~d}$ & \# run command for application model \\
\hline
\end{tabular}

\#\#\# printing options

1 \# scale-sensitivity: (0, none; 1 dimensionless scaled; 2 , one-percent scaled; 3,1 and 2)

$0 \quad$ \# print-intermediate: (0 no print, 1 print)

$1 \quad$ \# graph: print graphing files ( 0 no, 1 yes)

10 \# number of sets of normally distributed random numbers to generate

\#\#\# observations

\# NOTE: This example shows only a few observations. To estimate six parameters, far more \# than six observations would be needed.

\# The same plot-symbol values are given to observations in selected categories

\#obsname obs stat stat-flag plot-symbol

$\begin{array}{lcllll}\text { 1A } & 100.2 & 0.5 & 0 & 1 & \text { \# observation 1 } \\ \text { 1B } & 121.5 & 0.5 & 0 & 1 & \text { \# observation 2 } \\ \text { 1C } & 141.0 & 0.005 & 2 & 1 & \text { \# observation 3 } \\ \text { 2A } & 121.8 & 0.5 & 0 & 2 & \text { \# observation 4 } \\ \text { f low } & 2 . & 0.80 & 1 & 3 & \text { \# observation 5 }\end{array}$

\# observation identifiers can be up to 12 characters long

$\begin{array}{llllll}\text { concentratio } & 1.2 \mathrm{e}-7 & 0.03 & 2 & 4 & \text { \# observation } 6\end{array}$

$\begin{array}{llllll}\text { mass } & 2 \mathrm{e}-3 & 4 \mathrm{e}-4 & 1 & 5 & \text { \# observation } 7\end{array}$

END

Prepare File - fn.pre, Template, and Function (fn.fnc) Files

Unlike the other input files, the prepare input file is associated with additional input files.

These associated files are the template and function files, and also are discussed in this section.

\section{Directions for the Prepare Input File}

Indicator codes are used in the prepare file to indicate the purpose and composition of each line. Indicator codes are \#, F or $\mathrm{f},<,>, /$, and $\mathrm{P}$ or $\mathrm{p}$, and need to be in the very first column 
of all nonblank lines in the prepare file. Most lines can appear in any order, except as follows (these exceptions also are noted below): (1) if the $F$ (or $\mathrm{f}$ ) indicator code is used, only the \# indicator code can precede it; (2) the $<$ and $>$ indicator codes are associated pairs with the $<$ defining a template file and the following $>$ specifying the associated application model input file; and (3) all lines beginning with $P$ need to follow any lines beginning with /. Blank lines in the prepare file are ignored, and can be used to make the file easier to read. The indicator codes and information that needs to follow them are described here.

\# Comments - any information you may wish to note in the prepare file. Comments cannot be located as flexibly in the prepare file as in the universal, function, and extract files: in the prepare file the \# indicator code only can be located in the first column of a line; they cannot follow input data on the same line.

F Indicates whether functions will be applied to parameters before substitution, and needs to be the first line in the prepare file that is not blank or a comment. Only two possibilities exist:

F yes Use the function file.

F no Do not use the function file.

If the indicator code $\mathbf{F}$ does not appear in the prepare file, no function file is used.

$<\quad$ The name of a template file which contains symbols for which values are to be substituted.

$>\quad$ The name of the application model input file that is to be created by substituting numbers into the preceding template file.

I Each of these lines defines a parameter name, provides information for finding where the value of the parameter is to be substituted in a template file, specifies the starting parameter value, and lists other parameter information. Each line contains eight items separated by one or more blanks, and ordered as:

/SEARCH-STRING START-VALUE REASONABLE-MINIMUM REASONABLE-MAXIMUM PERTURBATION FORMAT LOG-TRANSFORM ESTIMATE

Each item is described below. 
SEARCH-STRING - A parameter name preceded by an exclamation point, and followed by commas and a final exclamation point; for example, !Rch1,,! The parameter name is used to label parameter-related values in UCODE output files, to define prior information (see the $\mathrm{P}$ indicator code below), and to define parameter-substitution functions (see the section 'Parameter-Substitution function file construction' below). Parameter names can include any combination of upper and lower case letters (A-Z, a-z) and numerals (0-9). The total number of characters in SEARCH-STRING, including the exclamation points, defines the number of spaces used to insert numbers into template files to create application model input files. For example, SEARCH-STRING !Rch 1, ! provides inserted numbers with nine spaces. A single parameter can be used to replace numbers in more than one template file to produce more than one application model input file, in which case the SEARCH-STRING for the parameter will appear in more than one template file.

START-VALUE - The starting value for this parameter, with which the parameter-estimation iterations begin. Do not specify the log of log-transformed parameters (discussed below); they are calculated by the program.

REASONABLE-MINIMUM - For PHASE=3, this is the reasonable minimum value for this parameter. The value is used solely to determine how the final optimized value of this parameter compares to a reasonable range of values. Do not specify the log of log-transformed parameters; they are calculated by the program. For PHASE=11, this value is used as the lower limit of the range over which the parameter value is varied for calculating the sum-of-squared, weighted residual objective function.

REASONABLE-MAXIMUM - For PHASE=3, this is the reasonable maximum value for this parameter. This value is used solely to determine how the final optimized value of this parameter compares to a reasonable range of values. Specify native values even if the parameter is log-transformed. For PHASE $=11$, this value is used as the upper limit of the range over which the 
parameter value is varied for calculating the sum-of-squared, weighted residuals objective function.

PERTURBATION - For most PHASES, this is the fractional amount the parameter is perturbed to calculate sensitivities. Starting with 0.01 , one percent of the parameter value, is recommended. A larger value is needed if too many calculated sensitivities for the parameter are printed as 0.0 . If a string of asterisks or if a divide-by-zero-error occurs; PERTURBATION can be increased or, in some situations, FORMAT (see below) can be redefined to provide more significant digits. For PHASE=11, PERTURBATION is the number of values the parameter is assigned, bounded by the values specified as REASONABLE-MINIMUM and REASONABLE-MAXIMUM. For PHASE=11, PERTURBATION needs to be greater than 1; for all other phases, values less than one are needed.

FORMAT - The format for the value of the SEARCH-STRING variable as read by its application model. This format needs to be compatible with the format specified for the input file in the application model documentation. (See the section 'Format Configuration Rules'). If a function is applied such that the value substituted for the SEARCH-STRING is many orders of magnitude different than the parameter value, the specified format needs to provide a format with sufficient significant digits to accommodate the computed value. UCODE supports $\mathrm{C}$ computer-language format configurations, as discussed in the following section.

LOG-TRANSFORM - Set this variable to 1 to log-transform the parameter and 0 otherwise. Note the restriction when applying prior information to logtransformed parameters below. Typically log-transformed parameters are those for which negative values are not reasonable. For PHASE $=11$, increments are generated in log space if the parameter is log transformed and both the native parameter value and its log transform are included in the output file for plotting. ESTIMATE - For PHASE $=3$, set to 1 to estimate the parameter by including it in the regression, and to 0 to leave the parameter at the specified value 
throughout the regression. For PHASE=11, set to 1 to vary the parameter value using the specified values of REASONABLE-MINIMUM, REASONABLEMAXIMUM, and PERTURBATION, set to 0 to leave the parameter value at START-VALUE

These statements define prior information on parameters. Search strings for all parameters must be specified before the prior equations are defined. Each definition of prior information occupies a single line composed of the following variables:

\section{P EQUATION stat STAT flag STAT-FLAG plot PLOT-SYMBOL} where $P$ is the indicator code, EQUATION is defined below, STAT, STATFLAG, and PLOT-SYMBOL are variables for which numbers are read, and stat, flag, and plot are labels. Items following EQUATION need to be separated by the indicated labels (stat, flag, and plot); the labels and variables need to be separated by at least one,spaces. EQUATION and the variables are defined as follows.

EQUATION - An equation of the form:

$$
\text { PVALUE }=\text { C1 } \times \text { P1 \& C2 x P2 ..., }
$$

where the components are defined as follows. Items within the equation can be separated by any number of spaces.

PVALUE - The prior information value. Specify the native value, even for a log-transformed parameter.

$=$ Indicates that the simulated value to be compared with PVALUE is calculated as follows.

C1, C2 Coefficients with values as specified by the user.

$x$ Indicates multiplication. Needs to be preceded and followed by one blank space.

P1, P2 Parameter names, such as Rch1, as defined within the SEARCHSTRINGs defined earlier in the prepare input file. For the prior information calculation, these names are replaced by the parameter value.

$\&$ - Indicates that the preceding and following products are to be summed; thus, it performs like $a+$. 
For one parameter, an example equation is $120=1 \times \mathrm{K} 1$. For parameters with LOG-TRANSFORM $=0$, the equation can contain as many products as desired.

For example, if prior information indicates that the annual recharge rate is 10 inches, and recharge is estimated for 6 months of winter and for 6 months of summer (using parameter names RCHWINT and RCHSUMR), then EQUATION would be:

$$
10=0.5 \times \text { RCHWINT \& } 0.5 \times \text { RCHSUMR }
$$

A similar type of equation on prior information could be applied to hydraulic conductivity values of multiple units determined by an aquifer test for which a single effective hydraulic conductivity was estimated and is used as prior information. As noted next, the multiple hydraulic conductivity parameters involved could not be log-transformed.

For log-transformed parameters only one term can be used in the equation. Thus, for log-transformed parameters, EQUATION is of the form

$$
\text { pvalue }=\text { C1xP1 }
$$

STAT - Statistic used to calculate the weight for the prior information. As for STATISTIC in the fn.uni file, the statistic can be a variance, standard deviation, or coefficient of variation, depending on the value of STAT-FLAG. For all three options, the statistic is used to calculate the variance, and the weight for the prior information is set to one divided by the variance. For log-transformed parameters, specify the log-transformed statistic, even though PVALUE is a native value.

STAT-FLAG -- A flag indicating whether STATISTIC is a variance, standard deviation, or coefficient of variation.

\begin{tabular}{cc} 
STAT-FLAG & STATISTIC \\
0 & variance \\
1 & standard deviation \\
2 & coefficient of variation \\
\hline
\end{tabular}

PLOT-SYMBOL - An integer printed in the UCODE output files used for graphical analyses. Different values for plot-symbol can be used to indicate 
different types of observations so they can be differentiated with a unique symbol on a graph. The utility of PLOT-SYMBOL will depend on the graphical software being used.

Completing one of the examples from above, a complete line beginning with the $\mathbf{P}$ indicator code is:

P $10=0.5 \times$ RCHWINT \& $0.5 \times$ RCHSUMR stat 0.20 flag 2 plot 4

END - indicates the end of data input for this file

\section{FORMAT Configuration Rules}

To specify FORMAT for the values replacing the SEARCH-STRING, C language formatting rules are used in UCODE. The most commonly used formats are described here; the numbers in the examples can be changed as needed.

$\% 6 \mathrm{~d} \quad$ Integer. Overall width is 6 places. 6 places are available for printing the value, and this needs to include a negative sign to allow for integers less than zero.

$\% 10.4 \mathrm{f}$ Real number. Overall width is 10 places with 4 digits to the right of the decimal point. For example, -1496.4945 would require a format of $\% 10.4 f$. If the significant digits to the left of the decimal point are too numerous for the number to be expressed within the defined overall width (10 in the example), many computers will print asterisks $\left({ }^{*}\right)$ instead of a number. For example, if $\% 9.4 \mathrm{f}$ is specified to print the number -1496.4945 , commonly nine asterisks are printed.

$\% 10.3 \mathrm{e}$ Real number in exponential notation. Overall width is 10 places, with one significant digit to the left of the decimal point. The number of significant digits after the decimal point depends on whether the number is negative or positive. For positive numbers, three significant figures are included to the right of the decimal point so that there are four significant digits total. For negative numbers, two significant digits are included to the right of the decimal point so that there are three significant digits total. For example, a FORMAT of $\% 10.3 \mathrm{e}$ produced the numbers $2.313 \mathrm{e}-002$ and $-1.20 \mathrm{e}+000$. If the exponential format is written more 
generally as \%a.be, a minus $b$ needs to be at least 7 , and the number of significant digits printed will be $b+1$ for positive numbers and $b$ for negative numbers.

\section{Template File Construction}

Template files generally are most easily constructed by starting with a working application model input file and identifying the numbers for which values are to be substituted by UCODE. Then, replace these numbers with SEARCH-STRINGS defined in the prepare input file. Such substitutions generally are straightforward, as shown in the annotated example shown below, but can be tedious.

\section{Parameter-Substitution Function File Construction-fn.fnc}

The function input file is an optional file which can be used to provide instructions for manipulating parameter values before substituting them into template files. If used, the first line that is not blank or a comment in the prepare file needs to start with indicator code $F$ (or $f$ ), followed by the word "yes", as follows:

$\mathrm{F}$ yes

Omitting this statement, or including the statement

F no

causes parameter values to be substituted directly, without manipulation. In such cases, the parameter-substitution function file is not read.

In addition to comment lines, the function file includes groups of lines with a specific structure. Each group completely describes how one parameter value is to be manipulated before being substituted into one template file. The required structure begins with two indicator code lines, the first with indicator code :file and the other with indicator code :key", followed by any number of lines with no indicator code.

The indicator code of the first line identifies the template file into which the manipulated values are to be substituted.

:file One or more spaces and the name of a template file follows; for example, :file bcf.tpl.

The indicator code of the second line identifies the parameter. 
These two lines are followed by any number of lines called occurrence and function lines. Each of these lines contains two entries: occurrence and function. Each occurrence entry identifies occurrence(s), in the file specified by the preceding :file indicator code, of the SEARCH STRING containing the parameter name specified by the preceding :key indicator code. The identified occurrence(s) are to be replaced using the function entry. The following paragraphs describe the occurrence and function entries in detail.

The occurrence entry is an integer or list of integers, where 1 indicates the first occurrence of the parameter name in the file specified by the preceding :file line, 2 indicates the second occurrence of the parameter name in the file, and so on. The counting starts at the top of the template file and proceeds left to right across each line. If the same function is to be applied to a number of sequential occurrences of the parameter name, the occurrence entry can be composed of the first and last number separated by two periods. For example, $1 . .6$ indicates that the function will be applied to occurrences 1 through 6 . If the occurrences are not sequential they need to appear on different lines. The occurrences under each :file indicator code need to be listed in increasing order . For example, the sequence 1, 3,5 on three consecutive lines is acceptable, while the sequence 1, 5, 3 is not. For occurrences that do not appear in the list, the parameter value is substituted without modification.

The function entry is separated from the occurrence entry by one or more spaces. The function expressions can use any of the AWK functions listed in table 2, and parentheses can be used to dictate the order of the operations. When parentheses are not used, common mathematical operation order is applied.

Table 2: AWK functions for the function file

\begin{tabular}{|c|l|}
\hline AWK function & \multicolumn{1}{|c|}{ Description } \\
\hline$+,-, *, 1$ & Addition, subtraction, multiplication, $\&$ division \\
\hline $\mathrm{x}^{\wedge} \mathrm{y}$ & Returns $\mathrm{x}$ raised to the power $\mathrm{y}$ \\
\hline $\operatorname{atan} 2(\mathrm{y}, \mathrm{x})$ & Returns arctangent of $\mathrm{y} / \mathrm{x}$. \\
\hline $\cos (\mathrm{x})$ & Returns cosine of $\mathrm{x} ; \mathrm{x}$ is in radians. \\
\hline $\sin (\mathrm{x})$ & Returns sin of $\mathrm{x} ; \mathrm{x}$ is in radians. \\
\hline $\exp (\mathrm{x})$ & Returns the exponential function of $\mathrm{x}$, base $\mathrm{e}$. \\
\hline $\log (\mathrm{x})$ & Returns the natural logarithm of $\mathrm{x}$. \\
\hline $\operatorname{sgrt}(\mathrm{x})$ & Returns the square root of $\mathrm{x}$. \\
\hline $\operatorname{int}(\mathrm{x})$ & Returns the value of $\mathrm{x}$ truncated to an integer. \\
\hline
\end{tabular}


The value of the parameter listed in the preceding :key line is represented by $\$ \mathrm{x}$ in the AWK expressions. Other parameter values can be represented in the function as the parameter name bounded by exclamation points, such as !rch1!. If two or more parameters are always functionally related in the same way, generally only one of the parameters should be estimated by regression to avoid extreme correlation between the parameters involved.

Numbers of any format can be used in the AWK expressions, including integers, real numbers, and real numbers expressed in exponential notation. Exponential notation is expressed using the common conventions; for example, e-8, E+10, and e-001.

The following is an example of a group of occurrence and function lines:

$$
\$ \mathrm{x} * 2.0 \mathrm{e}-03
$$

$2 . .5$

$\$ x * 35+6$

6

$\$ x^{*}(! \operatorname{rch} 1 !+! \mathrm{rch} 2 !)$

7

$\sin (\$ x)$

If manipulated values of the same parameter are to be substituted into more than one template file, another group of lines needs to be repeated for each template file. If the same template file includes more than one parameter for which the value needs to be manipulated before substitution, again another complete group of lines, including the :file line, needs to be repeated for each parameter.

\section{Annotated Example of a Prepare Input File}

\# Comments have a " $\#$ " in the first column of the line

\# Comments cannot follow data on any line in the prepare file

\# read a function file

F yes

\#\# list template files and associated application model input files

$$
\begin{aligned}
& \text { \# bcf file } \\
& \text { < bcf.tpl } \\
& \text { > ex.bcf } \\
& \text { \# river package } \\
& \text { < riv.tpl } \\
& \text { > ex.riv }
\end{aligned}
$$


\#\# parameter information

\# information for parameter $\mathrm{k} 1$

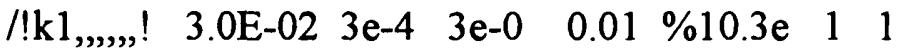

\# information for parameter $\mathrm{Krb}$

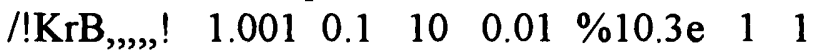

\# information for parameter rch1

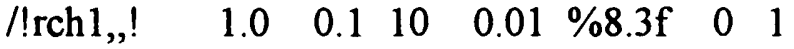

\# information for parameter $\mathrm{RCH} 2$

/!RCH2,,! $\quad \begin{array}{lllllll}1.5 & 0.5 & 5 & 0.01 & \% 8.3 f & 0 & 0\end{array}$

\#\# list additional template file and associated application model input file

$<$ dsp.tpl

$>$ mt3d.dsp

\#\# information for another parameter

\# information for parameter dspl

/!dspl! $\quad 10.1100 \quad 0.01 \quad \% 4.1 f \quad 0 \quad 1$

\#\# prior information

P $1.0=1 \times \mathrm{KrB} \quad$ stat 0.0625 flag 0 plot 5

P $1.25=0.5 \times \operatorname{rch} 1 \& 0.5 \times \mathrm{RCH} 2 \quad$ stat 0.25 flag 0 plot 6

\section{END}

\section{Annotated Example of a Template File}

The following file duplicates a file normally read by an application model, but SEARCHSTRINGS have been substituted for some of the numbers. UCODE replaces these SEARCHSTRINGS using parameter values. Only the spaces occupied by the SEARCH-STRING are replaced. The file has not been annotated internally because such annotation could interfere with the application model.
1
0
00

$\begin{array}{lc}0 & 1 \\ 0 & 1000 \\ 0 & 1000 \\ 0 ! \mathrm{k} 1, \ldots, \ldots ! \\ 0 ! \mathrm{kC}, \ldots, \ldots ! \\ 18 ! \mathrm{k} 2 \mathrm{~m}_{1}, \ldots,(18 \mathrm{~F} 3.0)\end{array}$




\section{Annotated Example of a Function Input File}

This annotated example displays a wide variety of the AWK functions, but it is expected that, most commonly, the function file will be used to apply different multiplication factors. For example, when simulating rivers in ground-water modeling, it is common to define a parameter to be the riverbed hydraulic conductivity and to use multiplication factors to represent river length, width, and thickness.

\#manipulate and substitute parameter $\mathrm{KrB}$ in template file a.tpl :file a.tpl

:key $\mathrm{KrB}$

$1 \quad(\$ x+3) / 10$

$2 \$ \mathrm{x} * 10$

$3 . .4 \$ \mathrm{x}-2$

\# sub rch1 in b.tpl,

\# for the $2^{\text {nd }}$ and $3^{\text {rd }}$ occurrences, the parameter value is

\# substituted directly

:file b.tpl

:key rchl

$1 \$ \mathrm{x} /(10 * 2)+5$

$4 \log (\$ \mathrm{x})$

$5.7 \cos (\$ x)-.0006$

$8 \$ \mathrm{x} * \$ \mathrm{x}$

$9 \operatorname{sqrt}(\$ x)$

\#sub rch2 in b.tpl

:file b.tpl

:key rch2

$6.10 \$ \mathrm{x}^{*} 1.5$

$16.20 \$ x^{*} 2.0$

$26.30 \$ \mathrm{x} * 2.5$

\section{Extract File-fn.ext}

The extract input file provides instructions for extracting values from application model output files. If needed, the extract file also provides instructions for using these values to calculate the simulated equivalent values that are to be compared with the observations specified in the universal input file.

\section{Directions for the Extract Input File}

Each line in the extract input file needs to be structured in one of the two ways: (1) the first space of the line needs to be one of nine indicator codes, or (2) the line needs to be blank or include only comments. In any line, anything after a \# sign is ignored by the program, and this 
provides a convenient method of including comments in the file. The input items can appear in nearly any order, but are executed sequentially. Thus, file must be opened before moving forward a given number of lines, or extracting a value between specified columns. The symbol designating comments and the nine indicator codes are as follows.

\# $\quad$ Comments (can be placed anywhere; any subsequent text on the line is ignored by the program).

The first indicator code identifies an observation from the universal input file, and is called an observation indicator code.

0

An OBS-NAME from the universal input file follows either directly or after one or more spaces.

A line with an $\mathbf{0}$ indicator code needs to be followed by instructions that define how to calculate a simulated value that is to be compared with the observation identified by OBS-NAME using extracted values and user-defined factors. The remaining indicator codes perform the functions needed to accomplish these calculations.

The next indicator code identifies the application model output file from which the subsequent extractions occur. This is called the file indicator code.

$<\quad$ The name of an application model output file follows; for example, <mod.out. The same file can be opened any number of times, but each time directions need to be given starting at the top of the file. When a file is opened, the position is at line zero. In order to operate on the first line, a subsequent code of +1 (discussed below) must be specified.

Three indicator codes are used to locate a line containing one or more values to be extracted. These are called locating indicator codes.

/..... A string of characters for which to search is listed between the forward slashes (the case of letters needs to be matched). For example, /HEADS/ would cause UCODE to search the file specified by the last file indicator code $<$ for the next occurrence of the string 'HEADS'. Note: Long strings are more efficient.

$+\quad$ Move down the following number of lines. For example, +3 indicates to move down 3 lines. To be positioned at the first line of a file requires that +1 be specified after opening the file. 
- $\quad$ Move up the following number of lines. For example, -13 indicates to move up 13 lines.

To ensure consistent results, use location indicator codes that function correctly in the presence of normal output file variations. For example, the number of lines printed by solvers often varies from run to run, and consistent results can not be achieved using only the + and indicator codes. Consistent results can be achieved by searching for a string that follows the solver output, and proceeding from there using + and - indicator codes.

Values are extracted with the extraction indicator code $\mathbf{c}$.

c

Extract the value that occurs between column numbers which follow the $\mathrm{c}$ and are separated by an underscore ( $\_$). Multiply the extracted value by a factor that equals 1.0 or a number which follows after a second underscore. For example, c52_63_0.5 extracts the value in columns 52 through 63 and multiplies it by 0.5 ; c52_63 extracts the value and multiplies it by 1.0. NOTE: Extract as many significant figures as possible, as discussed in the section "Calculation of Sensitivities by UCODE".

In simple situations, a line with observation indicator code $\mathbf{0}$ can be preceded or followed by a single line with file indicator code $<$, any number of lines with locating indicator codes, and a single line with extraction indicator code c. For example,

$<$ mod.out \# open a file

o $1 \mathrm{~A} \quad$ \# OBS-NAME $1 \mathrm{~A}$

$+1 \quad$ \# go to the first line in the file

c8_15 \# a value is extracted and a factor of 1.0 is used

Such a situation occurs when the product of one extracted value and its factor is directly comparable to an observed value specified in the universal input file, fn.uni.

For more complicated situations, UCODE includes three additional indicator codes, called function indicator codes, that define different ways in which extracted values and factors can be combined. These indicator codes may be followed by: one or more lines with file indicator code <, usually many lines with locating indicator codes, and usually many lines with extraction indicator code $c$. If all extractions are from the same file the single file indicator code can precede the function indicator code. 
Two function indicator codes perform exactly the same mathematical function, in that they sum the products of extracted values and their factors. That is, they perform calculations of the form

$$
\mathrm{Y}=\mathrm{X} 1 * \mathrm{~F} 1+\mathrm{X} 2 * \mathrm{~F} 2+\ldots
$$

where

$\mathrm{X} 1, \mathrm{X} 2, \ldots$ are values extracted using a $\mathrm{c}$ indicator code;

$\mathrm{F} 1, \mathrm{~F} 2, \ldots$ are the user-defined factors associated with $\mathrm{X} 1, \mathrm{X} 2, \ldots$ (the last of the three values listed after the $\mathbf{c}$ indicator code, or 1.0 if the third value is omitted); and

$\mathrm{Y}$ is a value that is to be compared with an observation.

Calculations of this form are commonly used both for interpolating values and summing values, and the different indicator code options are provided so that these different purposes can be identified more easily in the extract input file.

i

Interpolation is performed. For example, i4 indicates interpolation of the following 4 extracted values. For interpolation, the user-defined factors commonly sum to 1.0 .

s

Summation is performed. For example, $\mathbf{s} 20$ indicates summation of the following 20 extracted values. In summation the user-defined factors commonly each equal 1.0 .

The final indicator code performs a summation of the products of pairs of extracted values and their factors. That is, it performs calculations of the form:

$$
\mathrm{Y}=(\mathrm{X} 1 * \mathrm{~F} 1 * \mathrm{X} 2 * \mathrm{~F} 2)+(\mathrm{X} 3 * \mathrm{~F} 3 * \mathrm{X} 4 * \mathrm{~F} 4) \ldots,
$$

where:

$\mathrm{X} 1, \mathrm{X} 2, \mathrm{X} 3, \mathrm{X} 4, \ldots$ are values extracted using a $\mathrm{c}$ indicator code;

$F 1, F 2, F 3, F 4, \ldots$ are the factors associated with $X 1, X 2, \ldots$; and

$\mathrm{Y}$ is a value that is to be compared with an observation.

Calculations of this form are used in a variety of circumstances. A common ground-water example occurs when application model output files include flow rates and concentrations, and 
the observation of interest is a flux-averaged concentration. The applicable function indicator code is $\mathbf{p}$, which stands for product.

Sum a sequence of products of pairs of extracted values and their associated factors. For example, p2 indicates the product of the following 2 pairs of extracted values and their factors will be summed. That is, the product of the following 2 extracted values will be summed with the product of the subsequent 2 extracted values. Four values need to be extracted using four lines with extraction indicator codes (c). If the product of 5 pairs were to be summed, the code would be p5, and 10 extractions (code $\mathrm{c}$ lines) would follow before another observation name was specified.

END indicates the end of data input for this file.

\section{Annotated Example of an Extract Input File}

$<$ mod.out \#open application model output file

o 1A \#\#servation 1: simulated equivalent is extracted directly from the output file /IN LAY/ \# search for string

c8_15 \# extract the value in column 8 through 15 ; the factor is set to 1.0

o 1B \#\# observation 2: simulated equivalent is interpolated

+2 \# go down two lines from the line where the last observation was extracted

i2 \# interpolate using the next two extracted values and their factors

\# the observation lies halfway between two nodal points so both factors equal 0.5 c50_57_0.5 \# extract the value in column 50 through 57; the factor is set to 0.5 c64_71_0.5 \# extract the value in column 64 through 71 ; the factor is set to 0.5

o 1C \#\# observation 3: simulated equivalent is interpolated

+12 \# go down twelve lines from the line where the last observation was extracted

i4 \# interpolate using the next four extracted values and their factors

\# the coefficients below were calculated by bi-linear interpolation based on the

\# distance from the observation location to the grid nodes

c50_57_0.1875

c64_71_0.0625

$+2$

c50_57 0.5625

c64_71_0.1875

o flow \#\# observation 5; simulated equivalent is a sum 
-150 \# go up 150 lines above where the last value was extracted to get above the search string /RIVER LEAKAGE/ \#search for string

$+1 \quad$ \# go down one line

s3 \# sum the products of the next three extracted values and their factors

\# the negative factors below are used so that the sign conventions of the simulated value and

\# the observation are consistent

c_59_- 0.5 \# the absolute value of the factor is less than 1.0 to include only part in the sum

$+1$

c49_59_-1.0

$+1$

c49 $59-0.25$

o concentratio \#\# observation 6; simulated equivalent extracted from another output file

$<$ mt3d.out \# open new file

/CONCENTRATION/ \#search for string

$+25 \quad$ \# go down 25 lines

c53_63 \# extract value and set its factor to 1.0

o mass \#\# observation 7; simulated equivalent is calculated using a $p$ indicator code

p2 \# the sum the products of 2 pairs of extracted values and their factors.

\# first pair

$<$ mod.out

\# open file

/BOUNDARY LEAKANCE/

$+3$

c52_58 \# extract value; factor equals 1.0

$<\mathrm{m} \overline{\mathrm{J}}$ d.out $\quad$ \# open file

/CONCENTRATION STEP 6/

$+38$

c9_18 \# extract value; factor equals 1.0

\# second pair

$<$ mod.out \# open file

/BOUNDARY LEAKANCE/

$+4$

c52_58 \# extract value; factor equals 1.0

$<\mathrm{mt} 3$ d.out \# open file

/CONCENTRATION STEP 6/

$+38$

c19 28

\# extract value; factor equals 1.0

END 
Input Files for Predictions and Differences and Linear Confidence and Prediction Intervals

Predictions and differences, and their linear confidence and prediction intervals, are discussed in sub-section "Predictions and Differences and Their Linear Confidence and Prediction Intervals" within the section "Inverse Modeling Considerations". These quantities are calculated with UCODE using PHASE=44 and 45, with a slightly modified version of the computer program YCINT (Hill, 1994). In UCODE, PHASE=44 is used to calculate predictions for conditions that can (but may not) differ from the calibration conditions; PHASE $=45$ is used to calculate differences. The differences are calculated by subtracting values produced by a base simulation (simulated when PHASE=45) from values produced by a predictive simulation (simulated when PHASE =44). That is:

(value from predictive simulation with $\mathrm{PHASE}=44$ )

- (value from base simulation with PHASE=45)

$=$ difference

Confidence and prediction intervals generally are calculated only for a satisfactorily calibrated model. $\mathrm{PHASE}=44$ can be executed only after running $\mathrm{PHASE}=3$ with $\mathrm{GRAPH}=1$ in fn.uni, which creates files: fn._tp, temp.u44, temp.p44, temp.f44, and temp.e44. For PHASE=44, files temp.u44, temp.p44, temp.f44, and temp.e44, either need to be modified by the user, as described below and saved with the prefix $f n$; or, for those files where no modifications are needed, they must be copied to the filenames fn.u44, fn.p44, fn.f44, and fn.e44, respectively. The modified files need to be present in the directory in which UCODE with PHASE $=3$ was executed and from which UCODE with $\mathrm{PHASE}=44$ is initiated. PHASE=45 can be executed only after running PHASE=44 in the same directory and modifying, then saving or copying the files: temp.u45, temp.p45, temp.f45, and temp.e45, to filenames: fn.u45, fn.p45, fn.f44, and fn.e45, respectively.

The rest of this section describes how to construct files for PHASE $=44$ and 45 , including files fn.u44, fn.p44, fn.f44, and fn.e44, for PHASE=44, and files fn.u45, fn.p45, fn.f45, and fn.e45, for PHASE=45. These files are constructed in the same manner as the universal, prepare, function, and extract files discussed above, and are referred to as the prediction universal file, the prediction prepare file, and so on, and the base universal file, base prepare file, and so on.

Although it may seem redundant to create these additional files, this organization makes it easy to 
return to $\mathrm{PHASE}=3$ after executing the latter phases, as often is needed to evaluate alternative conceptual models.

\section{Directions for Input Files for Predictions--PHASE=44}

Input files for $\mathrm{PHASE}=44$ are constructed as follows.

1. Change the application model(s), the application model input files, and associated template files, as needed to simulate the predictions. The following checklist includes common changes, but additional changes also may be needed.

a) Change the batch file(s) that execute the application model(s). If the name of the batch file is changed, or if a batch file is added, include this new information in the prediction universal file, fn.u44.

b) Change the files used by the application model(s). For example, in a ground-water simulation, the imposed pumpage may need to be changed.

c) Change the prediction prepare and function files, as required if application code input files used for the prediction simulation do not conform to the input files used during model calibration. In this circumstance, the prediction prepare file, fn.p44, needs to be changed to specify the file names pertinent to the predictive simulation. If used, the prediction function file, fn.f44, also needs to have file names changed, and, though unlikely, the occurrences also may need to be changed. If such changes are made, it is suggested that the application model(s) be checked to ensure that the substitutions produce the same system characteristics as they did for the calibration.

d) As needed, change the batch files used to run the application model(s) for the prediction conditions.

2. Set $\mathrm{PHASE}=44$ in file fn.uni. Although the rest of fn.uni is ignored for $\mathrm{PHASE}=44$, usually it is most convenient not to modify the rest of the file.

3. List the predictions and specify information about the predictions using the prediction universal file, fn.u44. Use the last part of the file, which was used to specify observations in the fn.uni file. The format described for observations also is used for predictions, so that the lines are of the form:

\section{OBS-NAME OBS-VALUE STATISTIC STAT-FLAG PLOT-SYMBOL} where, for $\mathrm{PHASE}=45$, 
OBS-NAME - Prediction name (can be up to 12 characters long).

OBS-VALUE - Specify a number, but the number is not used.

STATISTIC - The standard deviation or variance of the measurement error expected for the prediction used to calculate prediction intervals (see Hill, 1994, eq. 15,16 , and 17).

STAT-FLAG - Set to 0 if STATISTIC is a variance and 1 if STATISTIC is a standard deviation.

PLOT_SYMBOL - Used as before.

4. Edit prediction extract file fn.e44, which was produced by UCODE with PHASE=3 and GRAPH=1. As produced, fn.e44 simply contains comment statements with instructions. The completed fn.e44 needs to extract values from application model output file(s) using the same mechanisms defined for the extract file above, and define how to calculate the predictions from the extracted values.

\section{Directions for Input Files for Differences--PHASE=45}

Input files for $\mathrm{PHASE}=45$ are constructed as follows.

1. Change the application model(s) and application model input files as needed to represent the base conditions, which are used to calculate differences from the PHASE $=44$ execution. See the list presented for PHASE $=44$ for suggested changes. Set PHASE $=45$ in file fn.uni. Although the rest of fn.uni is ignored for $\mathrm{PHASE}=45$, usually it is most convenient not to modify the rest of the file.

2. List the base quantities and specify information about them using the base universal file, fn.u45. Use the last part of the file, which was used to specify the predictions in fn.u44. The order needs to be identical to that of the predictions listed in fn.u44 because the base values are subtracted from the predictions using that order. Thus, the first base value defined in fn.e45 is subtracted from the first prediction specified in fn.e44, the second base value is subtracted from the second prediction, and so on. As before, lines in the last part of the file need to be of the form:

\section{OBS-NAME OBS-VALUE STATISTIC STAT-FLAG PLOT-SYMBOL} where, for PHASE=45,

OBS-NAME - Name of the difference (can be up to 12 characters long). 
OBS-VALUE - Specify a number, but the number is not used.

STATISTIC - The standard deviation or variance of the measurement error that would be likely if the base value were measured. STATISTIC is used to calculate prediction intervals (see discussion above).

STAT-FLAG - Set to 0 if STATISTIC is a variance, and 1 if STATISTIC is a standard deviation.

PLOT_SYMBOL - Used as before.

3. Edit the base extraction file fn.e45, which was produced by UCODE with PHASE=44. As produced, fn.e 45 is identical to fn.e44. The completed fn.e 45 file needs to extract values from application model output files that reflect the base case, using the same mechanisms used in the extract file discussed above, and to define how to calculate the base values from the extracted values. The base values can be extracted in any order; they are subtracted from values produced when PHASE=44 using the order established in the fn.u44 and fn.u45 files.

\section{USING UCODE OUTPUT}

Different output files are produced by UCODE depending on the value of PHASE designated in fn.uni. For PHASE=1, 2, 22, and 3, the primary output file is fn._ot. Example output files are distributed with UCODE in the ex subdirectory as Testph1._ot, Testph2._ot, Testph22._ot, and Testph3._ot. An example fn._ot file for PHASE=3 is presented in Appendix A, and the contents of fn._ot for other PHASES are described in the following sections. For PHASE $=11,33,44$, and 45 , the primary output files are fn._11, fn._33, fn._44, and fn._45, respectively. Additional output files are described below, and suggestions for using the output files are presented. As stated elsewhere in this report, when using UCODE, the $f n$ in the filenames is replaced by the user-defined prefix specified in the UCODE run command. The filenames are italicized to remind the reader of this substitution.

\section{Output Files from a Forward Simulation--PHASE $=1$ and 11}

When PHASE=1, UCODE executes the application model(s) once using the starting parameter values and produces files fn._ck and fn._ot. 
Before executing UCODE with PHASE=1, it is imperative that the application model(s) execute correctly from the directory where UCODE is executed, using the command line specified in fn.uni. To ensure this, execute the application model(s) from the directory where UCODE will be executed, using the command(s) that are to be specified in fn.uni. Check that the output file(s) from the application model(s) are generated from this run, and are correct. Resolve any problems.

fn._ck contains the extraction commands as executed, the values extracted from the application output files, the simulated equivalent values, and the corresponding observation values from fn.uni. The extracted values appear in lines such as :

$$
\ll<\text { extracted item }=-0.218391>>>
$$

and the extracted characters start one space after the equal sign and end just before the first greater-than sign. In the case shown above, no blank spaces were included in the extraction, It is acceptable, however, and at times desirable, to include blanks. For example, the length of an extracted value may vary depending on the values of the parameters used to generate the output. In this case, the extraction needs to be large enough to include all possibilities, while excluding unwanted characters. Check fn._ck to determine if extracted characters are missing or are incorrect. Use fn._ck and the application output file(s) to find and correct all errors in fn.ext.

After executing UCODE with PHASE=1, fn._ot includes the table and statistics described in the top of table 3 . When calibration begins or when a new conceptual model is first being tested, these values reflect the model fit given the initial model configuration and starting parameter values, and the initial ideas about how to calculate equivalent simulated values to be compared with the observations. Exceptionally large discrepancies between simulated and observed values may indicate, for example, that there is a conceptual error either in the model configuration or in the calculation of the simulated values. Inspection of these values for PHASE $=1$, and correction of obvious problems, can eliminate many hours of frustration.

Additional suggested checks include the following:

1. Delete the application model output file(s) listed in fn.ext and the application model input file(s) listed in fn.pre, if they are present in the directory, before executing UCODE with PHASE $=1$. After execution, check that the correct application model input files were created by UCODE and scrutinize the application model output file(s) to check that UCODE executed the application model correctly. If errors are found, continue to review and correct the fn.pre file and the template files, until the application model input files are correct. 
2. Check that the application model(s) are executed correctly from the directory where UCODE is executed using the command line specified in fn.uni. Check all other directories and files referenced in the UCODE input.

3. Check fn._ot to determine that the UCODE input items are echoed correctly. Use the instructions in the section "Input File Construction", the example files in Appendix A, and the Testph\#._ot files distributed with UCODE in the ex subdirectory to determine what should be printed in fn._ot. (This suggestion applies to all PHASES).

4. If the simulated values are not being related to the correct observations in fn._ck, check the names of the observations and make necessary changes.

It is essential for UCODE to perform correctly at PHASE=1. Proceeding with errors will result in an invalid regression and wasted time. After obtaining satisfactory extractions and resolving major errors with $\mathrm{PHASE}=1$, proceed to $\mathrm{PHASE}=11$, or 2 and(or) 22 by changing the value of PHASE in fn.uni.

When PHASE=11, UCODE executes the application model many times using parameter values at increments within ranges defined by the user in the prepare file. The primary output file is fn._11, which contains data for generating contour graphs of the objective function. These data are arranged in space-delimited columns. The first column contains values of the first parameter in the fn.pre for which ESTIMATE=1 for PHASE=11. If a parameter is log transformed, the next column will contain the base- $10 \log$ of the first parameter value. Otherwise, the next column contains values of the second parameter, and so on, until all parameters indicated by the user have been included. The final two columns include the sum-of-squared, weighted residuals, with and without prior, respectively. Labels describing the columns of values written in the fn._11 file are printed at the bottom of the $f n . \_o t$ and in the $f n . \_l b$ file (lb represents label). The $f n . l b$ file is created because execution of subsequent phases will overwrite the fn._ot file. The fn._11 file is intended for use with external plotting software. Many such packages will not function if anything other than the data appears in the file, thus the separate file for labeling the columns. 


\section{Output Files from Sensitivity Calculations--PHASE=2 and 22}

When $\mathrm{PHASE}=2$, UCODE uses the starting parameter values and slightly perturbed sets of parameter values (as described after equation 1) to execute the application model(s) as many times as needed to calculate sensitivities. Files fn._ot and fn._ck are produced.

When PHASE $=2$, fn._ot contains the quantities presented in table 3 and the first two rows of table 4; when PHASE=22, fn._ot contains all of the quantities listed in tables 3 and 4.

fn._ck contains the values extracted from the application model output file(s) created using the starting, unperturbed, parameter values. Thus, the extracted values will not be consistent with the final PHASE $=2$ or 22 application model output file(s) because these are produced using the final set of parameter values, for which one value is perturbed from its starting value. If any errors in the extraction are recognized during a PHASE $=2$ or 22 run, it is best to return to PHASE $=1$ to correct them.

Whether UCODE is executed for both PHASE=2 and 22 or only for one of them depends on the execution time of the application model(s) and whether anticipated problems include parameter insensitivity or extreme parameter correlation or both. If DIFFERENCING $=1$ in fn.uni, as suggested, $\mathrm{PHASE}=22$ requires about twice the execution time of $\mathrm{PHASE}=2$. Problems of parameter insensitivity often can be diagnosed using the composite scaled sensitivities, which are printed when PHASE=2 or 22 and SCALE-SENSITIVITIES $=1$ in fn.uni. Problems of extreme parameter correlation need to be diagnosed using the correlation coefficients printed when PHASE=22. For problems with small execution times (forward execution times of less than about 1 minute), probably only $\mathrm{PHASE}=22$ is needed. For problems with larger execution times, PHASE $=2$ can be used to investigate and address parameter insensitivity before proceeding to PHASE $=22$ to investigate and address both parameter insensitivity and correlation. Approaches to addressing parameter insensitivity and correlation are discussed above in the section "Inverse Modeling Considerations".

A problem that sometimes occurs when $\mathrm{PHASE}=2$ or 22 is that the printed sensitivities equal zero. If this occurs, consider the suggestions presented in the section "Calculation of Sensitivities".

After satisfactory conclusion of $\mathrm{PHASE}=2$ and(or) 22, proceed to $\mathrm{PHASE}=3$ by changing the value of PHASE in fn.uni. 


\section{Output Files from Nonlinear Regression--PHASE=3}

When PHASE=3, UCODE performs nonlinear regression and produces files fn._ck, fn._st, and fn._ot, as well as files for proceeding to higher phases, such as fn._b1, which is not generally accessed by the user, and temp.u44, temp.p44, temp.f44, and temp.e44, which are edited by the user to produce, fn.u44, fn.p44, fn.f44, and fn.e44 for subsequent execution of Phase 44. In addition, when GRAPH=1 in fn.uni, files containing data for analysis of residuals are created, as listed in table 5 .

fn._ck contains values extracted from the application model output file(s) created using the starting parameter values. Thus, the extracted values in fn._ck will not be consistent with the final PHASE=3 application model output file(s). If any errors in the extraction are recognized during a PHASE=3 run, it is best to return to PHASE=1 to correct them. Such errors likely would become evident when evaluating the observed and simulated values printed in fn._ot, which is discussed below.

fn._st is a restart file that contains updated parameter values for each iteration. Values from this file can be used to replace the starting parameter values in the prepare file so that (1) fn._ck can be produced for intermediate parameter values using $\mathrm{PHASE}=1$ and $\mathrm{PHASE}=2$ and(or) 22 to investigate extracted values and sensitivities calculated with these parameter values, and (2) the regression can be started using values from intermediate parameter-estimation iterations that are likely to be closer to the optimal parameter values. The second use of the values listed in the restart file often reduces execution time.

fn._ot is the main output file for PHASE=3, and indicates whether or not the regression converged. In either case, fn._ot lists the statistics described in tables 3 through 6. A sample fn._ot file for PHASE=3 is included in Appendix A of this report and is called test._ot. The best way to become familiar with the file is to review that example and the comments in tables 3 through 6 .

Residual analysis can be accomplished using the statistics listed in table 3 and the files listed in table 5. Examples of the files with their contents labeled are shown in Appendix A. Filenames with two letters in the suffix include two columns of values and generally are used to create $x-y$ plots. Filenames with a single letter suffix contain only one column of values and generally are used to create maps, temporal plots, or higher-dimensional images of residuals. Each line includes the information related to one observation or piece of prior information. In all files, 
each line includes the OBS-NAME from the fn.uni file or, for prior information, the PLOTSYMBOL from the fn.pre file. Comments about how to use the generated plots are presented in table 3. Additional discussion can be found in Hill (1998) and references cited therein.

During the calibration of most models, UCODE with PHASE $=3$ will be executed many times as various aspects of the model are changed to test hypotheses about the system. Once a satisfactory parameter estimation is obtained, linearity of the model at the optimized parameter values can be evaluated by executing UCODE with PHASE $=33$ in fn.uni.

\section{Output Files from Test of Linearity--PHASE=33}

When PHASE=33, UCODE calculates the modified Beale's measure of model linearity of Cooley and Naff (1990) and statistics that indicate the magnitude of the nonlinearity of each parameter. These calculations are executed using a slightly modified version of the computer program BEALEP (Hill, 1994). PHASE=33 produces primary output file fn._33 and file fn._b2.

Generally, the user does not access the latter two files. An example fn._33 file is presented in Appendix A as test._33. Some information related to interpretation of the output is included in the file. Hill (1994) explains of the modified Beale's measure and the information printed in the fn._33 file. 
Table 3: Residual and model fit statistics printed in fn._ot when PHASE=1, 2, 22 or 3

[Summarized from Hill (1998, sections "Graphical Analysis of Model Fit and Related Statistics" and "Statistical Measures of Model Fit"); see example file test. ot in Appendix A of this report.]

\begin{tabular}{|c|c|}
\hline $\begin{array}{l}\text { Statistic as labeled in } \\
\text { fn._ot }\end{array}$ & Comments \\
\hline $\begin{array}{l}\text { Table of observations, } \\
\text { simulated values, residuals, } \\
\text { and weighted residuals }\end{array}$ & $\begin{array}{l}\text { Residuals are calculated as the observations minus the simulated values. Use } \\
\text { this table to investigate model fit for individual observations. }\end{array}$ \\
\hline $\begin{array}{l}\text { MAXIMUM WEIGHTED } \\
\text { RESIDUAL } \\
\text { MINIMUM WEIGHTED } \\
\text { RESIDUAL } \\
\end{array}$ & $\begin{array}{l}\text { The maximum weighted residual indicates where the worst fit occurs relative } \\
\text { to the expected fit, and often reveals gross errors. The minimum provides a } \\
\text { little context by which to judge the maximum value. }\end{array}$ \\
\hline $\begin{array}{l}\text { AVERAGE WEIGHTED } \\
\text { RESIDUAL }\end{array}$ & $\begin{array}{l}\text { An average weighted residual near zero is needed for an unbiased model fit } \\
\text { (usually satisfied if regression converges). }\end{array}$ \\
\hline $\begin{array}{l}\# \text { RESIDUALS }>=0 . \\
\# \text { RESIDUALS }<0 .\end{array}$ & $\begin{array}{l}\text { The number of positive and negative residuals indicates whether the model } \\
\text { fit is consistently low or high. Preferably, the two values are about equal. }\end{array}$ \\
\hline NUMBER OF RUNS & $\begin{array}{l}\text { Number of sequences of residuals with the same sign ( }+ \text { or }-) \text {. Too few or } \\
\text { too many runs could indicate model bias. The related statistic is printed and } \\
\text { interpreted in fn.-ot. See Appendix A, file test._ot for an example of the } \\
\text { runs test and its interpretation. Hill (1998) explains the test. }\end{array}$ \\
\hline \multicolumn{2}{|c|}{ The following are printed only for PHASE=22 and 3 . } \\
\hline $\begin{array}{l}\text { LEAST-SQUARES OBJ FUNC } \\
\text { (DEP.VAR. ONLY) } \\
\text { (W/ PARAMETERS) } \\
\end{array}$ & $\begin{array}{l}\text { Weighted least-squares objective function value. Given randomly distributed } \\
\text { residuals and the same observations and weight matrix, a lower value of the } \\
\text { least-squares objective function indicates a closer model fit to the data. }{ }^{2}\end{array}$ \\
\hline $\begin{array}{l}\text { CALCULATED ERROR } \\
\text { VARIANCE }\end{array}$ & $\begin{array}{l}\text { Given randomly distributed residuals, smaller values are desirable. Values } \\
\text { less than } 1.0 \text { indicate that the model generally fits the data better than is } \\
\text { consistent with the variances used to weight the observations and prior } \\
\text { information, values greater than } 1.0 \text { indicate that the fit is worse. } \\
\text { See Hill }(1998 \text {, Guideline } 6)\end{array}$ \\
\hline $\begin{array}{l}\text { STANDARD ERROR OF THE } \\
\text { REGRESSION }\end{array}$ & $\begin{array}{l}\text { The square root of the calculated error variance, and the same comments } \\
\text { apply. }\end{array}$ \\
\hline $\begin{array}{l}\text { CORRELATION OEFFICIENT } \\
\text { W/PRIOR }\end{array}$ & $\begin{array}{l}\mathrm{R} \text { of Hill (1998). Correlation between weighted observed or prior } \\
\text { information and simulated values. Correlation coefficient values below about } \\
0.9 \text { indicate poor model fit. }\end{array}$ \\
\hline $\begin{array}{l}\text { MAX LIKE OBJ FUNC } \\
\text { AIC } \\
\text { BIC }\end{array}$ & $\begin{array}{l}\text { The maximum likelihood objective function, and the AIC and BIC statistics. } \\
\text { Given randomly distributed residuals, lower values indicate better fitting } \\
\text { models. }\end{array}$ \\
\hline $\begin{array}{l}\text { ORDERED WEIGHTED } 1 \\
\text { RESIDUALS }\end{array}$ & The weighted residuals are ordered smallest to largest. ${ }^{2}$ \\
\hline $\begin{array}{l}\text { CORRELATION BETWEEN } \\
\text { ORDERED WEIGHTED } \\
\text { RESIDUALS AND NORMAI } \\
\text { ORDER STATISTICS }\end{array}$ & $\begin{array}{l}\mathrm{R}_{\mathrm{N}}^{2} \text { of Hill (1998). Values above the critical values listed in Hill (1998, } \\
\text { Appendix D) and printed in fn._ot indicate independent, normal weighted } \\
\text { residuals, and that the points of file fn._nm (table 5) are likely to fall on a } \\
\text { straight line. }\end{array}$ \\
\hline
\end{tabular}

1. THIS FONT is used for labels taken directly from the output

2. To allow detection of unusually poor fit to one type of regression data, these statistics are calculated both for a) the observed dependent variables (the observations) and b) the observations and prior information. 
Table 4: Parameter statistics printed in fn._ot when PHASE=2, 22, and 3

[Summarized from Hill (1998, section "Parameter Statistics" and Guidelines 3 and 9); see example file test. ot in Appendix A of this report.]

\begin{tabular}{|c|c|}
\hline $\begin{array}{l}\text { Parameter statistic or } \\
\text { characteristic }\end{array}$ & Function of item in interpreting results \\
\hline $\begin{array}{ll}\text { DIMENSIONLESS } & \text { SCALED } \\
\text { SENSITIVITIES } & \text { (SCALED BY } \\
\left.B^{\star}(W T * * .5)\right)^{1} & \end{array}$ & $\begin{array}{l}\text { Indicates the importance of an observation to the estimation of a parameter } \\
\text { or, conversely, the sensitivity of the simulated equivalent of the observation } \\
\text { to the parameter. These values are listed in a table with a row for each } \\
\text { observation and a column for each parameter. }\end{array}$ \\
\hline $\begin{array}{l}\text { COMPOSITE SCALED } \\
\text { SENSITIVITIES } \\
\text { ((SUM OE THE SQUARED } \\
\text { VALUES }) / N D)^{* * .5} 1\end{array}$ & $\begin{array}{l}\text { Indicates the information content of all of the observations for the estimation } \\
\text { of a parameter. Printed at the end of the scaled sensitivity table. Values less } \\
\text { than } 0.01 \text { times the largest value indicate parameters with much less } \\
\text { information, and that the regression is likely to have trouble converging. }\end{array}$ \\
\hline \multicolumn{2}{|c|}{ The statistics below are printed only for PHASE $=22$ and 3 . } \\
\hline $\begin{array}{l}\text { Parameter covariance } \\
\text { matrix }\end{array}$ & $\begin{array}{l}\text { The diagonal tems of this matrix are variances, the off-diagonal terms are } \\
\text { covariances. These values are used to calculate the statistics listed below. }\end{array}$ \\
\hline \multicolumn{2}{|c|}{ The statistics in this box are printed in a table labeled "PARAMETER SUMMARY". } \\
\hline Parameter values & $\begin{array}{l}\text { When parameter estimation converges, these are the optimized parameter } \\
\text { values and the rest of table } 4 \text { constitutes a linear uncertainty analysis of } \\
\text { these optimized parameter values. Unreasonable optimal parameter values } \\
\text { indicate a problem with the observations or the model. }\end{array}$ \\
\hline $\begin{array}{l}\text { Parameter standard } \\
\text { deviations }\end{array}$ & $\begin{array}{l}\text { Confidence Intervals on optimized parameter values indicate the precision } \\
\text { with which the values are estimated. }\end{array}$ \\
\hline $\begin{array}{l}\text { Parameter coefficients of } \\
\text { variation }\end{array}$ & $\begin{array}{l}\text { Provides a dimensionless measure of the precision with which the } \\
\text { parameters are estimated which can be used to compare the precision of } \\
\text { parameters with different dimensions. }\end{array}$ \\
\hline $\begin{array}{l}\text { Parameter } 95 \% \text { linear } \\
\text { individual confidence } \\
\text { Intervals }^{3}\end{array}$ & $\begin{array}{l}\text { Given normally distributed residuals, reasonable optimized parameter } \\
\text { values, a satisfactory model fit, and a linear model, linear confidence } \\
\text { intervals are likely to reflect the uncertainty of the optimal parameter } \\
\text { values. Model linearity is tested using PHASE }=33 \text {. }\end{array}$ \\
\hline $\begin{array}{l}\text { Parameter correlation } \\
\text { coefficients }\end{array}$ & $\begin{array}{l}\text { For any set of parameter values, absolute values larger than about } 0.95 \text { may } \\
\text { indicate that two or more parameters can not be uniquely estimated. } \\
\text { Explore uniqueness by varying starting parameter values and checking for } \\
\text { changes in optimized parameter values. (see instructions printed in } f n \text {. ot) }\end{array}$ \\
\hline
\end{tabular}

1. Printed for SCALE-SENSITIVITIES $=1$ in fn.uni. Replaced by a table of unscaled sensitivities when SCALE-SENSITIVITIES $=0$, and a table of one-percent sensitivities when SCALESENSITIVITIES $=2$. For SCALE-SENSITIVITIES $=3$, both dimensionless and one-percent scaled sensitivity tables are printed.

2. For log-transformed parameters, the parameter value and associated confidence intervals are calculated and printed first as log-transformed values, and next as exponential (native) values. The native values generally will be of most interest.

3. Calculated as usual; see eq. 28 of Hill (1998). 


\section{Table 5: Files created by UCODE that contain data sets for graphical residual analysis}

[Summarized from Hill (1998, section "Graphical Analysis of Model Fit and Related Statistics"); example files with the contents labeled are presented in Appendix A; these files are produced when PHASE $=3$ and GRAPH=1]

\begin{tabular}{|c|c|c|}
\hline Filename $^{1}$ & Intended graph or analysis & Comments $^{2}$ \\
\hline fn._os & $\begin{array}{l}\text { Observed versus simulated } \\
\text { values }\end{array}$ & $\begin{array}{l}\text { Ideally points lie along a line with a slope of } 1.0 \text {. Uneven } \\
\text { spreading along the length of the line does not } \\
\text { necessarily indicate problems because the values are not } \\
\text { weighted. }\end{array}$ \\
\hline fn._ww & $\begin{array}{l}\text { Weighted observed versus } \\
\text { weighted simulated values. }\end{array}$ & $\begin{array}{l}\text { Ideally the points lie along a line with a slope of } 1.0 \text {. A } \\
\text { different slope or uneven spreading along the length of } \\
\text { the line may indicate problems. }\end{array}$ \\
\hline fn._ws & $\begin{array}{l}\text { Weighted residuals versus } \\
\text { weighted simulated values. } \\
\text { Traditionally, weighted } \\
\text { simulated values are on the } x \\
\text { axis. }\end{array}$ & $\begin{array}{l}\text { Ideally the points are evenly distributed above and } \\
\text { below the zero weighted residual axis, which indicates } \\
\text { random weighted residuals. Uneven spreading along the } \\
\text { zero axis may indicate problems. }\end{array}$ \\
\hline fn._r & $\begin{array}{l}\text { The residuals listed in this file } \\
\text { can be plotted against any } \\
\text { independent variable of interest. }\end{array}$ & $\begin{array}{l}\text { Possible displays include plotting values from a single } \\
\text { location against time on an } x-y \text { graph, on maps, on } \\
\text { three-dimensional images of a contaminant plume, and } \\
\text { on nested maps representing different times. Useful to } \\
\text { display model fit, but use of unweighted residuals } \\
\text { means that large values may not indicate problems. }\end{array}$ \\
\hline fn._w & $\begin{array}{l}\text { The weighted residuals listed } \\
\text { can be plotted as suggested for } \\
\text { fn._r }\end{array}$ & $\begin{array}{l}\text { The plotted values should be random, which can be } \\
\text { tested using a runs test. Individual extreme values and } \\
\text { areas of consistent negative or positive values are likely } \\
\text { to indicate problems. They should be closely examined } \\
\text { and the model corrected if possible. }\end{array}$ \\
\hline fn._nm & $\begin{array}{l}\text { Normal probability graph of the } \\
\text { weighted residuals. The } \\
\text { probability values are } \\
\text { transformed so that they plot on } \\
\text { an arithmetic scale. }\end{array}$ & $\begin{array}{l}\text { Ideally the weighted residuals fall along a straight line. } \\
\text { If not, possibilities include: (1)The apparent } \\
\text { nonrandomness results from limited number of values or } \\
\text { from the regression itself, which can be tested using } \\
\text { fn._rd and } f \text {._rg, (2) problems are indicated. }{ }^{3}\end{array}$ \\
\hline fn._rd & $\begin{array}{l}\text { Normal probability graph of } \\
\text { random numbers. }\end{array}$ & $\begin{array}{l}\text { Demonstrates the variation from a straight line caused } \\
\text { by the limited number of plotted values. }\end{array}$ \\
\hline fn._rg & $\begin{array}{l}\text { Normal probability graph of } \\
\text { correlated random numbers. }\end{array}$ & $\begin{array}{l}\text { Demonstrates the variation from a straight line caused } \\
\text { by the limited number of weighted residuals and by the } \\
\text { regression fitting of the data. }\end{array}$ \\
\hline
\end{tabular}

1. fn is replaced by the prefix defined by the user on the UCODE command line.

2. The phrase "indicate problems" means that the circumstance described indicates that the processes represented by the data may not be adequately modeled.

3. For examples, see Hill (1998) and references cited therein. 
Table 6: Regression performance measures printed in fn._ot when $\mathrm{PHASE}=3$

[These measures are printed for each parameter-estimation iteration; see example file test._ot in Appendix A of this report]

\begin{tabular}{|l|l|}
\hline $\begin{array}{c}\text { Performance measure as } \\
\text { labeled in } f \text { n._ot }\end{array}$ & \multicolumn{1}{|c|}{ Comments } \\
\hline $\begin{array}{l}\text { MARQUARDT PARAMETER } \\
\text { (AMP) }\end{array}$ & $\begin{array}{l}\text { Used as described in Hill (1998, eq. 4). Non-zero values indicate an ill- } \\
\text { conditioned problem. }\end{array}$ \\
\hline $\begin{array}{l}\text { FACTOR FOR SCALING PAR. } \\
\text { CHANGE (AP) }\end{array}$ & $\begin{array}{l}\text { The damping parameter of eq. 4 of Hill (1998). Values less than 1.0 } \\
\text { indicate that the maximum fractional parameter change exceeded the } \\
\text { MAX-CHANGE value specified in fn.uni, or that oscillation control was } \\
\text { active (Hill, 1998, Appendix B). }\end{array}$ \\
\hline $\begin{array}{l}\text { MAX. FRACT IONAI PAR. } \\
\text { CHANGE (DMX) }\end{array}$ & $\begin{array}{l}\text { Maximum fractional change calculated for any parameter in the parameter- } \\
\text { estimation iteration. The fractional change is always relative to the native } \\
\text { parameter value, even if the parameter is log-transformed (Hill, 1998, } \\
\text { Appendix B). When this value is less than the user specified } \\
\text { TOLERANCE of file fn.uni, the regression converges. }\end{array}$ \\
\hline $\begin{array}{l}\text { MAX. FRAC. CHANGE } \\
\text { OCCURRED FOR PAR. \# }\end{array}$ & $\begin{array}{l}\text { The parameter for which the maximum fractional change occurs. If the } \\
\text { regression does not converge, the parameters listed here are likely to be } \\
\text { contributing to the problem. }\end{array}$ \\
\hline
\end{tabular}

1. The names in parentheses, AMP, AP, and DMX are used to label these performance measures in a table printed in fn._ot.

\section{Output Files from Predictions and Differences--PHASE=44 and 45}

When PHASE=44, UCODE calculates predictions and the 95-percent linear confidence and prediction intervals on the predictions using a slightly modified version of the computer program YCINT of Hill (1994), as described above in the section "Predictions and differences and their linear confidence and prediction intervals". PHASE $=44$ produces primary output file fn._44, file fn._y1, which generally is not accessed by the user, and files, temp.u45, temp.p45, temp.f45, and temp.e45, for the user to edit and create, fn.u45, fn.p45, fn.f45, and fn.e45 for subsequent execution of Phase 45. Tables in the fn._44 file are labeled, indicating the type of confidence or prediction interval included in the table. The labels used are:

INDIVIDUAL 95\% CONFIDENCE INTERVALS

$\mathrm{k}$ SIMULTANEOUS $95 \%$ CONFIDENCE INTERVALS, ( $\mathrm{k}$ is replaced by a number) or UNDEFINED NUMBER OF SIMULTANEOUS 95\% CONFIDENCE INTERVALS 
The first label is followed by individual confidence intervals. The second label is followed by the Bonferroni or $d=k$ Scheffe $(d=N P$ Scheffe if $k>N P$ ) confidence intervals, whichever are smaller (Bonferroni are used when they are equal). These are labeled as:

\section{BONFERRONI CONFIDENCE INTERVALS ARE USED}

\section{SCHEFFE CONFIDENCE INTERVALS ARE USED}

The last of the three labels is followed by $d=N P$ Scheffe confidence intervals. An example of a fn._44 file is presented in Appendix A.

When PHASE=45, UCODE calculates 95-percent linear confidence and prediction intervals on predictions and differences, as described above in the section "Predictions and differences and their linear confidence and prediction intervals". PHASE $=45$ produces the primary output file fn._ 45 . Tables in the $f$._. 45 file are labeled, indicating the type of confidence or prediction interval included in the table. An example of a fn._ 45 file is presented in Appendix A. PHASE $=45$ also produces file $f n .-y 2$, which generally is not accessed by the user.

The output files $f n . \_44$ and fn._ 45 are largely self-explanatory. The theory for calculating confidence and prediction intervals, and the contents of the $f n . \_44$ and $f n . \_45$ files are discussed by Hill (1994). The linearity assumption of these confidence and prediction intervals can be evaluated using file fn._33, generated by PHASE=33.

\section{Troubleshooting}

Most of the problems encountered in using UCODE arise from omitting required data items from the input files, listing data in the input files in improper order, specifying incorrect values, or specifying filenames and pathnames incorrectly. A typical resulting problem is that UCODE does not run to completion. Input errors can be minimized by following the suggestions presented for PHASE=1 and elsewhere in the text and tables of this section and in the section "Input File Construction". When problems are encountered the user is encouraged to review those suggestions. Often, termination messages are printed to the screen and provide guidance on how to correct the error.

Another common problem is that the extractions are correct but UCODE fails for PHASE $=2$ or 22 or the regression fails to converge for PHASE $=3$. One situation that can cause this problem is that too many of the calculate sensitivities equal zero. It is common for some 
sensitivities to be zero, but most of the sensitivities for each parameter generally need to be nonzero. If more than a few sensitivities equal zero, consider the suggestions presented in the section "Calculation of Sensitivities". The existence of zero sensitivities can be investigated as follows.

1. Check for sensitivities equal to zero in the fn._ot file produced for PHASE=2 or 22.

Sensitivities at these PHASES are calculated using the starting parameter values.

2. Sensitivities calculated for the values of the parameters just prior to failure can be investigated by substituting these parameter values as starting values in the prepare file and executing UCODE with PHASE $=2$ or 22 .

3. Sensitivities for all intermediate sets of parameter values can be investigated by setting PRINT-INTERMEDIATE=1 in fn.uni and executing UCODE again with PHASE=3.

Other problems commonly encountered result from the regression problem being poorly posed because at least some of the defined parameters are insensitive to the available data, the parameters are extremely correlated, or the model exhibits strong nonlinearity. These problems can be addressed as discussed in the section "Inverse Modeling Considerations".

\section{REFERENCES}

Christensen, Steen and Cooley, R.L, in press, Simultaneous confidence intervals for a steady-state leaky aquifer groundwater flow model: Advances in Water Resources Special Issue of Model Calibration and Reliability Evaluation.

Cooley, R. L., and R.L. Naff, 1990, Regression modeling of ground-water flow: U.S. Geological Survey Techniques in Water Resources Investigations, book 3, chap, B4, 232\#p.

D'Agnese, F.A. Faunt, C.C., Hill, M.C, and Turner, A.K., in press, Death Valley regional groundwater flow model calibration using optimal parameter estimation methods and geoscientific information systems: Advances in Water Resources, Special Issue on Groundwater Model Calibration and Reliability.

D'Agnese, F.A. Faunt, C.C., Turner, A.K, and Hill, M.C., 1998, Hydrogeologic evaluation and numerical simulation of the Death Valley Regional ground-water flow system, Nevada and California: U.S. Geological Survey Water-Resources Investigation Report 96-4300, 124p. 
Harbaugh, A.W. and McDonald, M.G., 1996, User's documentation for MODFLOW'96, an update to the U.S. Geological Survey Modular Finite Difference Ground-Water Flow Model: U.S. Geological Survey Open-File Report 96-485, 56 p.

Hill, M.C., 1990, Preconditioned Conjugate Gradient 2 (PCG2), A computer program for solving ground-water flow equations, U.S. Geological Survey, Water-Resources Investigations Report 98-4048, p. 43.

Hill, M.C., 1992, A computer program (MODFLOWP) for estimating parameters of a transient, three-dimensional, ground-water flow model using nonlinear regression: U.S. Geological Survey Open-File Report 91-484, 358 p.

Hill, M.C., 1994, Five computer programs for testing weighted residuals and calculating linear confidence and prediction intervals on results from the ground-water parameter estimation computer program MODFLOWP: U.S. Geological Survey Open-File Report 93-481, 81 p.

Hill, M.C., 1998, Methods and guidelines for effective model calibration: U.S. Geological Survey, Water-Resources Investigations Report 98-4005.

Poeter, E. P. and M.C. Hill, 1996, Unrealistic parameter estimates in inverse modeling: A problem or a benefit?: in Kovar, Karel and van der Heidje, Paul, eds, Calibration and reliability in groundwater modeling, Proceedings of ModelCARE'96, Golden Colorado, September, 1996, International Association of Hydrologic Scientists Publication, 237, p. 277-285.

Poeter, E. P. and Hill, M.C., 1997, Inverse models: A necessary next step in groundwater modeling: Ground Water, v. 35(2), p. 250-260.

\section{APPENDIX A: EXAMPLE}

\section{Physical System}

The physical system illustrated in figure B1 uses the application model MODFLOW'96 (Harbaugh and McDonald, 1996). The system includes two confined aquifers separated by a confining unit. A river extends along one boundary of the system. The opposite boundary represents a low hydraulic conductivity upland from which minimal ground-water flow enters the system. The system is at steady state. Properties in the model include: the storage coefficient and homogeneous transmissivity of the shallow aquifer; the storage coefficient and a spatially varying 
transmissivity of the deep aquifer; the vertical hydraulic conductivity of the confining unit; the hydraulic conductivity of the material on the upland side of the aquifers; and the conductivity of the riverbed. Application model input file $t 2$ defines the spatial distribution of transmissivity of the deep aquifer, which increases linearly with distance from the river. Stresses on the system include recharge for two regions: one within $9000 \mathrm{~m}$ of the river and one between $9000 \mathrm{~m}$ from the stream and the adjoining hillside.

Six parameter values are estimated, including: (1) hydraulic conductivity of the shallow aquifer, (2) vertical hydraulic conductivity of the confining unit, (3) hydraulic conductivity of the deep aquifer below the river, (4) riverbed conductivity, (5) recharge rate on the half of the area closest to the river and 6) recharge rate on the remaining area.

The $18 \times 18$ finite-difference grid used to simulate the system is shown in figure 3 . The cells are 1000-m squares.

As a synthetic example, the true values of all parameters are known, and are listed in figure 2. A forward run of this model using the true parameter values was used to generate ten simulated hydraulic heads and one flow that are then used as observations in a regression that starts from other parameter values. The ten hydraulic-head observation locations and the river reach for which the flow applies are shown in figure 3. The generated hydraulic-head values were rounded to the nearest $0.1 \mathrm{~m}$ before entering them as observations, and the flow was rounded to the nearest $1 \mathrm{~m}^{3} / \mathrm{s}$. The rounding and the limited number of observations results in optimized parameter values that do not exactly match the true parameter values. To become more familiar with UCODE input and output files and nonlinear regression, it may be useful to experiment with the example, starting with different parameter values, adding noise to the observations, using different observations, and selecting different values for some of the solution control parameters.

Selected segments of most of the application model (MODFLOW96) input and output files and UCODE input and output files for PHASE=3, 33, 44, and 45 follow in this appendix. A complete listing of all the files for this problem are provided with UCODE. 


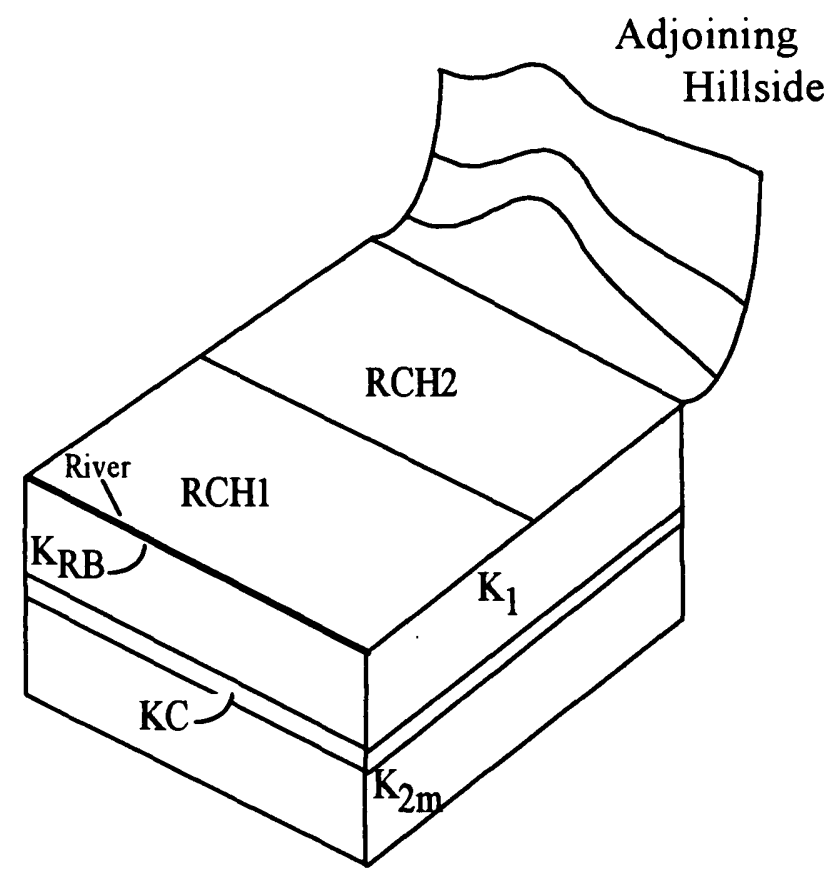

Surface area is 18,000 by 18,000 meters

Aquifer layers are $50 \mathrm{~m}$ thick

Confining Layer is $10 \mathrm{~m}$ thick

Riverbed is 10 meters wide and 10 meters thick

True model input values, parameters in bold type are included as parameters in the UCODE example files

$$
\begin{aligned}
& \text { Transmissivity of layer } 1=50 \mathrm{~m}^{*} \mathrm{~K}_{1} ; \mathrm{K}_{1}=0.03 \mathrm{~m} / \mathrm{s} \\
& \text { Transmissivity of layer } 2=50 \mathrm{~m} * \mathrm{~K}_{2 \mathrm{~m}} *(1+\mathrm{x}(8 / 18,000)) \\
& \mathrm{x} \text { is the distance from the river, in meters } \\
& \mathrm{K}_{2 \mathrm{~m}}=\mathrm{K} \text { under the river, in meters } \\
& \mathrm{K}_{2 \mathrm{~m}}=2.2 \times 10^{-3} \mathrm{~m} / \mathrm{s} \\
& \mathrm{K}_{\mathbf{c}}=\mathrm{K}_{\mathrm{v}} / \text { thickness }=1 \times 10^{-8} / \mathrm{s} ; \mathrm{Kv}=1 \times 10^{-7} \mathrm{~m} / \mathrm{s} \\
& \mathrm{KRB}=1 \times 10^{-3} \mathrm{~m} / \mathrm{s} \\
& \mathrm{RCH1}=1 \times 10^{-8} \mathrm{~m} / \mathrm{s} \\
& \mathrm{RCH2}=1.5 \times 10^{-8} \mathrm{~m} / \mathrm{s}
\end{aligned}
$$

Figure 2: Physical system for the example case 

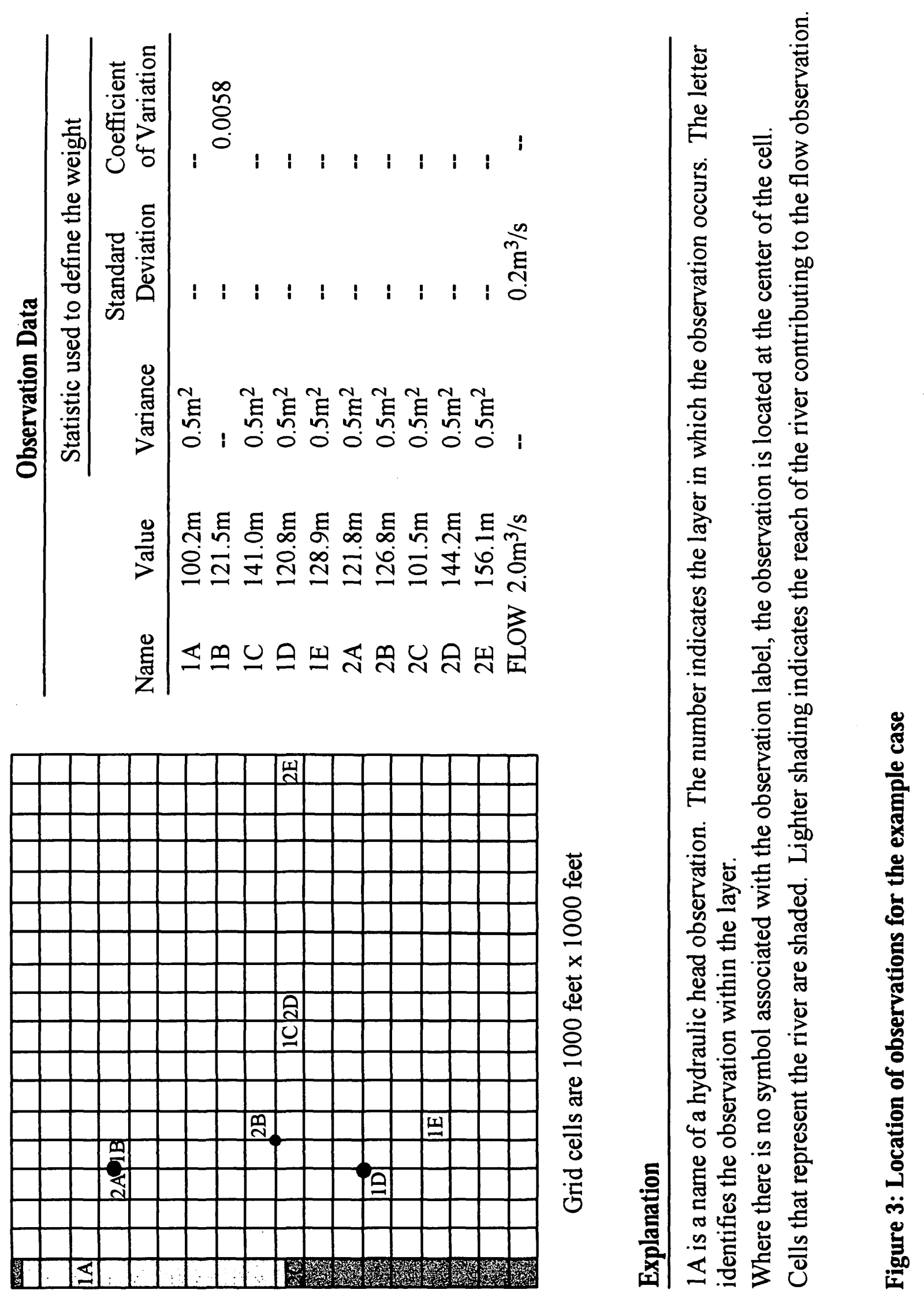


\section{Application Model Input Files}

The application model input files listed here are those that are created by UCODE from template files, or used by files created by UCODE. The values replaced are presented in bold. Application model input files that are not listed or partially listed here, but are provided with distribution of UCODE, are as follows: For PHASE=3, ex.oc, ex.bas, ex.pcg, ex.ghb, and ex.fil are not listed, and the files ex.t2 and ex..arr are only partially listed. For PHASE=44, expred.bas is not listed.

For phase 3, using starting values (in bold):

ex.bcf

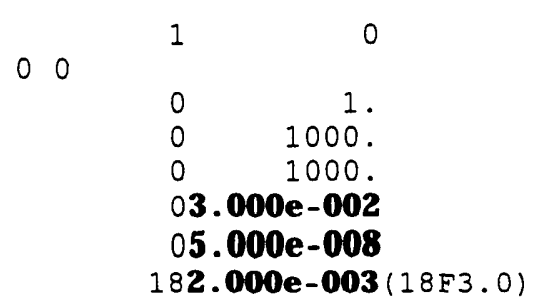

t2

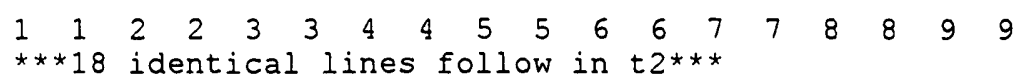

ex.riv

$\begin{array}{rrrrrr}18 & -1 & & & & \\ 18 & 1 & 1 & 100 & \mathbf{2 . 0} & 90 \\ 1 & 2 & 1 & 100 & \mathbf{2 . 0} & 90 \\ 1 & 3 & 1 & 100 & \mathbf{2 . 0} & 90 \\ 1 & 4 & 1 & 100 & \mathbf{2 . 0} & 90 \\ 1 & 5 & 1 & 100 & \mathbf{2 . 0} & 90 \\ 1 & 6 & 1 & 100 & \mathbf{2 . 0} & 90 \\ 1 & 7 & 1 & 100 & \mathbf{2 . 0} & 90 \\ 1 & 8 & 1 & 100 & \mathbf{2 . 0} & 90 \\ 1 & 9 & 1 & 100 & \mathbf{2 . 0} & 90 \\ 1 & 10 & 1 & 100 & \mathbf{2 . 0} & 90 \\ 1 & 11 & 1 & 100 & \mathbf{2 . 0} & 90 \\ 1 & 12 & 1 & 100 & \mathbf{2 . 0} & 90 \\ 1 & 13 & 1 & 100 & \mathbf{2 . 0} & 90 \\ 1 & 14 & 1 & 100 & \mathbf{2 . 0} & 90 \\ 1 & 15 & 1 & 100 & \mathbf{2 . 0} & 90 \\ 1 & 16 & 1 & 100 & \mathbf{2 . 0} & 90 \\ 1 & 17 & 1 & 100 & \mathbf{2 . 0} & 90 \\ 1 & 18 & 1 & 100 & \mathbf{2 . 0} & 90 \\ 1 & & & & & \end{array}$


ex.rch

$$
\begin{array}{rccc}
1 & 0 & \text { NRCHOP } & \text { IRCHBD } \\
0 & 0 & & \\
30 & \text { I.E-0 (9e11.3) }
\end{array}
$$

\section{ex.arr}

5.000e-009 5.000e-009 5.000e-009 5.000e-009 5.000e-009 5.000e-009 5.000e-009 5.000e-009 5.000e-009

2.000e-008 2.000e-008 2.000e-008 2.000e-008 2.000e-008 2.000e-008 2.000e-008 2.000e-008 2.000e-008 $* * \star 18$ identical sets of lines follow***

ex.oc

$\begin{array}{llll}2 & 0 & 0 & 0 \\ 0 & 1 & 1 & 1 \\ 1 & 0 & 0 & 0\end{array}$

\section{ex.fil}

$\begin{array}{lrl}\text { LIST } & 6 & \text { mod.out } \\ \text { BAS } & 1 & \text { ex.bas } \\ \text { BCF } & 3 & \text { ex.bcf } \\ \text { RIV } & 13 & \text { ex.riv } \\ \text { GHB } & 12 & \text { ex.ghb } \\ \text { RCH } & 31 & \text { ex.rch } \\ \text { PCG } & 9 & \text { ex.pcg } \\ \text { OC } & 11 & \text { ex.oc } \\ \text { DATA } & & 18 \text { t2 } \\ \text { DATA } & & 30 \text { ex.arr }\end{array}$

\section{For phase 44:}

expred.wel (defines pumpage for predictive conditions)

$\begin{array}{llll}1 & -1 & & \\ 1 & 10 & 5 & -1 .\end{array}$

files.prd (includes the well package)

$\begin{array}{lrl}\text { LIST } & 6 & \text { modpred.out } \\ \text { BAS } & 1 & \text { ex.bas } \\ \text { BCF } & 3 & \text { ex.bcf } \\ \text { RIV } & 13 & \text { ex.riv } \\ \text { WEL } & 14 & \text { expred.wel } \\ \text { GHB } & 12 & \text { ex.ghb } \\ \text { RCH } & 31 & \text { ex.rch } \\ \text { PCG } & 9 & \text { ex.pcg } \\ \text { OC } & 11 & \text { ex.oc } \\ \text { DATA } & & 18 \text { t2 } \\ \text { DATA } & & 30 \text { ex.arr }\end{array}$




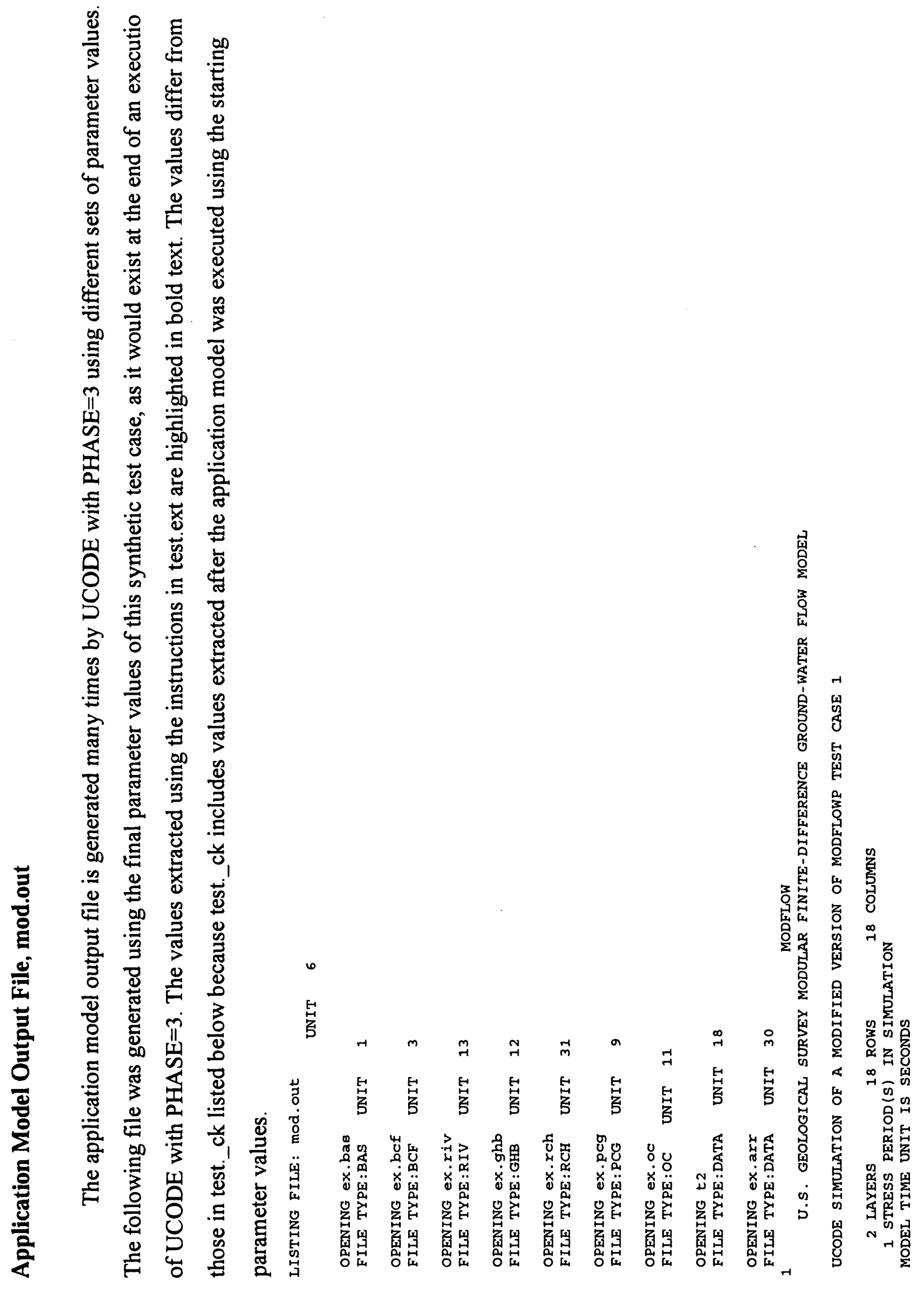



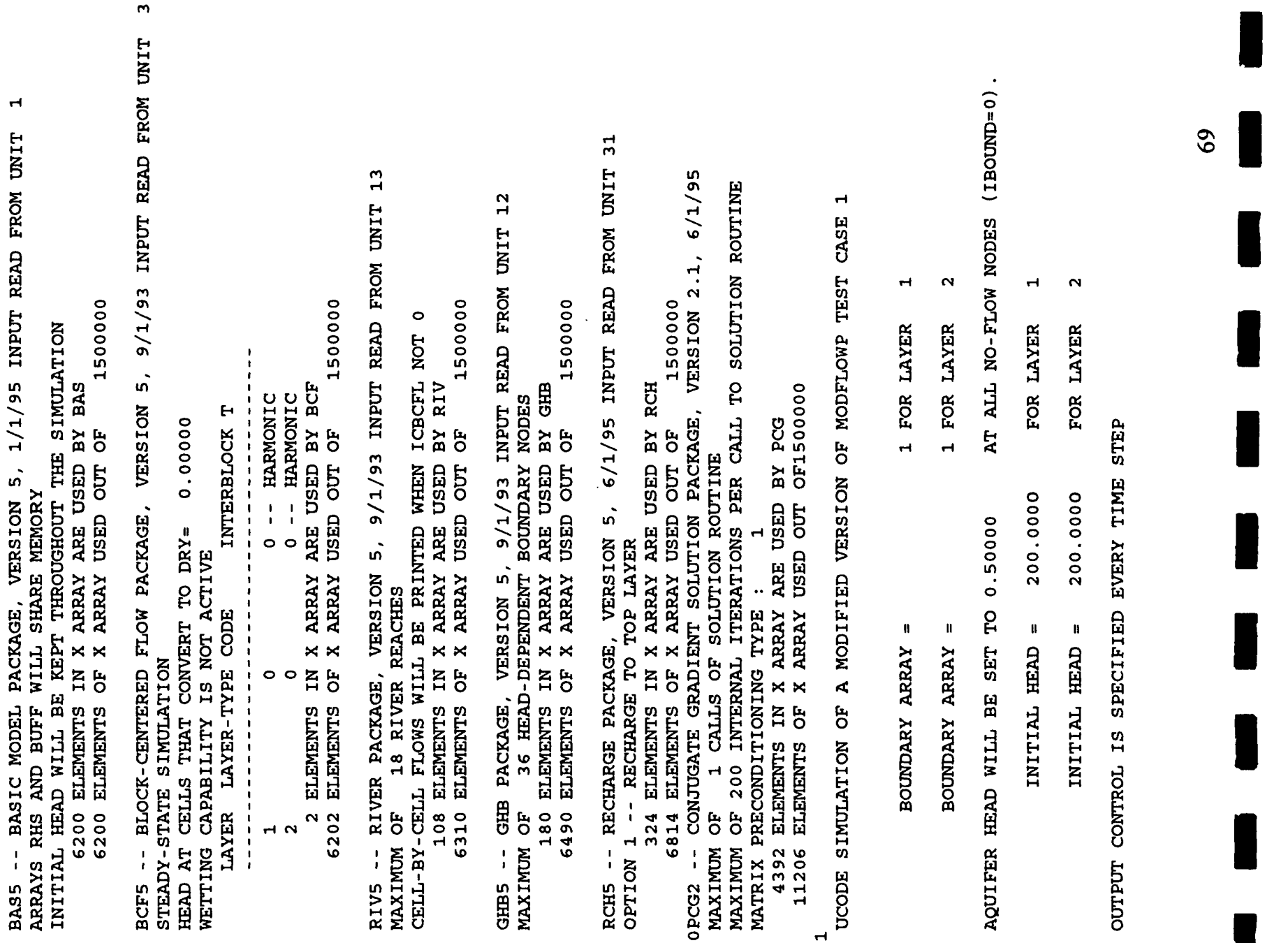


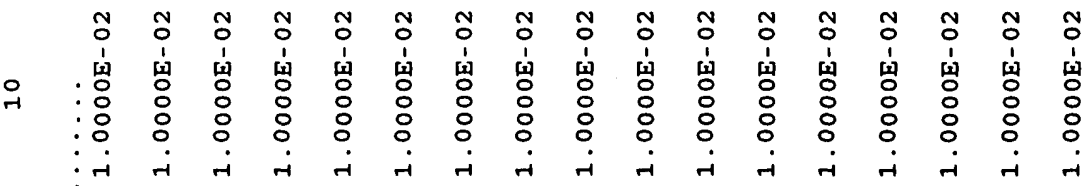

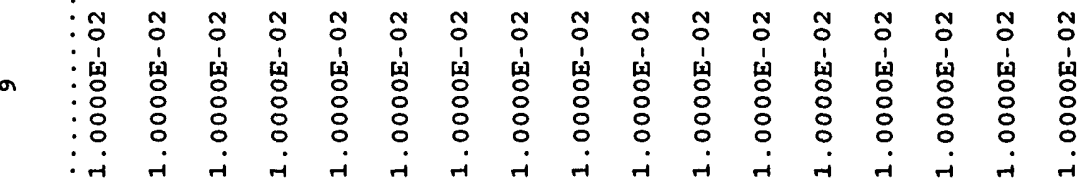

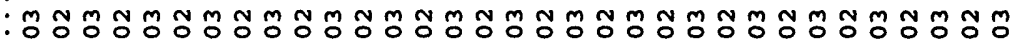

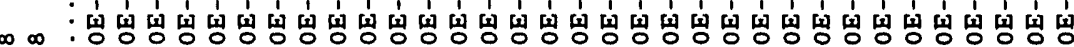
: :

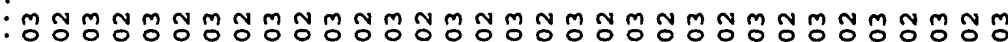

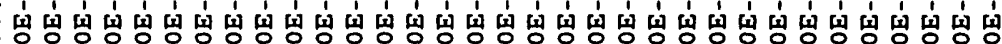

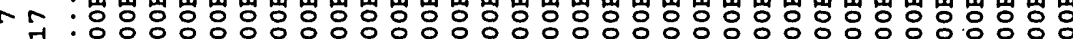

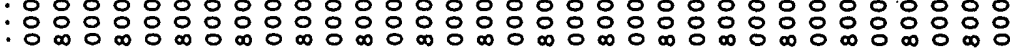
:

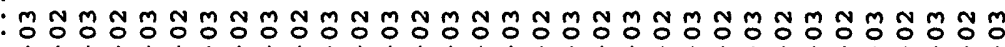
-

○

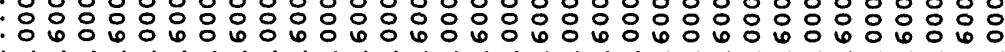

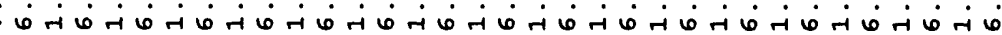

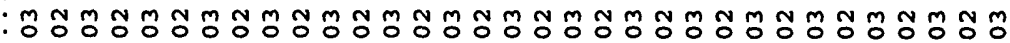

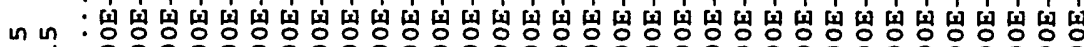

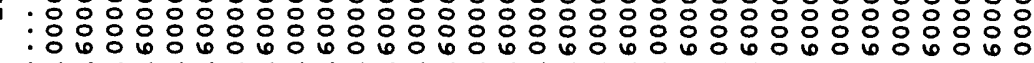

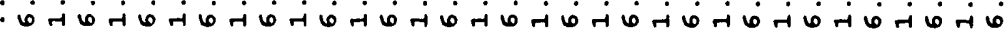

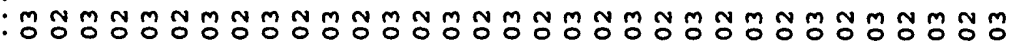

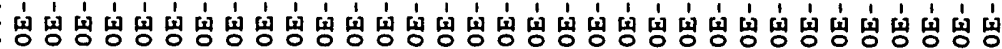
开 :

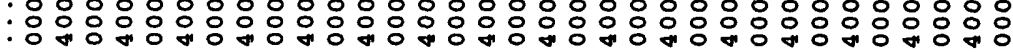

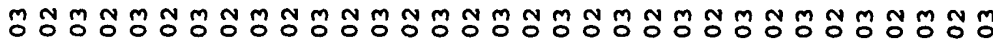

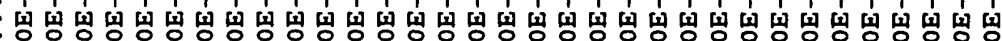

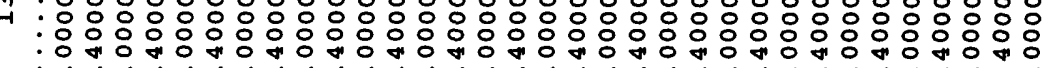

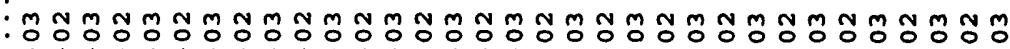

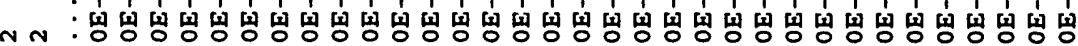

n

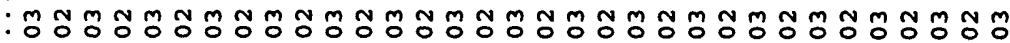

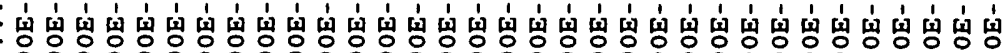
- 7 :

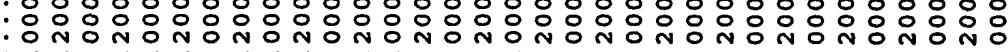

inhan 


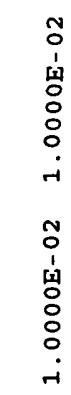

ํํㅇㅇ

뵝빙

응융

नं

กั $\mathrm{m}$ N

1형형 동

응

तi

ํํㅇ

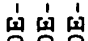

융

निं

N 9 \%

봉 뵝

응유

iो

Nㅗㅇ 옹

봉 봉

응응

त苗

ํํㅇㅇㅡ

뵝 봉 됭

응유

4i

ํㅗㅇ 웅

봉 뵝

응응

तi

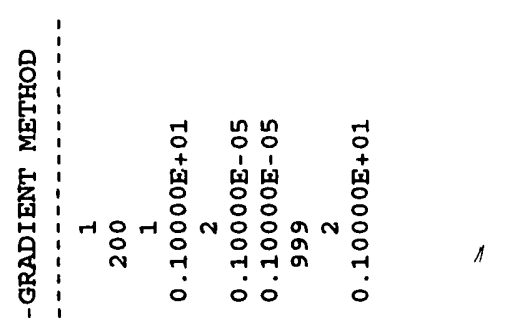

奥!

‘ी "

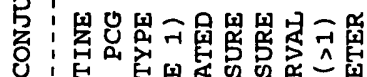

○

文

z

茧

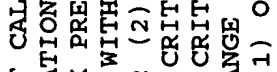

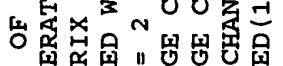

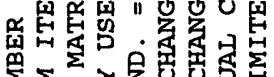

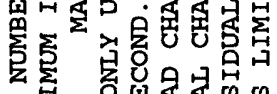

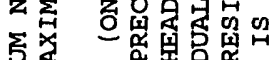

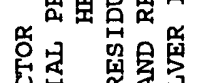

究

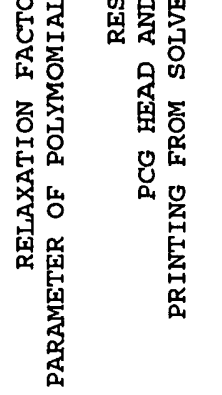

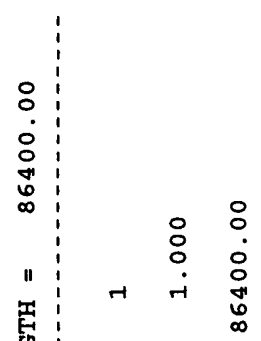

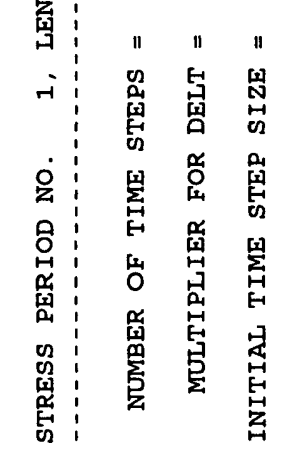

ก้ ติ กี

봉봉명

융

in

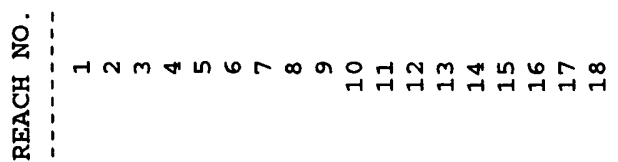

F

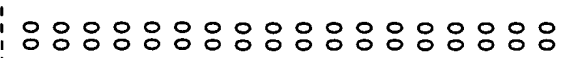

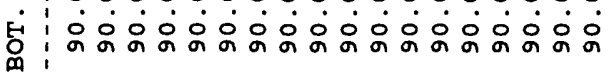

$\stackrel{\infty}{\sim}$

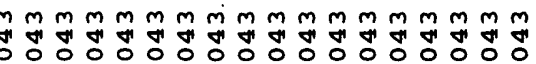

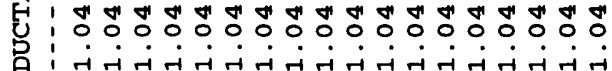

ठ

\section{봉}

000000000000000000

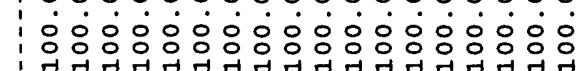

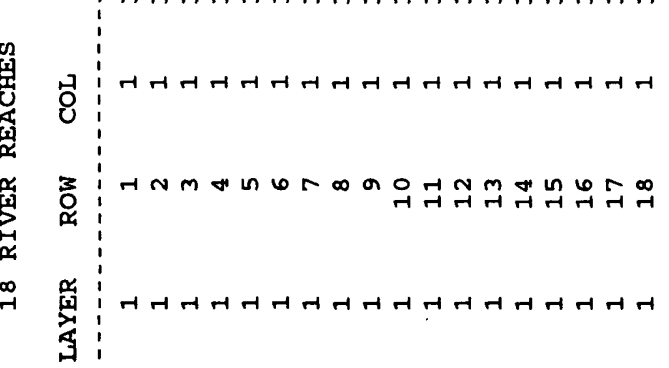



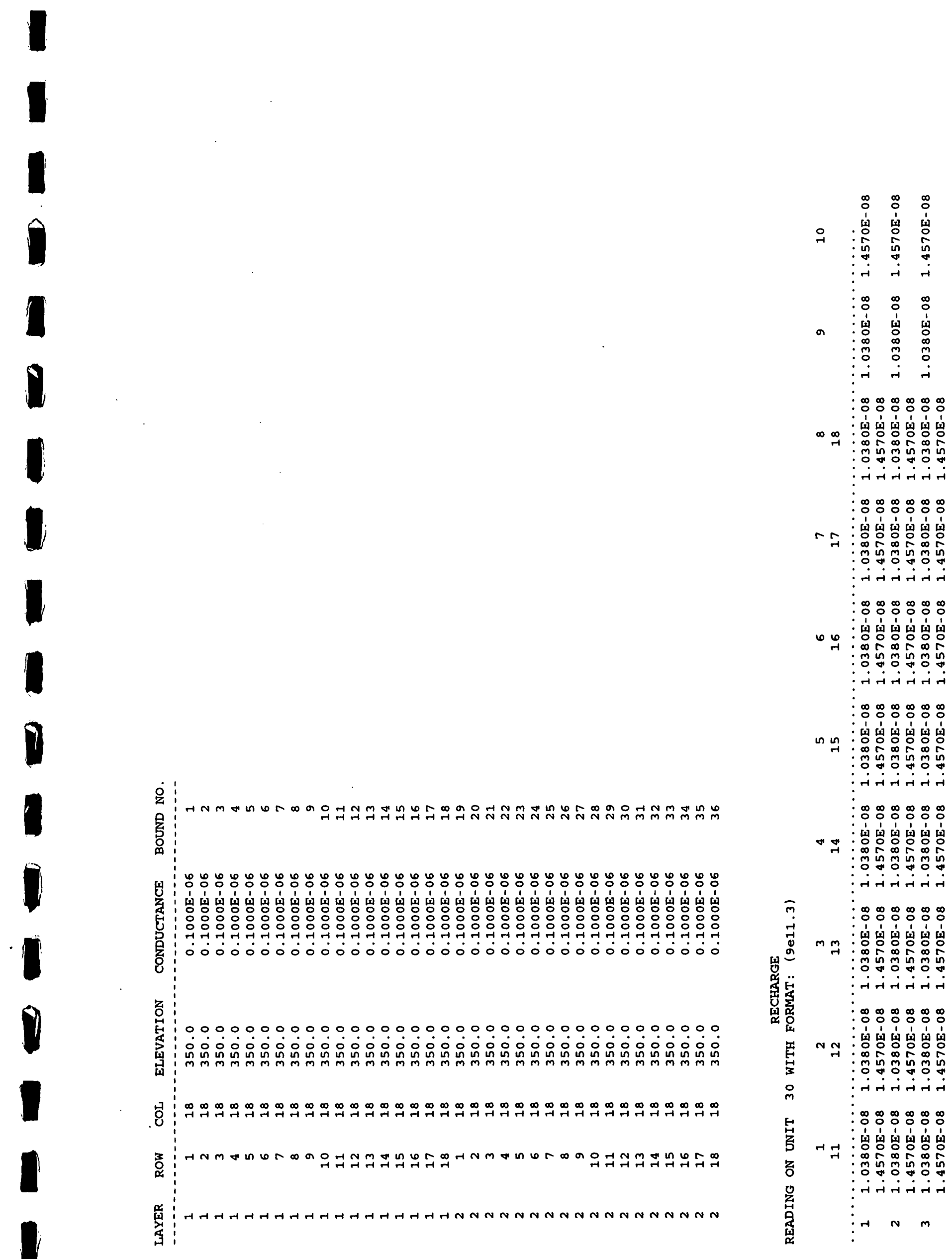


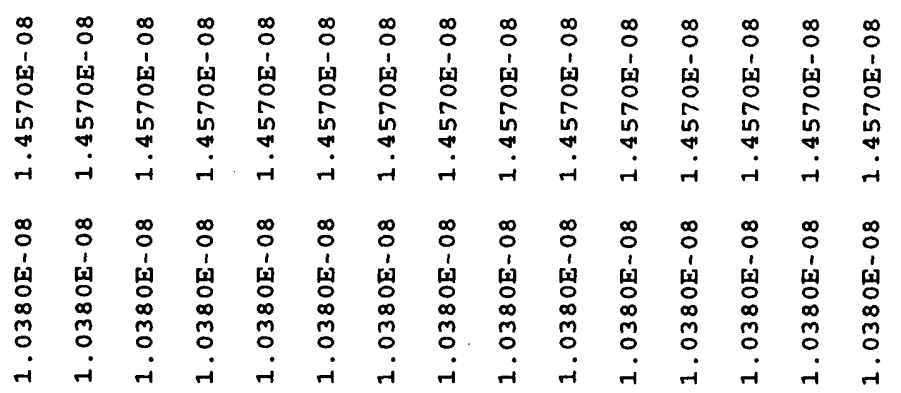

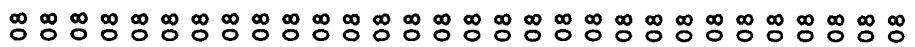

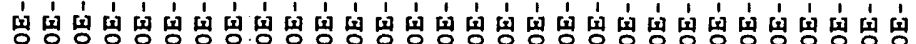

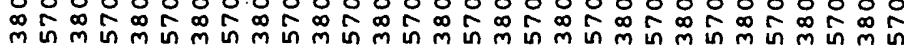
每 न न

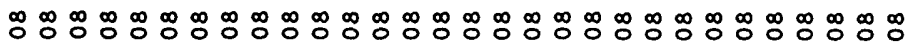

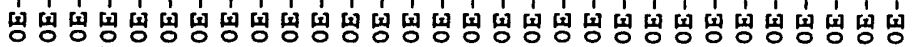

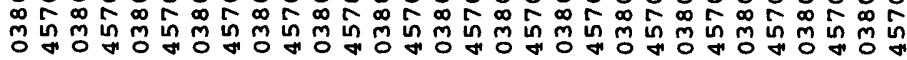
म

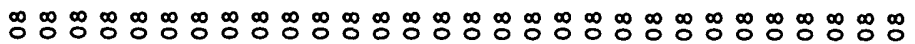

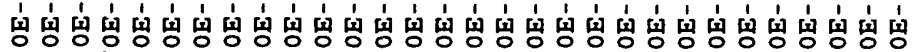

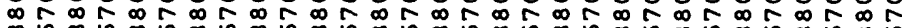
mon

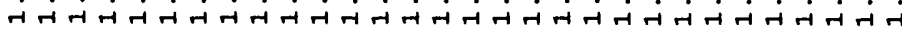
車 冓 。

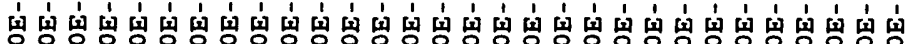

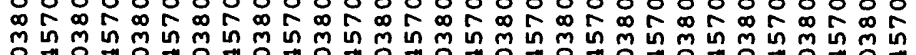

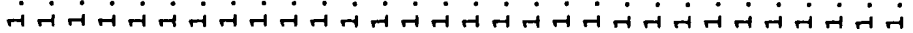

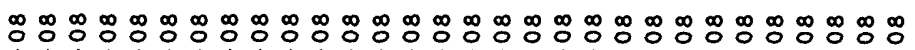

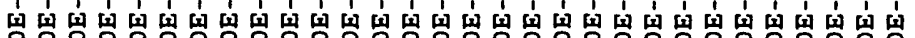

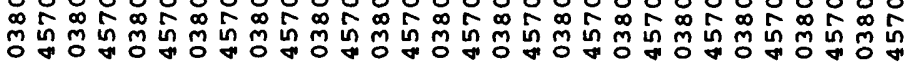

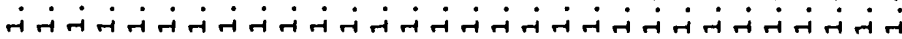

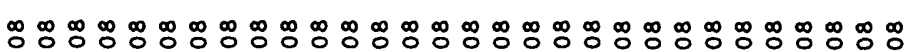

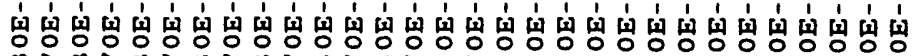

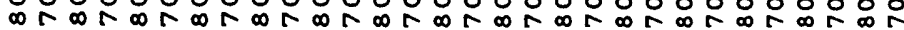

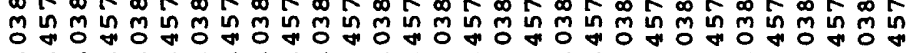

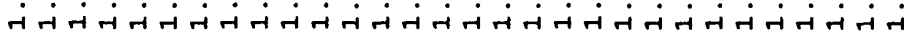
冓 :

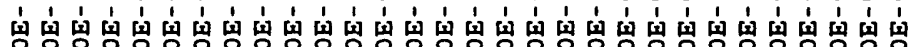

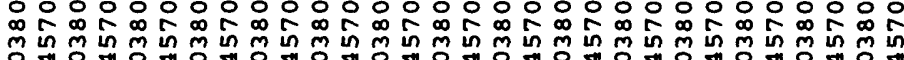

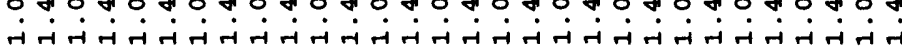

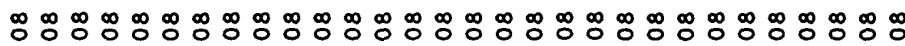

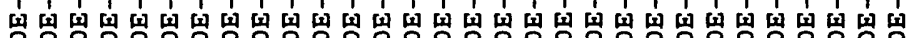

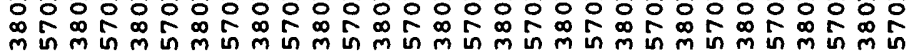
mon न नं

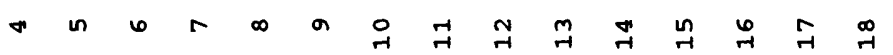

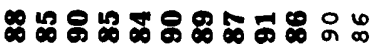

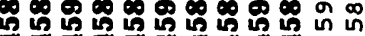
ה

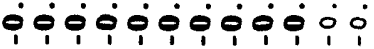

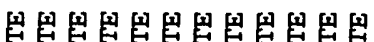

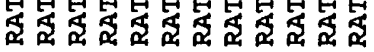
:

$44 h 4 h 4444 h 44$ 4

m

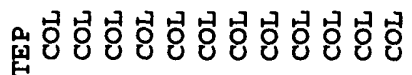
s

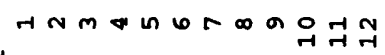

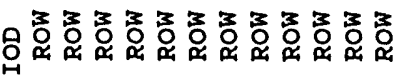
盗 秉是: 兽

资娄 员题客:

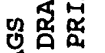

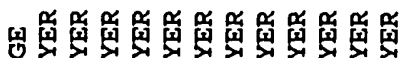

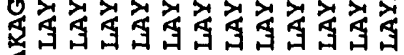
G

茫落

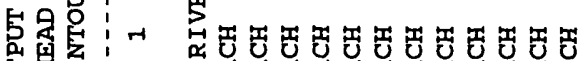

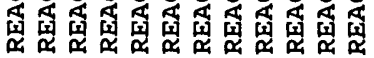




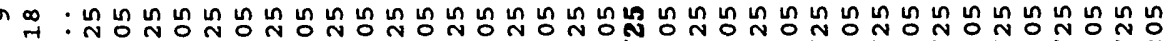

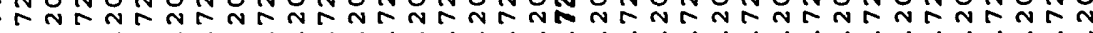

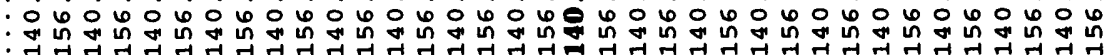

F: :

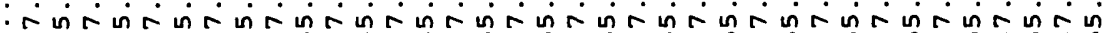
:

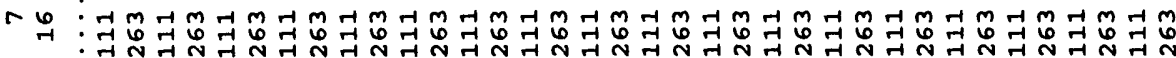
舟

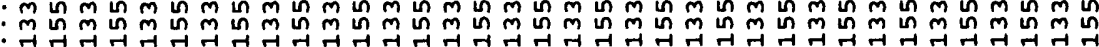

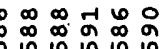

$n$ N $N$ N

i. io

国罢罢罢

品

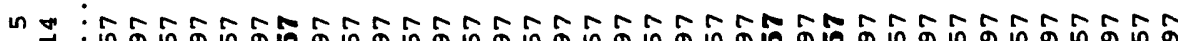

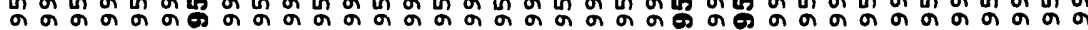

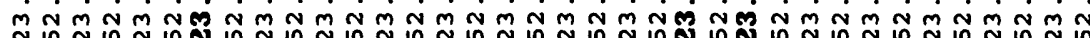

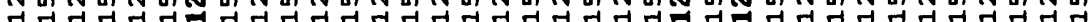

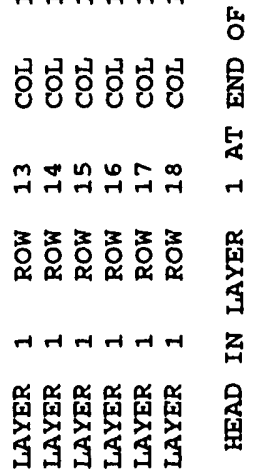

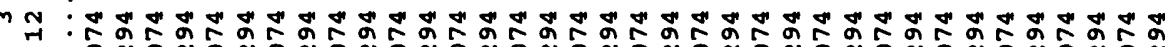

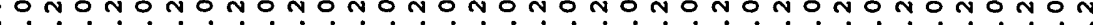
mamamamamamamamamamamamamamamamamama

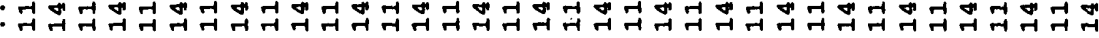

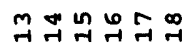

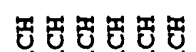

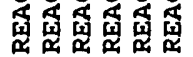

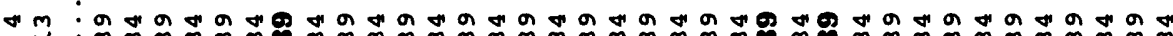

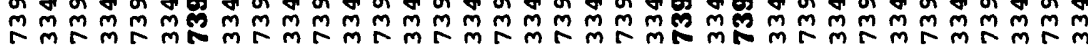

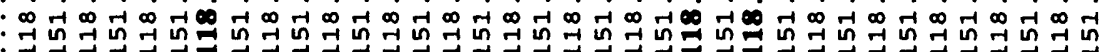

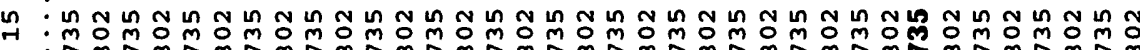
N

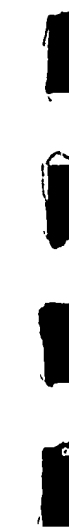

要

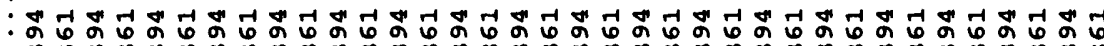
:

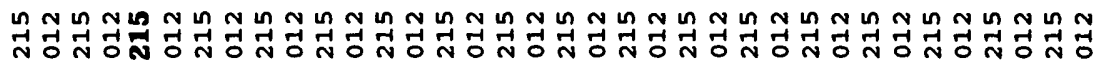

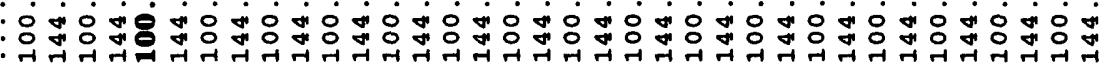

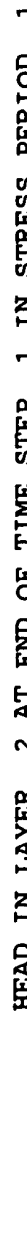




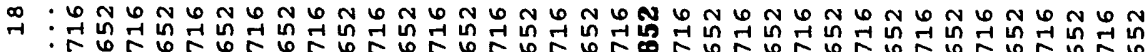

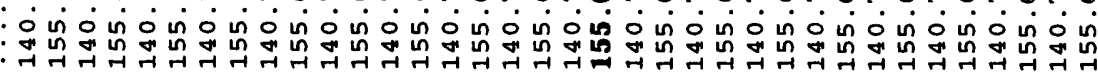

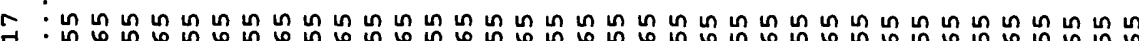
नm

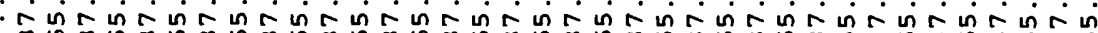

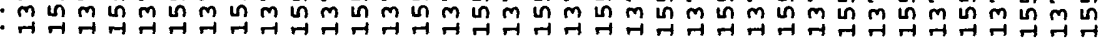

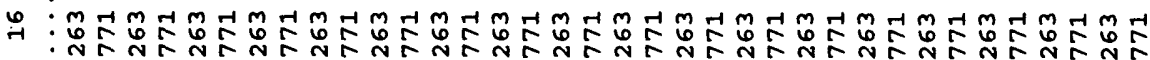

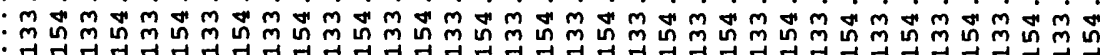

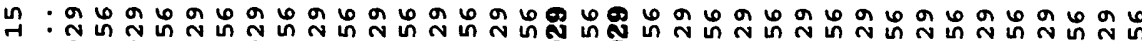

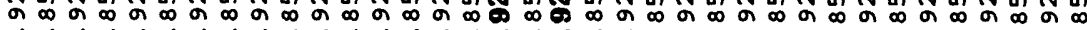

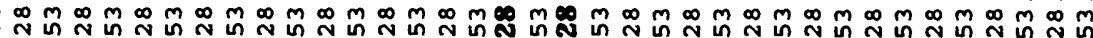

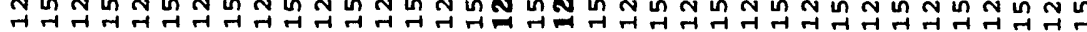

ㄴำ 促

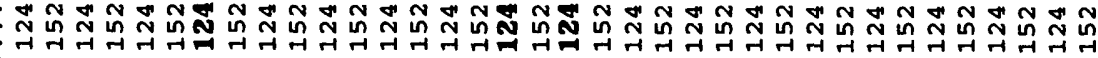

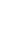

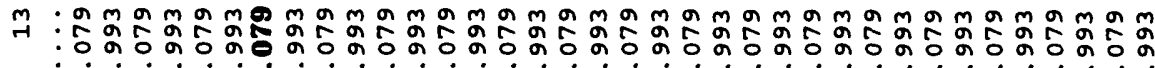
舟 :

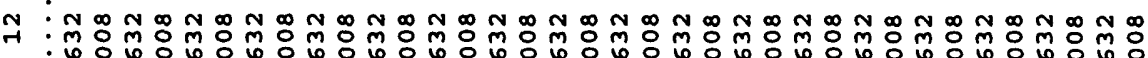

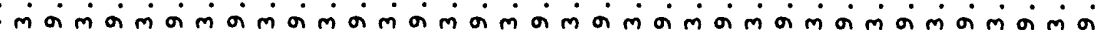
:

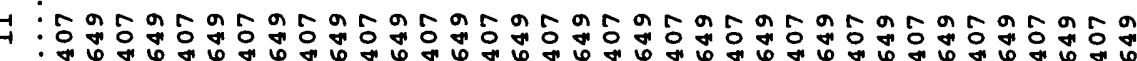

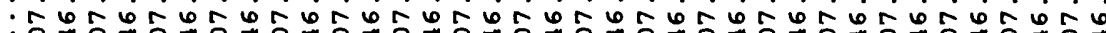

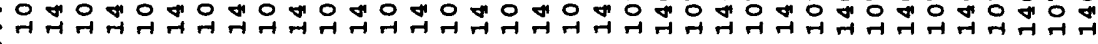

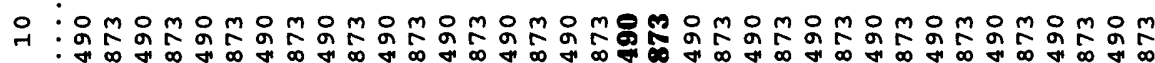
:

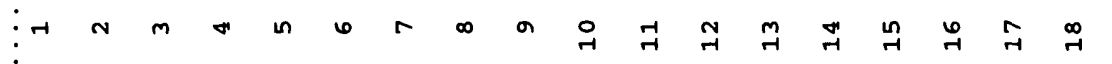

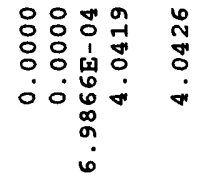

n

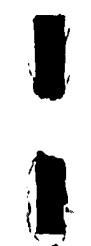

皇罚罚

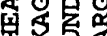

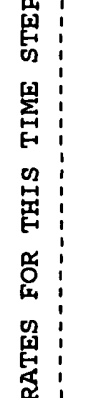

: 窟

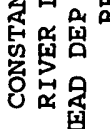
봉

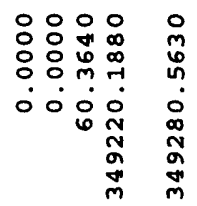

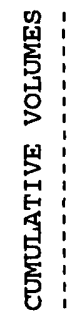

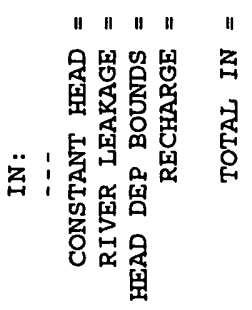



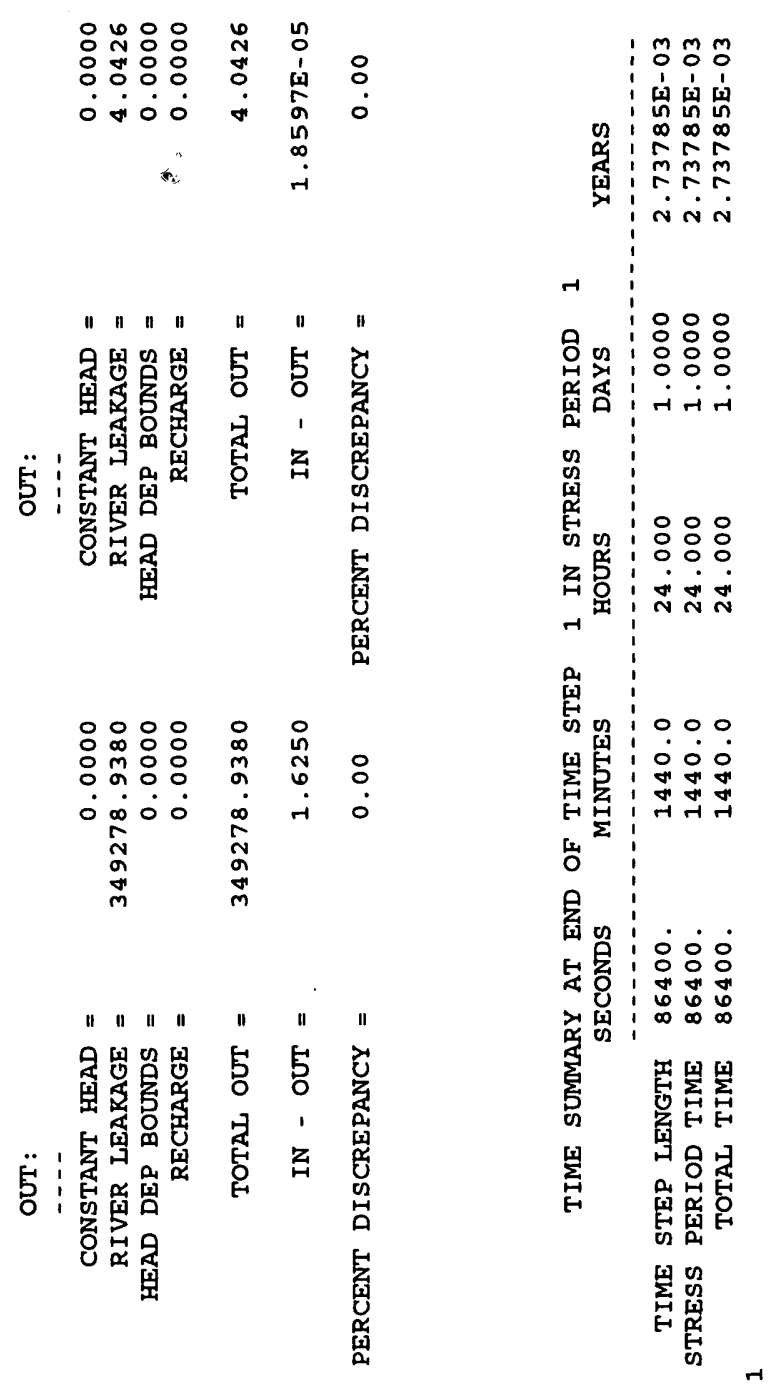
UCODE Input Files

\section{Template Files}

\section{bcf.tpl}

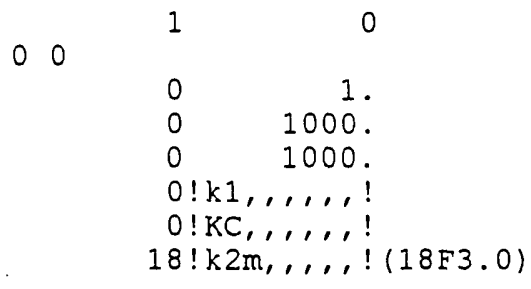

\section{riv.tpl}

\begin{tabular}{|c|c|c|c|c|}
\hline $\begin{array}{l}18 \\
18\end{array}$ & -1 & & & \\
\hline 1 & 1 & 1 & $100 ! \mathrm{KrB},, \ldots !$ & 90 \\
\hline 1 & 2 & 1 & $100 ! \mathrm{KrB}, 1,1$, & 9 \\
\hline 1 & 3 & 1 & $100 ! \mathrm{KrB},,, 1$, & 9 \\
\hline 1 & 4 & 1 & $100 ! \mathrm{KrB}, \ldots, 1$ & 90 \\
\hline 1 & 5 & $\overline{1}$ & $100 ! \mathrm{KrB}, \ldots,$, & 9 \\
\hline 1 & 6 & 1 & $100 ! \mathrm{KrB}, 1,1, !$ & 90 \\
\hline 1 & 7 & 1 & $100 ! \mathrm{KrB}, 1,1, !$ & 90 \\
\hline 1 & 8 & 1 & $100 ! \mathrm{KrB}, \ldots,$, & 90 \\
\hline 1 & 9 & 1 & $100 ! \mathrm{KrB},,,,$, & 9 \\
\hline 1 & 10 & 1 & $100 ! \mathrm{KrB}, \ldots, \ldots !$ & 9 \\
\hline 1 & 11 & 1 & $100 ! \mathrm{KrB}, \ldots,$, & 9 \\
\hline 1 & 12 & 1 & $100 ! \mathrm{KrB}, \ldots,$, ! & 9 \\
\hline 1 & 13 & 1 & $100 ! \mathrm{KrB}, \ldots$, & 9 \\
\hline 1 & 14 & 1 & $100 ! \mathrm{KrB}, \ldots, \ldots$ & 9 \\
\hline 1 & 15 & 1 & $100 ! \mathrm{KrB}, \ldots, \ldots$ ! & 9 \\
\hline 1 & 16 & 1 & $100 ! \mathrm{KrB}, \ldots, \ldots !$ & 9 \\
\hline 1 & 17 & 1 & $100 ! \mathrm{KrB}, 1,1$, & 9 \\
\hline 1 & 18 & 1 & $100 ! \mathrm{Kr} B, \ldots$, & 90 \\
\hline
\end{tabular}

\section{rcharr.tpl}

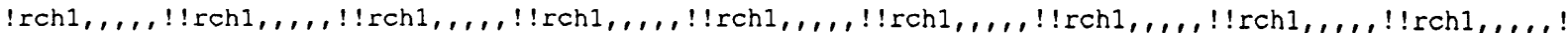

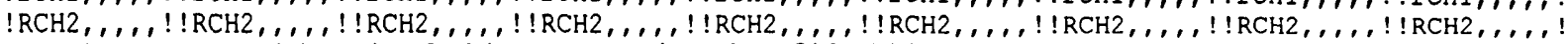
$* \star * 18$ sets of identical lines are in the file*** 


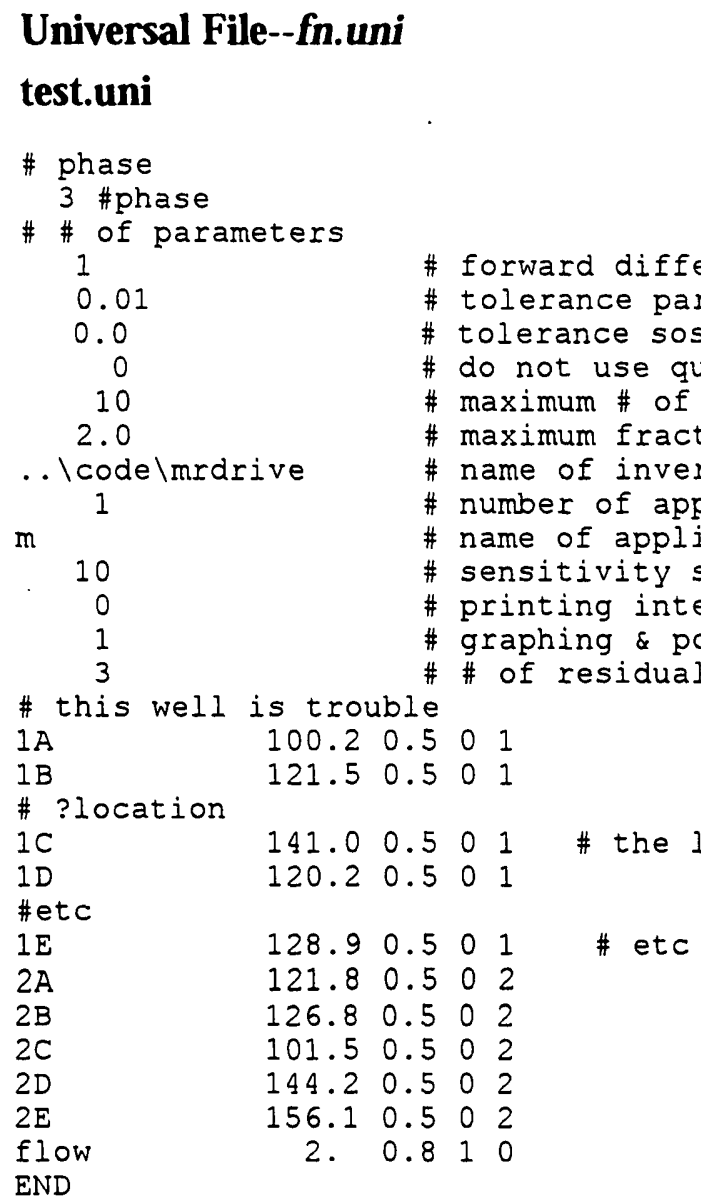

END

Batch file $m$.bat executes the application model and specifies a file called "in" which contains input that the application model expects from the screen. Output that the application code(s) route to the screen will be printed to the file "out".

\section{m.bat}

. Iapplic $\backslash$ modflw96 < in > out

in

ex.fil 


\section{Prepare File--fn.pre}

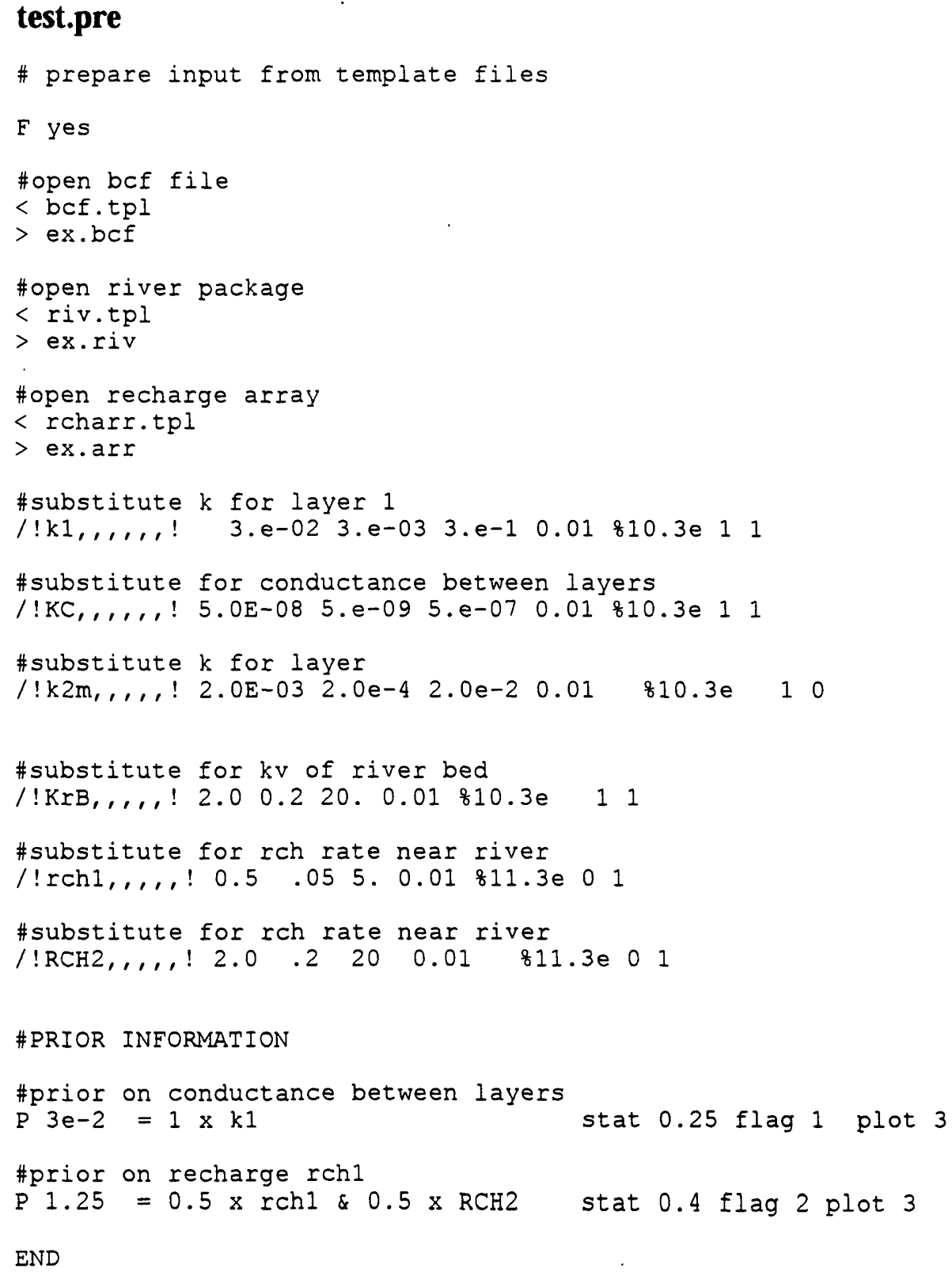




\section{Function File--fn.fnc}

\section{test.fnc}

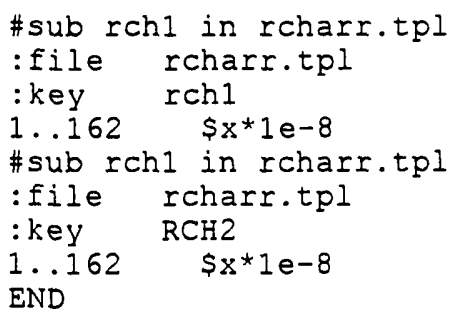

\section{Extract File--fn.ext}

The backward movements included in the extract file are not necessary, but are included to demonstrate how the "." code is used

\section{test.ext}

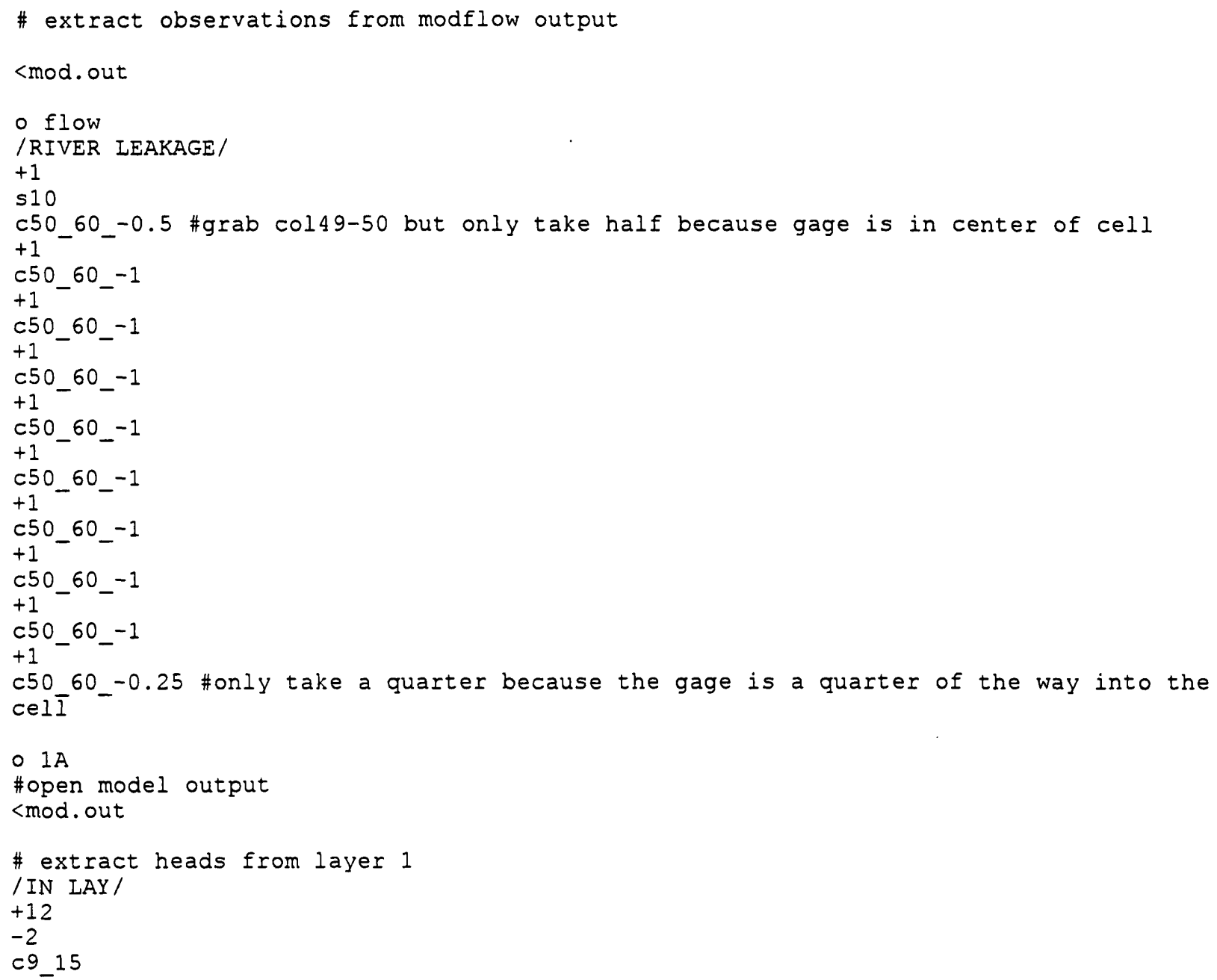




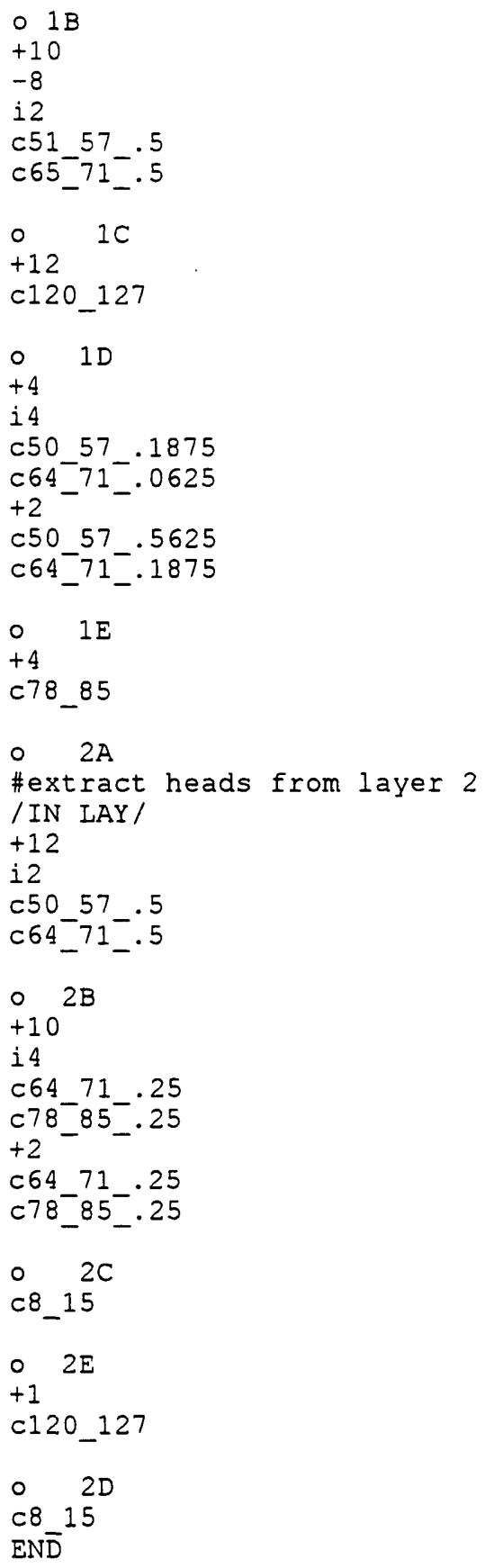

Input Files for Predictions and Their Confidence and Prediction Intervals--fn.u44 and fn.e45 test.u44

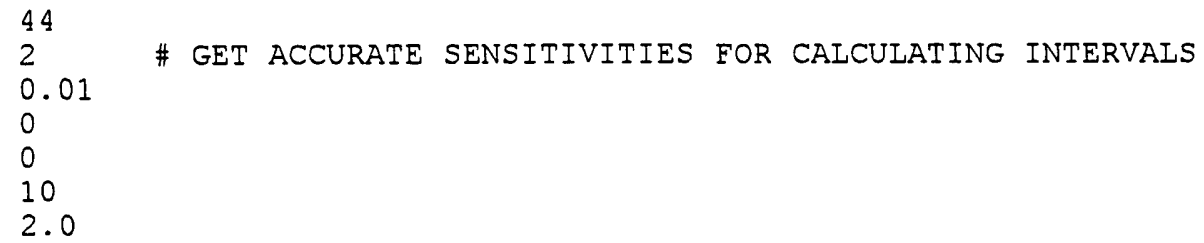




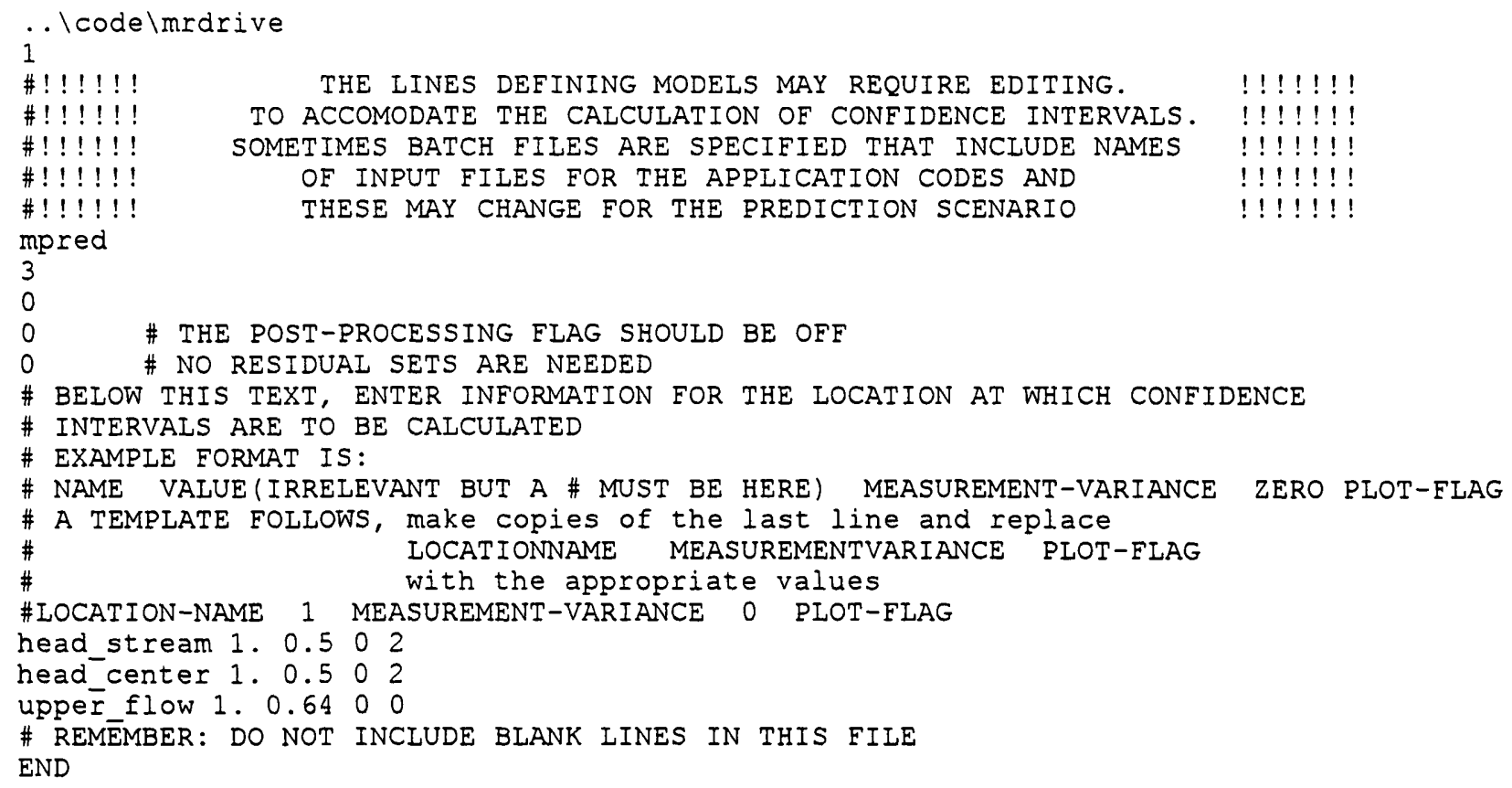

\section{test.e44}

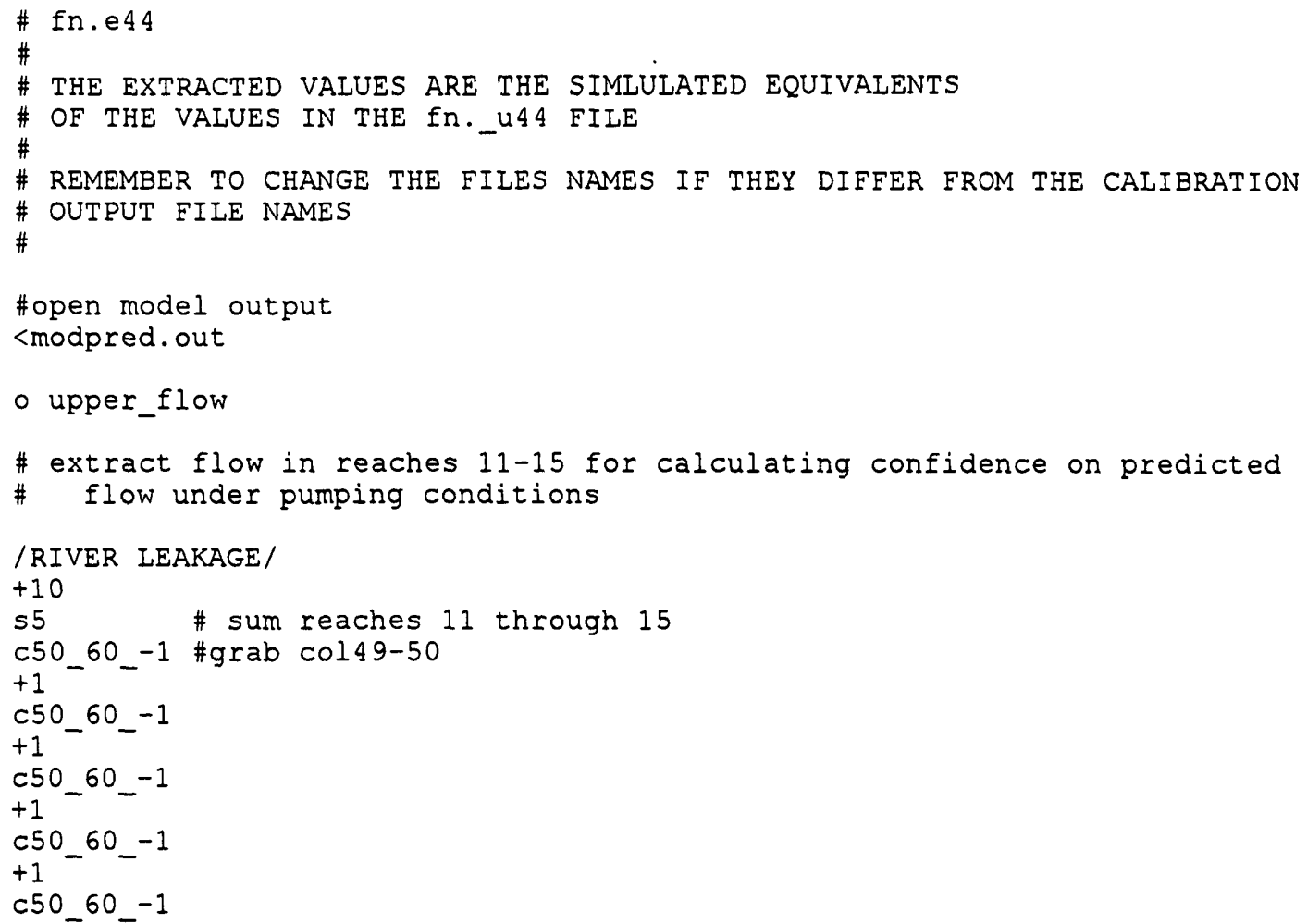




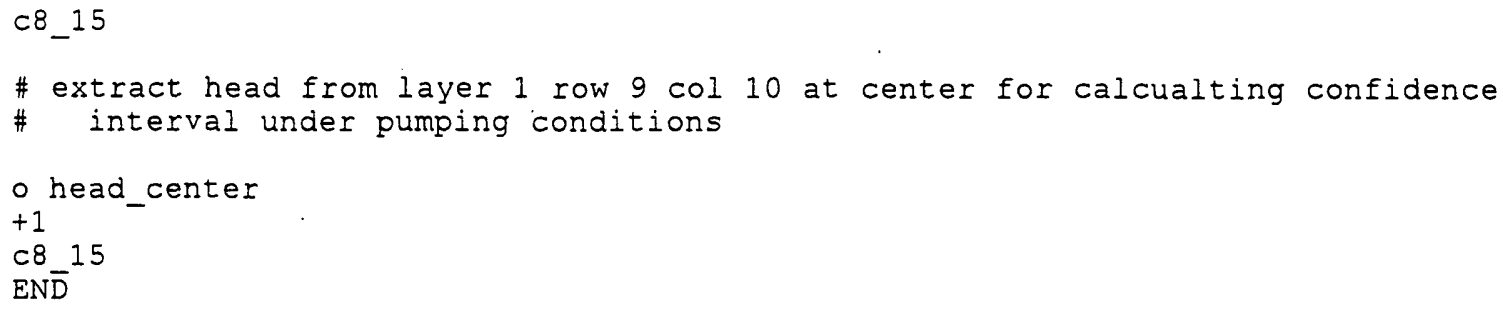

Input Files for Differences and Their Confidence and Prediction Intervals--fn.u45 and fn.e45

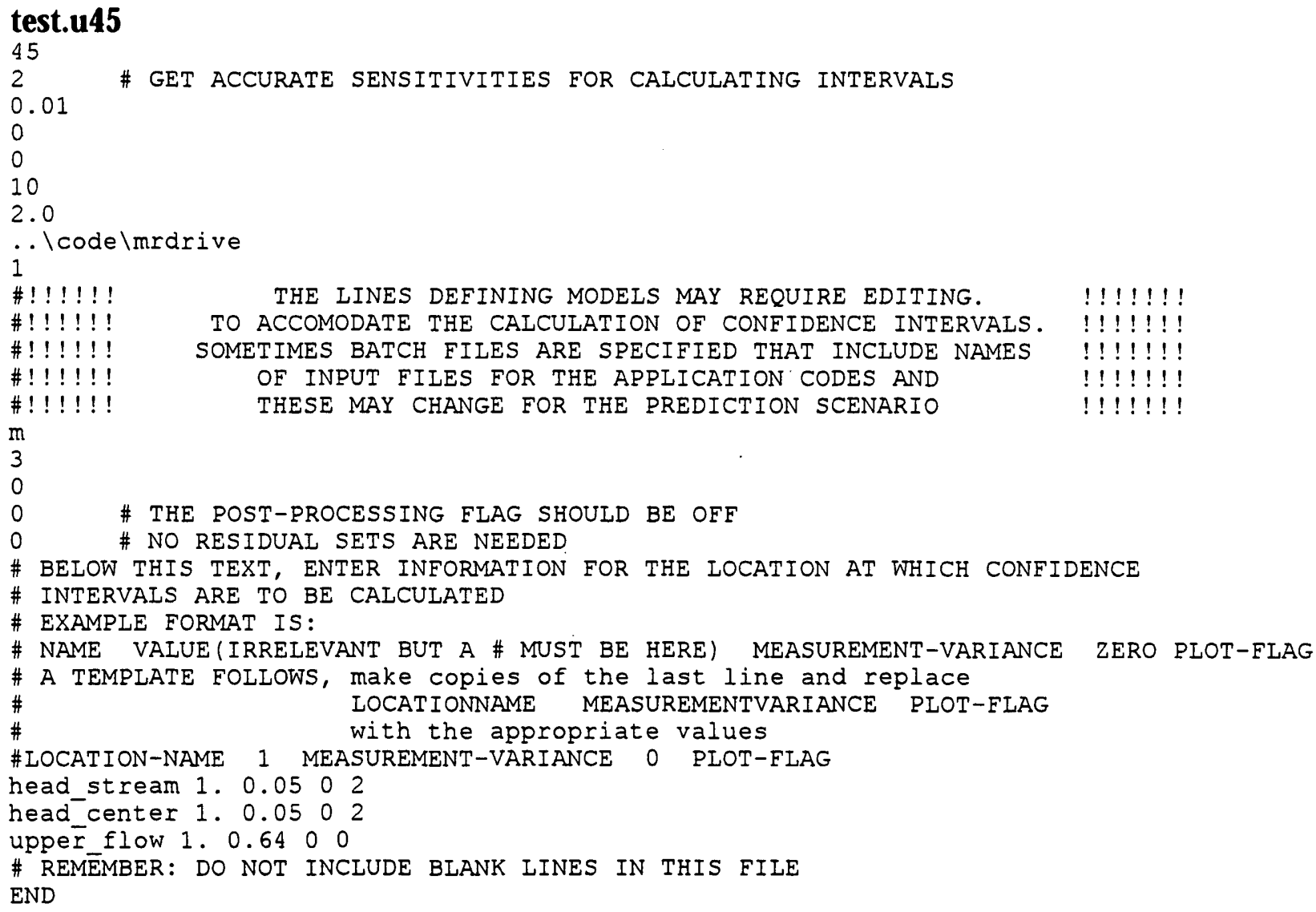

\section{test.e45}

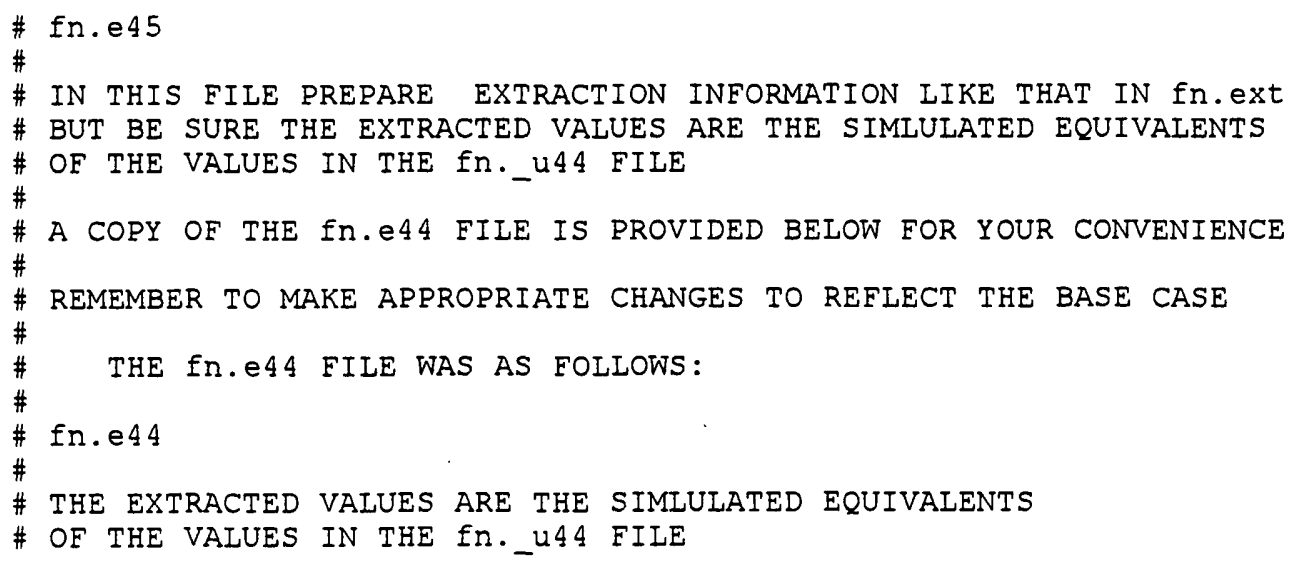




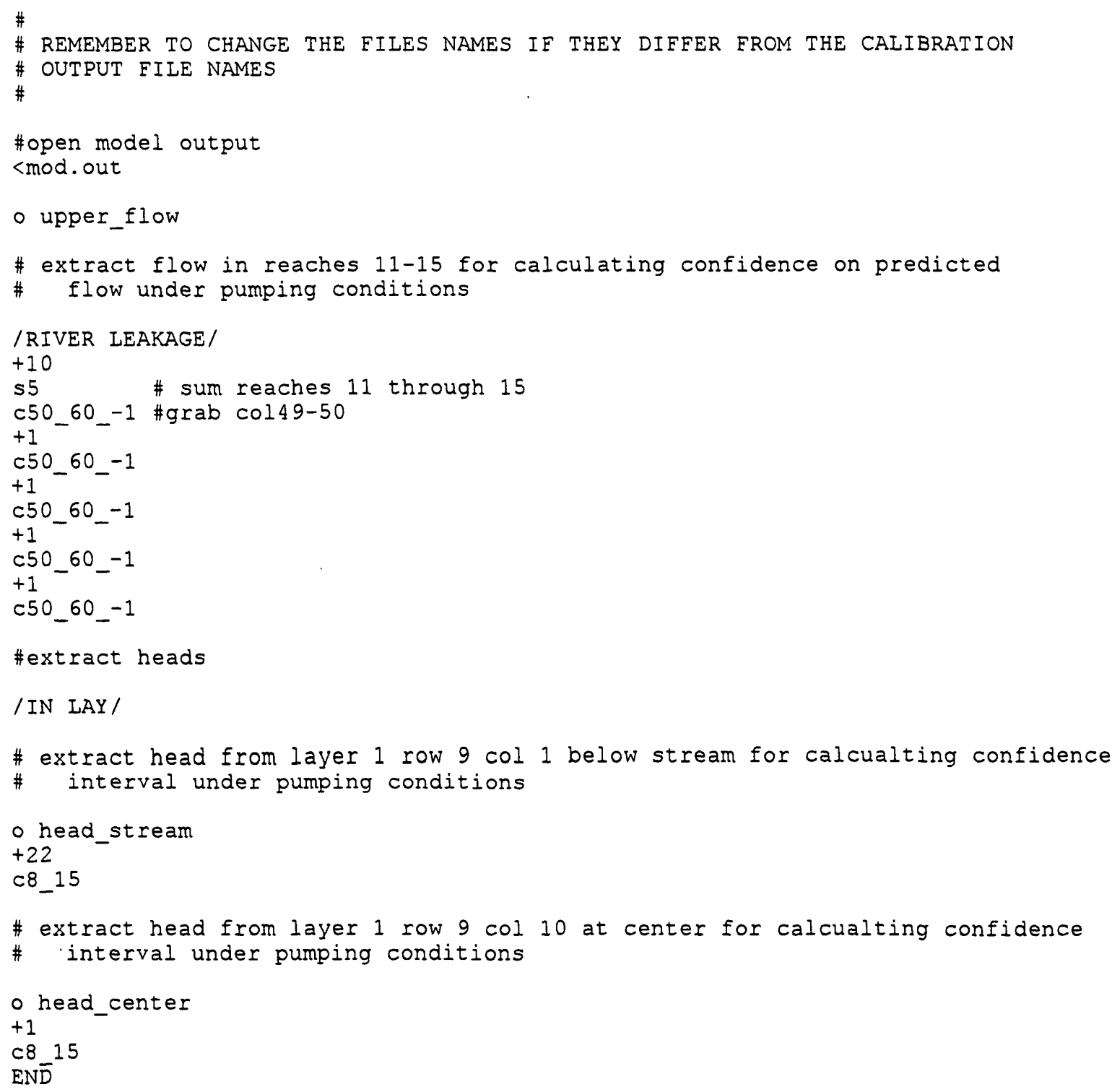

Input Prepare File for PHASE=11--fn.pre

\section{test.pre for PHASE=11}

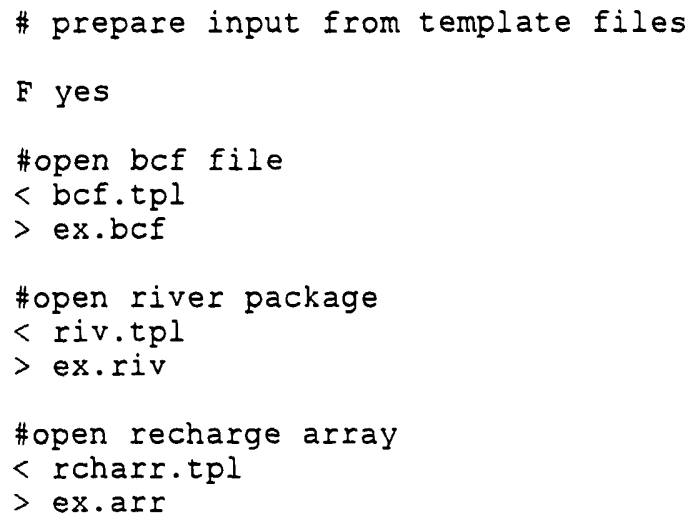




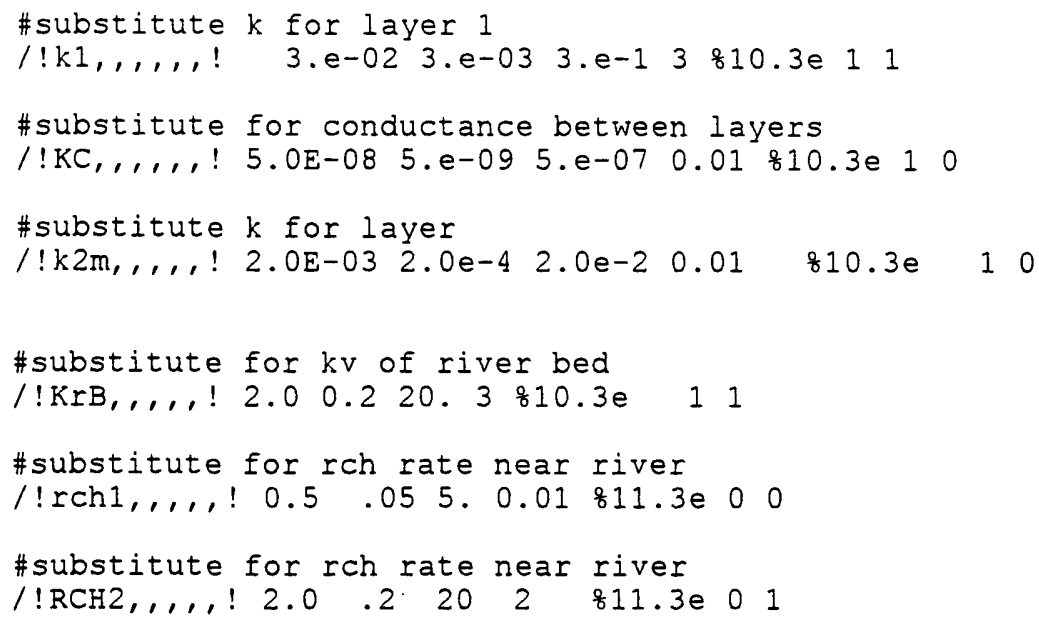

\section{Selected UCODE Output Files}

\section{Listing File--fn._ot}

Note the low relative sensitivity to parameter KrB and the correlation between parameters $\mathrm{k} 1$ and $\mathrm{RCB2}$. These results would warrant further consideration and testing as discussed in the text of this report and in Bill (1998). Also note the low calculated error variance. This is the result of assigning variance that are too large given the minor errors in the synthetic observations. This is typical of synthetic problems where fairly accurate values are used as observations, yet typical field variances are assigned when the observations are input to the code.

test._ot

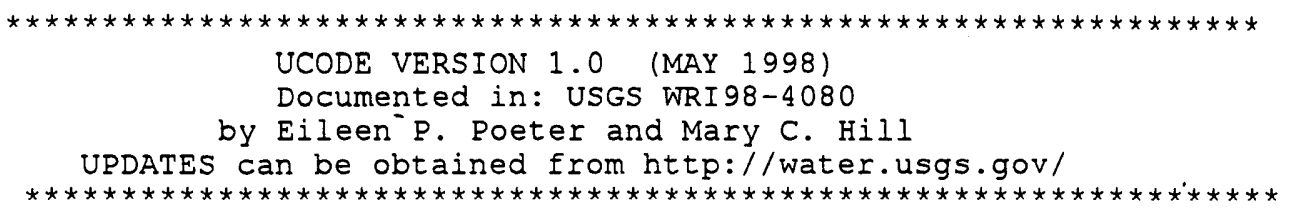


1) MAXIMUM FRACTIONAL PARAMETER CHANGE IS LESS THAN $\ldots \ldots \ldots \ldots 0.01$

2) SUM-OF-SQUARED WEIGHTED RESIDUALS DIFFERS OVER THREE ITERATIONS BY LESS THAN A FACTOR OF: ........ 0.0 OPTIONAI QUASI-NEWTON UPDATING $(0=$ NO $1=$ YES $) \ldots \ldots \ldots \ldots \ldots \ldots$ MAXIMUM NUMBER OF PARAMETER ITERATIONS BEFORE TERMINATION $\ldots \ldots .10$ MAXIMUM ALLOWABLE FRACTIONAL PARAMETER CHANGE $\ldots \ldots \ldots \ldots \ldots \ldots \ldots$

NAME OF INVERSION ALGORITHM IS $\quad$. \code \mrdrive

NUMBER OF APPIICATION CODES TO RUN IS $\ldots \ldots \ldots \ldots \ldots \ldots \ldots \ldots$ CODE NAME

m

\section{PRINTING CONTROLS:}

SENSITIVITY SCAIING (0=NO-SCALING 1 =DIMENSIONLESS $2=18 \quad 3=1 \& 2) \cdot 3$ INTERMEDIATE PRINTING $(0=$ NONE, $1=$ PRINT) $\ldots \ldots \ldots \ldots \ldots \ldots \ldots \ldots$ PRODUCE GRAPHING AND POSTPROCESSING FILES $(0=N O, 1=Y E S) \ldots \ldots$ \# OF RESIDUAI SETS FOR EVALUATION OF APPARENT NON-RANDOMNESS $\ldots 10$

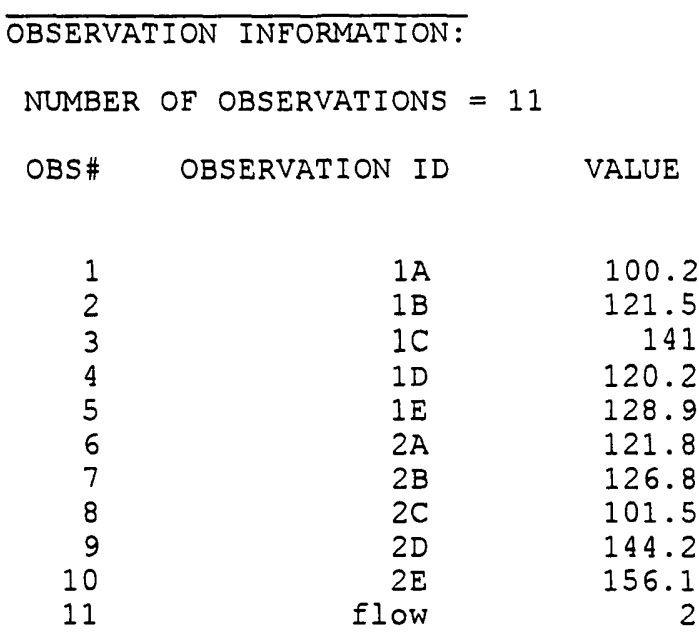

\section{PRIOR INFORMATION:}

PRIOR EQUATION \# 1:

$3 e-2=1 * \mathrm{kl}$

STD DEV =

0.25, LOG transformed, PLOT-SYMBOL =

3

PRIOR EQUATION \#2:

$1.25=0.5 *$ rCh $1+0.5 * \mathrm{RCH} 2$

COEF VAR $=$

0.4, NOT transformed, PLOT-SYMBOL =

1. 414

1.414

1. 414

1. 414

1. 414

1. 414

1.414

1. 414

1.414

1. 414

1.25

PLOT

SYMBOL

0.5 VAR

0.5 VAR

0.8 STD

1
1
1
1
1
2
2
2
2
2
0

\section{PARAMETER INFORMATION:}

INITIAL INFORMATION FOR 6 PARAMETERS

(ONLY ESTIMATE THE FIRST 5 PARAMETERS IN THE LIST)

\begin{tabular}{|c|c|c|c|c|c|c|}
\hline $\begin{array}{l}\text { PARAMETER } \\
\text { NAME }\end{array}$ & $\begin{array}{l}\text { INITIAL } \\
\text { VALUE }\end{array}$ & $\begin{array}{c}\text { REASONABIE } \\
\text { MINIMUM }\end{array}$ & $\begin{array}{l}\text { REASONABIE } \\
\text { MAXIMUM }\end{array}$ & $\begin{array}{c}\text { PERTURBATION } \\
\text { ERACTIONAL } \\
\text { AMOUNT }\end{array}$ & $\begin{array}{l}\text { LOG } \\
\text { TRANS } \\
\text { FLAG }\end{array}$ & $\begin{array}{l}\text { ESTIMATE } \\
\text { FLAG }\end{array}$ \\
\hline $\begin{array}{l}\mathrm{k} 1 \\
\mathrm{KC}\end{array}$ & $\begin{array}{r}0.03 \\
5 e-008\end{array}$ & $\begin{array}{r}0.003 \\
5 e-009\end{array}$ & $\begin{array}{r}0.3 \\
5 e-007\end{array}$ & $\begin{array}{l}0.01 \\
0.01\end{array}$ & $\begin{array}{l}\text { YES } \\
\text { YES }\end{array}$ & $\begin{array}{l}\text { YES } \\
\text { YES }\end{array}$ \\
\hline
\end{tabular}




\begin{tabular}{|c|c|c|c|c|c|c|}
\hline$K r B$ & 2 & 0.2 & 20 & 0.01 & YES & YES \\
\hline $\operatorname{rch} 1$ & $0 . \overline{5}$ & 0.05 & 5 & 0.01 & NO & YES \\
\hline $\mathrm{RCH} 2$ & 2 & 0.2 & 20 & 0.01 & NO & YES \\
\hline $\mathrm{k} 2 \mathrm{~m}$ & 0.002 & 0.0002 & 0.02 & 0.01 & YES & No \\
\hline
\end{tabular}

Analyzing Parameter IDs in file: \{bcf.tpl\}

\{3\} lines out of $\{8\}$ include Parameter IDs for substitution the last line with a substitution is \{8\}

Parameter ID: $\{! k 1, \ldots, 1, !\}$ occurs: \{1\} times in the template file

Parameter ID: \{!KC, , , , !\} occurs: \{1\} times in the template file

Parameter ID: $\{! \mathrm{k} 2 \mathrm{~m},, \ldots, !\}$ occurs: \{1\} times in the template file

Analyzing Parameter IDs in file: \{riv.tpl\}

\{18\} lines out of $\{20\}$ include parameter IDs for substitution

the last line with a substitution is $\{20\}$

Parameter ID: $\{! \mathrm{Kr} B, \ldots,, !\}$ occurs: $\{18\}$ times in the template file

Analyzing Parameter IDs in file: \{rcharr.tpl\}

\{36\} lines out of $\{36\}$ include Parameter IDs for substitution the last line with a substitution is $\{36\}$

Parameter ID: \{!rch1, , , !\} occurs: \{162\} times in the template file

Parameter ID: \{!RCH2,,, , !\} occurs: \{162\} times in the template file

EXECUTING MRDRIVE VERSION 1.0 (MAY 1998)

SUM OF SQUARED RESIDUALS FOR INITIAL PARAMETERS
SUM OF SQUARED WEIGHTED RESIDUALS
SUM OF SQUARED WEIGHTED RESIDUALS (WITH PRIOR)
SU

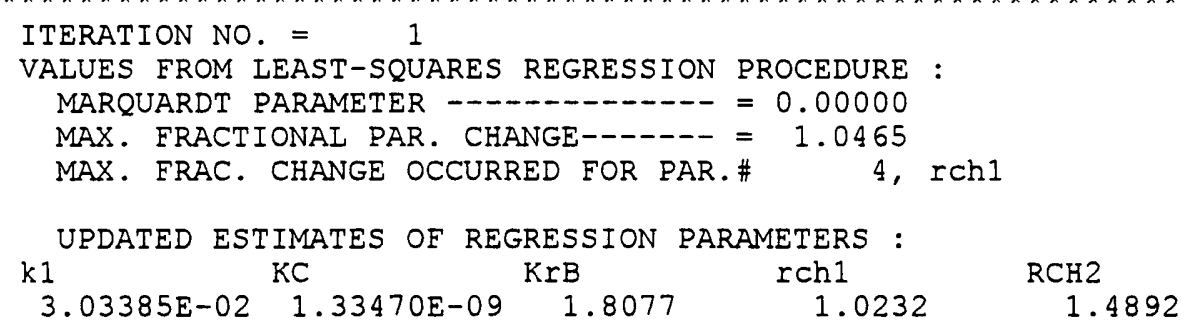

SUM OF SQUARED RESIDUALS FOR PARAMETERS AS UPDATED IN ITERATION NO. 1 SUM OF SQUARED WEIGHTED RESIDUALS 76.831

SUM OF SQUARED WEIGHTED RESIDUALS (WITH PRIOR) 76.832

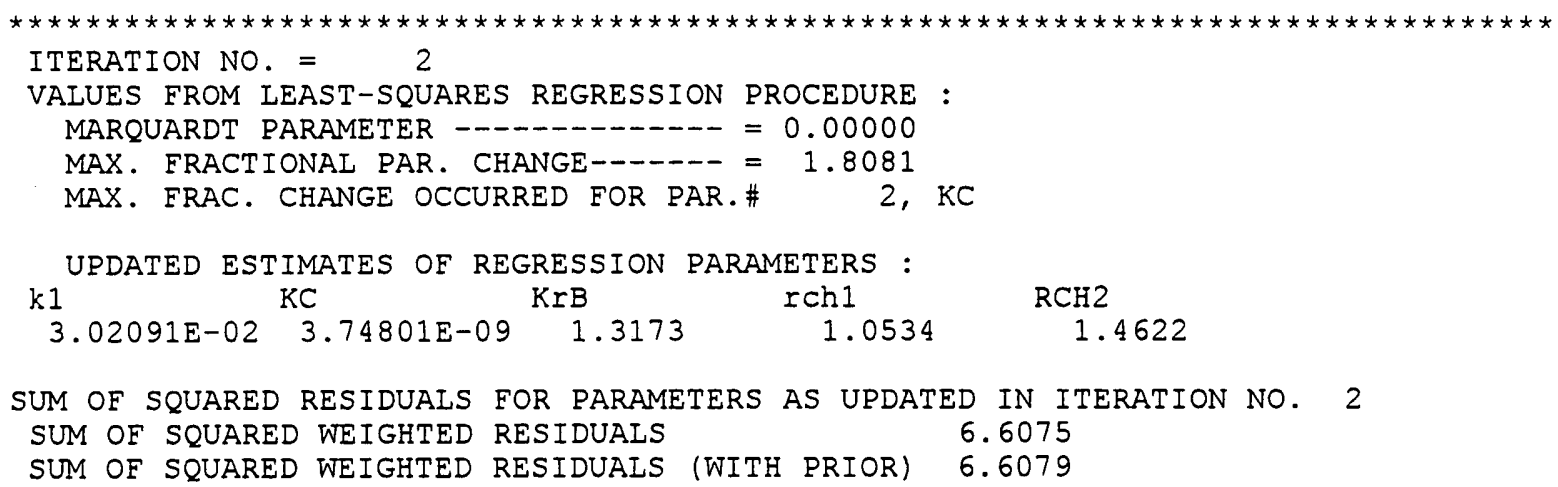




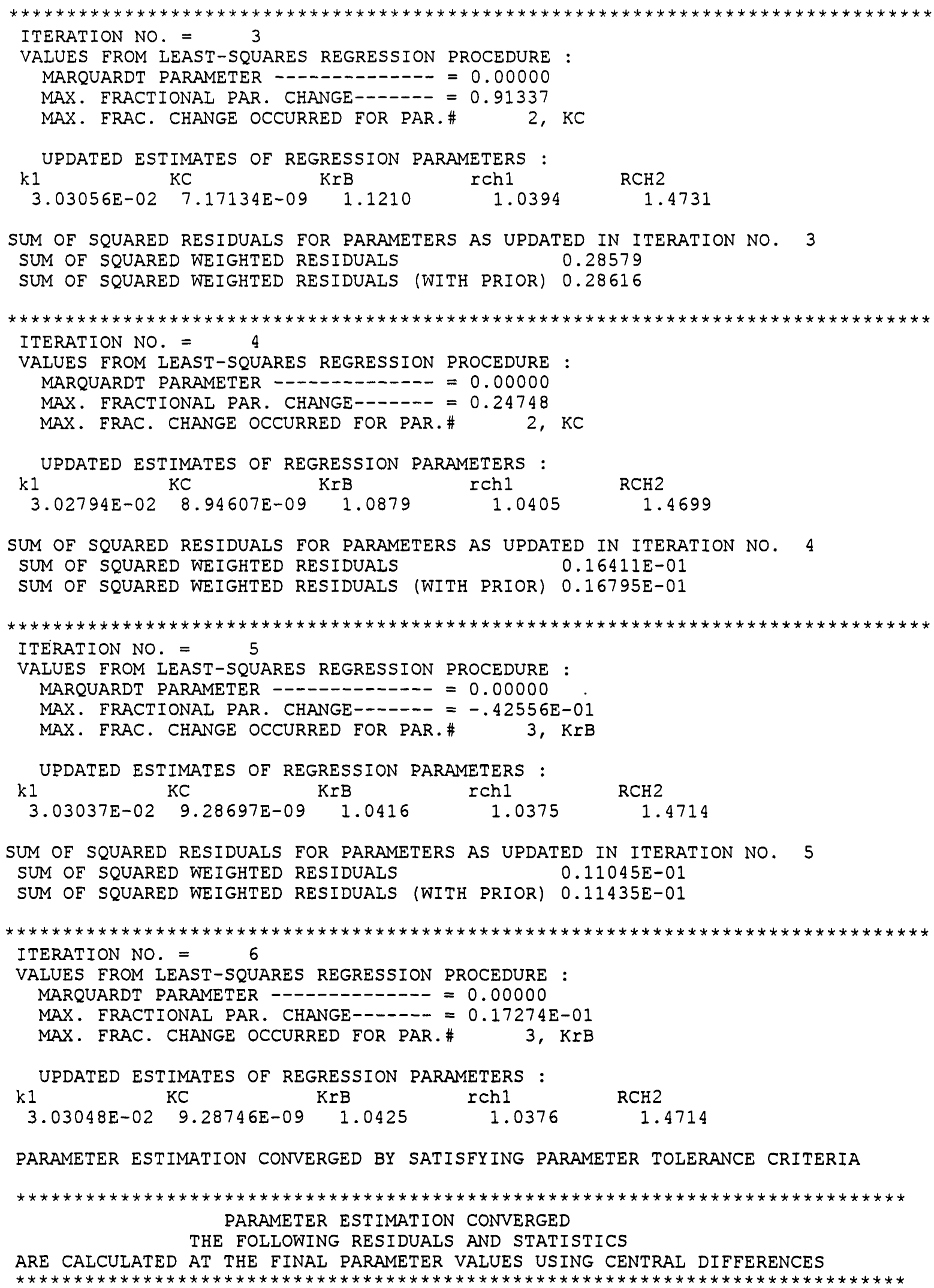


OBSERVATIONS

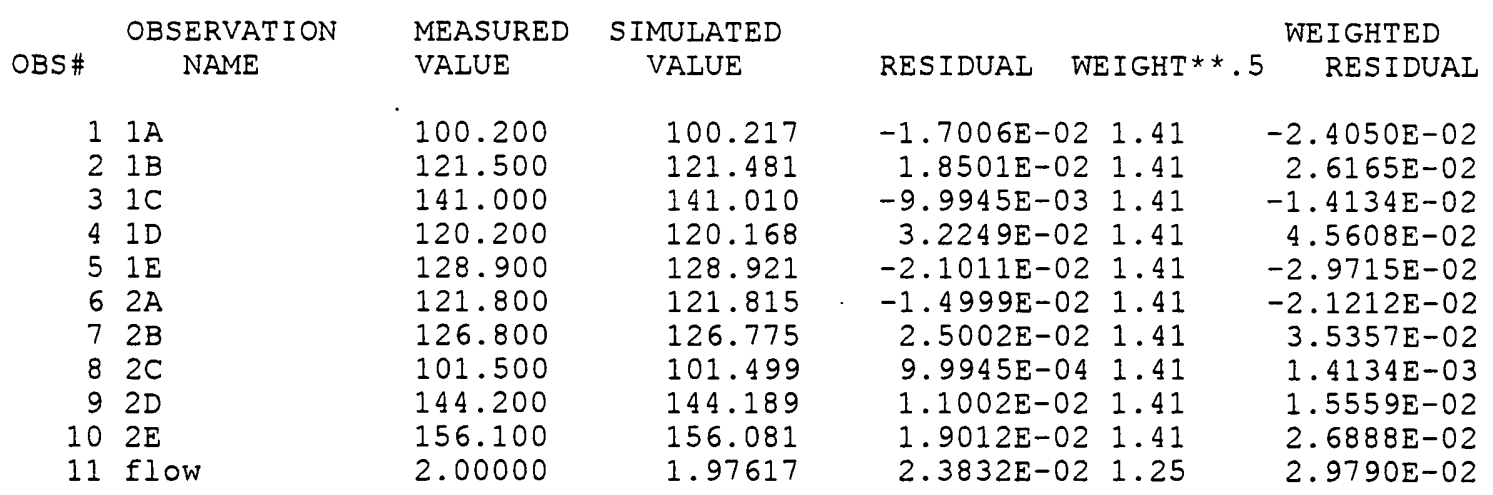

STATISTICS FOR THESE RESIDUALS :

MAXIMUM WEIGHTED RESIDUAL : $0.456 \mathrm{E}-01$ OBS\# $41 \mathrm{D}$

MINIMUM WEIGHTED RESIDUAL :-0.297E-01 OBS\# $51 \mathrm{E}$

AVERAGE WEIGHTED RESIDUAL : $0.833 \mathrm{E}-02$

\# RESIDUALS $>=0$. :

\# RESIDUALS < 0 . :

NUMBER OF RUNS : 6 IN 11 OBSERVATIONS

SUM OF SQUARED WEIGHTED RESIDUALS

$0.79804 \mathrm{E}-02$

PRIOR INFORMATION

\begin{tabular}{cccccc}
\multicolumn{7}{c}{ RESIDUAL } \\
EQ.\# & MEAUES & CALC. & (IOG IF LOG & WEIGHT & WEIGHTED \\
1 & $0.300000 E-01$ & $0.303048 E-01$ & $-0.439 E-02$ & 4.00 & $-0.176 E-01$ \\
2 & $0.125000 E+01$ & $0.125452 E+01$ & $-0.452 E-02$ & 2.00 & $-0.905 E-02$
\end{tabular}

STATISTICS FOR THESE RESIDUALS :

MAXIMUM WEIGHTED RESIDUAL :-0.905E-02 EQTN\# 2

MINIMUM WEIGHTED RESIDUAI :-0.176E-01 EQTN\# 1

AVERAGE WEIGHTED RESIDUAI :-0.133E-01

\# RESIDUALS $>=0$. :

\# RESIDUALS < $0 .:$

SUM OF SQUARED WEIGHTED RESIDUALS (WITH PRIOR) $0.83706 \mathrm{E}-02$

STATISTICS FOR ALL RESIDUALS :

AVERAGE WEIGHTED RESIDUAL : 0.500E-02

\# RESIDUALS $>=0$. : 7

\# RESIDUALS < $0 .: 00$

NUMBER OF RUNS : 7 IN 13 OBSERVATIONS

DIMENSIONLESS SCALED SENSITIVITIES (SCALED BY (PARAMETER_VALUE* (wt**.5))

\begin{tabular}{|c|c|c|c|c|c|}
\hline $\begin{array}{l}\text { PARAMETER \#: } \\
\text { PARAMETER ID: }\end{array}$ & $k 1^{1}$ & $\mathrm{KC}$ & $K r B^{3}$ & $\begin{array}{r}4 \\
\operatorname{rch} 1\end{array}$ & $\begin{array}{r}5 \\
\mathrm{RCH} 2\end{array}$ \\
\hline OBS\# OBS ID & & & & & \\
\hline $11 \mathrm{~A}$ & $0.00 E+00$ & $0.00 E+00$ & $-1.47 E-02$ & $7.07 \mathrm{E}-02$ & $2.13 \mathrm{E}-01$ \\
\hline $21 \mathrm{~B}$ & $9.64 \mathrm{E}+01$ & $1.31 E+00$ & $-1.33 E-02$ & $7 E+01$ & +01 \\
\hline $31 \mathrm{C}$ & $1.76 \mathrm{E}+02$ & $3.91 E+00$ & $-1.47 E-02$ & $1.57 E+01$ & $4.18 E+01$ \\
\hline $41 D$ & $9.07 E+01$ & $1.31 E+00$ & $-1.40 E-02$ & $1.01 E+01$ & $1.82 E+01$ \\
\hline $51 \mathrm{E}$ & $1.28 E+02$ & $1.30 \mathrm{E}+00$ & $-1.47 E-02$ & $1.34 E+01$ & $3 E+01$ \\
\hline $62 \mathrm{~A}$ & $9.75 E+01$ & $9.81 E+00$ & $-1.18 \mathrm{E}-02$ & $1.06 \mathrm{E}+01$ & $2.00 E+01$ \\
\hline $72 B$ & $1.19 E+02$ & $7.84 \mathrm{E}+00$ & $-1.32 \mathrm{E}-02$ & $1.25 \mathrm{E}+01$ & $2.52 E+01$ \\
\hline $82 C$ & $6.18 E+00$ & $3.01 E+01$ & $-1.47 E-02$ & $8.49 E-01$ & $1.27 E+00$ \\
\hline
\end{tabular}




$\begin{array}{rlrrrrr}9 & 2 \mathrm{D} & 1.88 \mathrm{E}+02 & 1.32 \mathrm{E}+00-1.47 \mathrm{E}-02 & 1.56 \mathrm{E}+01 & 4.63 \mathrm{E}+01 \\ 10 & 2 \mathrm{E} & 2.30 \mathrm{E}+02 & -7.84 \mathrm{E}+00 & -1.18 \mathrm{E}-02 & 1.57 \mathrm{E}+01 & 6.29 \mathrm{E}+01 \\ 11 \text { flow } & -6.51 \mathrm{E}-04-1.01 \mathrm{E}-02 & -8.22 \mathrm{E}-05 & 1.04 \mathrm{E}+00 & 1.43 \mathrm{E}+00\end{array}$

COMPOSITE SCALED SENSITIVITIES

((SUM OF THE SQUARED VALUES) /ND)**. 5

\begin{tabular}{lccccrr} 
PARAMETER \#: & \multicolumn{1}{c}{1} & 2 & 3 & 4 & 5 \\
PARAMETER ID: & $\mathrm{k} 1$ & $\mathrm{KC}$ & $\mathrm{KrB}$ & $\mathrm{rCh} 1$ & $\mathrm{RCH} 2$ \\
& & 127. & 10.2 & $1.317 \mathrm{E}-02$ & 11.3 & 30.7
\end{tabular}

1 \& SCALED SENSITIVITIES (SCALED BY (PARAMETER VALUE)/100.)

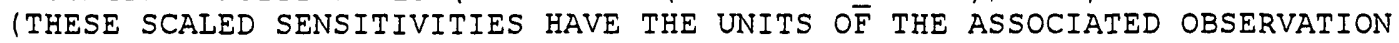

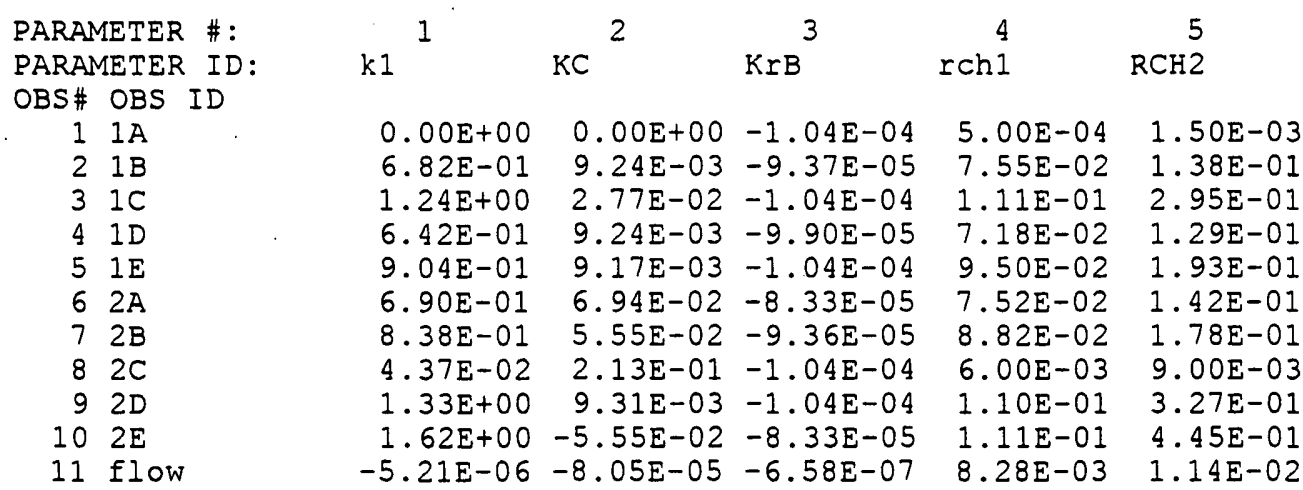

\begin{tabular}{|c|c|c|c|c|c|}
\hline & 1 & 2 & 3 & 4 & 5 \\
\hline $\begin{array}{l}\ddot{1} \\
2 \\
3 \\
4 \\
5\end{array}$ & $\begin{array}{r}7.4045 \mathrm{E}-05 \\
4.2267 \mathrm{E}-06 \\
-5.5560 \mathrm{E}-06 \\
9.2544 \mathrm{E}-05 \\
8.1395 \mathrm{E}-05\end{array}$ & $\begin{array}{r}4.2267 \mathrm{E}-06 \\
6.0744 \mathrm{E}-04 \\
-1.2921 \mathrm{E}-03 \\
-2.1461 \mathrm{E}-06 \\
-6.1076 \mathrm{E}-06\end{array}$ & $\begin{array}{r}-5.5560 \mathrm{E}-06 \\
-1.2921 \mathrm{E}-03 \\
7.1509 \mathrm{E}-03 \\
1.8228 \mathrm{E}-04 \\
-1.6903 \mathrm{E}-05\end{array}$ & $\begin{array}{r}9.2544 \mathrm{E}-05 \\
-2.1461 \mathrm{E}-06 \\
1.8228 \mathrm{E}-04 \\
1.3262 \mathrm{E}-04 \\
9.5503 \mathrm{E}-05\end{array}$ & $\begin{array}{r}8.1395 \mathrm{E}-05 \\
-6.1076 \mathrm{E}-06 \\
-1.6903 \mathrm{E}-05 \\
9.5503 \mathrm{E}-05 \\
9.2664 \mathrm{E}-05\end{array}$ \\
\hline
\end{tabular}

PARAMETER SUMMARY

PARAMETER VALUES IN "REGRESSION" SPACE -- LOG TRANSFORMED AS APPLICABLE

\begin{tabular}{|c|c|c|c|c|c|}
\hline $\begin{array}{l}\text { PARAMETER \#: } \\
\text { PARAMETER ID: } \\
\text { * = LOG TRNS: }\end{array}$ & $k 1$ * & $\mathrm{KC}^{2}$ & $\stackrel{3}{K r B}^{*}$ & $\begin{array}{l}4 \\
\operatorname{rch} 1\end{array}$ & 5 RCH2 \\
\hline $\begin{array}{l}\text { UPPER } 95 \% \text { C.I. } \\
\text { FINAL VALUES } \\
\text { LOWER } 958 \text { C.I. }\end{array}$ & $\begin{array}{l}-1.510 E+00 \\
-1.518 E+00 \\
-1.527 E+00\end{array}$ & $\begin{array}{l}-8.007 E+00 \\
-8.032 E+00 \\
-8.057 E+00\end{array}$ & $\begin{array}{r}1.028 \mathrm{E}-01 \\
1.809 \mathrm{E}-02 \\
-6.660 \mathrm{E}-02\end{array}$ & $\begin{array}{l}1.064 E+00 \\
1.038 E+00 \\
1.011 E+00\end{array}$ & $\begin{array}{l}1.494 E+00 \\
1.471 E+00 \\
1.449 E+00\end{array}$ \\
\hline STD. DEV. & $3.737 E-03$ & $1.070 \mathrm{E}-02$ & $3.673 \mathrm{E}-02$ & $1.152 E-02$ & $9.626 \mathrm{E}-03$ \\
\hline $\begin{array}{l}\text { COEF. OF VAR. } \\
\text { * if value }=0\end{array}$ & $2.461 \mathrm{E}-03$ & $1.333 E-03$ & $2.030 E+00$ & $1.110 \mathrm{E}-02$ & $6.542 \mathrm{E}-03$ \\
\hline
\end{tabular}




\section{PHYSICAL PARAMETER VALUES --- EXP1O OF LOG TRANSFORMED PARAMETERS}

\begin{tabular}{|c|c|c|c|c|c|}
\hline $\begin{array}{l}\text { PARAMETER \#: } \\
\text { PARAMETER ID: } \\
\text { * = LOG TRNS: }\end{array}$ & $k^{11}$ & $\mathrm{KC}^{2}$ & $\begin{array}{c}3 \\
K r B\end{array}$ & $\begin{array}{l}4 \\
r \operatorname{ch} 1\end{array}$ & ${ }^{5} \mathrm{RCH} 2$ \\
\hline $\begin{array}{l}\text { UPPER } 958 \text { C.I. } \\
\text { FINAI VALUES } \\
\text { LOWER } 95 \% \text { C.I. }\end{array}$ & $\begin{array}{l}3.091 E-02 \\
3.030 E-02 \\
2.971 E-02\end{array}$ & $\begin{array}{l}9.831 E-09 \\
9.287 E-09 \\
8.774 E-09\end{array}$ & $\begin{array}{l}1.267 \mathrm{E}+00 \\
1.043 \mathrm{E}+00 \\
8.578 \mathrm{E}-01\end{array}$ & $\begin{array}{l}1.064 \mathrm{E}+00 \\
1.038 \mathrm{E}+00 \\
1.011 \mathrm{E}+00\end{array}$ & $\begin{array}{l}1.494 E+00 \\
1.471 E+00 \\
1.449 E+00\end{array}$ \\
\hline $\begin{array}{l}\text { REASONABLE } \\
\text { UPPER LIMIT } \\
\text { REASONABLE } \\
\text { LOWER LIMIT }\end{array}$ & $3.000 E-01$ & $5.000 \mathrm{E}-07$ & $2.000 \mathrm{E}+01$ & $5.000 E+00$ & $2.000 \mathrm{E}+01$ \\
\hline
\end{tabular}

ESTIMATE ABOVE (1)

BELOW $(-1)$ LIMITS

ENTIRE CONE. INT.

ABOVE (1) BELOW $(-1)$

$\begin{array}{lllll}0 & 0 & 0 & 0 & 0 \\ 0 & 0 & 0 & 0 & 0\end{array}$

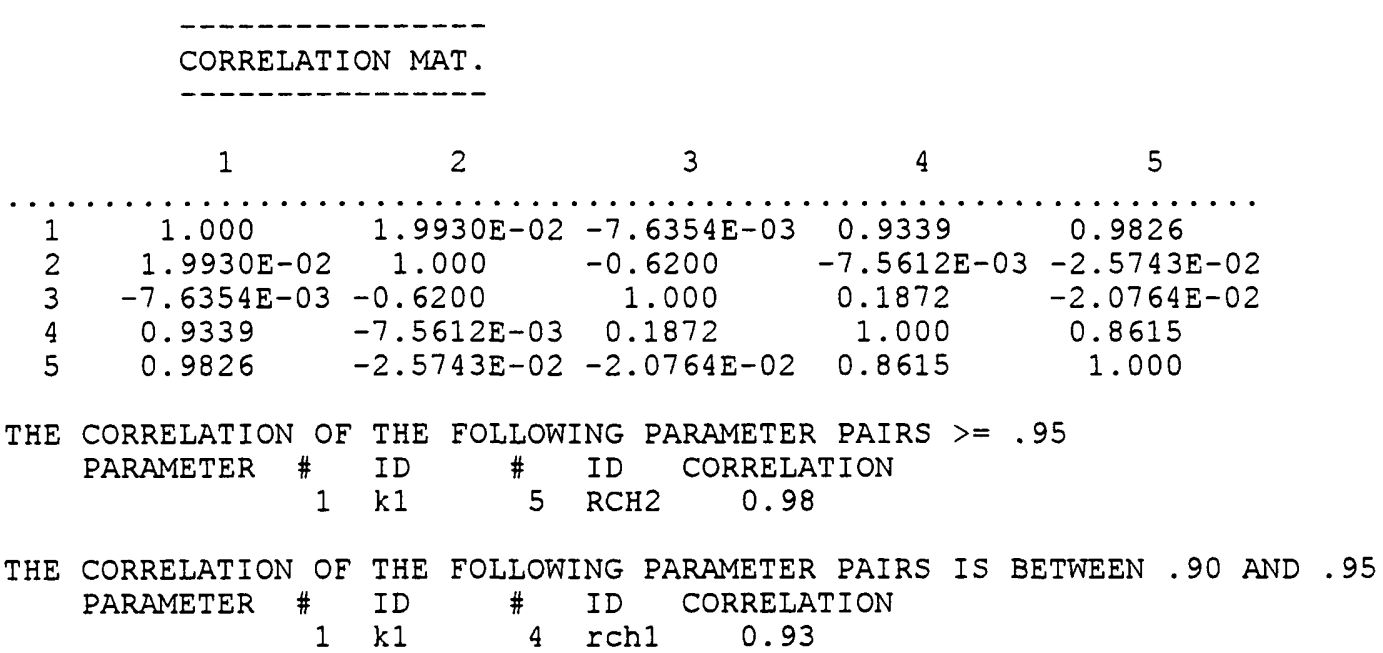

THE CORRELATION OF THE FOLLOWING PARAMETER PAIRS IS BETWEEN .85 AND .90 PARAMETER \# ID \# ID CORRELATION

CORRELATIONS GREATER THAN 0.95 COULD INDICATE THAT THERE IS NOT ENOUGH INFORMATION IN THE OBSERVATIONS AND PRIOR USED IN THE REGRESSION TO ESTIMATE PARAMETER VALUES INDIVIDUALLY.

TO CHECK THIS, START THE REGRESSION FROM SETS OF INITIAL PARAMETER VALUES THAT DIFFER BY MORE THAT TWO STANDARD DEVIATIONS FROM THE ESTIM ATED VALUES. IF THE RESULTING ESTIMATES ARE WELL WITHIN ONE STANDARD DEVIATION OF THE PREVIOUSLY ESTIMATED VALUE, THE ESTIMATES ARE PROBABLY DETERMINED INDEPENDENTLY WITH THE OBSERVATIONS AND PRIOR USED IN THE REGRESSION. OTHERWISE, YOU MAY ONLY BE ESTIMATING THE RATIO OR SUM OF THE HIGHLY CORRELATED PARAMETERS.

FOR UCODE, THE INITIAL PARAMETER VALUES ARE IN THE PREPARE FILE.

LEAST-SQUARES OBJ FUNC (DEP.VAR. ONLY) $-=0.79804 \mathrm{E}-02$

LEAST-SQUARES OBJ FUNC (W/PARAMETERS) $--=0.83706 \mathrm{E}-02$

CALCULATED ERROR VARIANCE--------- $=0.10463 \mathrm{E}-02$ 


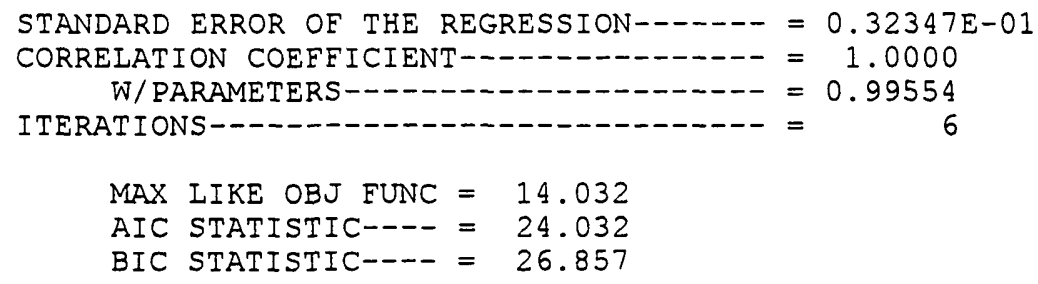

ORDERED DEPENDENT-VARIABLE WEIGHTED RESIDUALS NUMBER OF RESIDUALS INCLUDED

$0.262 E-01 \quad 0.269 E-01 \quad 0.298 E-01$

1

CORELATION BETWEEN ORDERED WEIGHTED RESIDUALS

AND NORMAL ORDER STATISTICS $=0.925$

(CALCULATED USING EQ.38 OF HILL, 1992 OR EQ.23 OF HILL, 1998)

ORDERED WEIGHTED RESIDUALS INCLUDING PRIOR INFORMATION
\begin{tabular}{ccccrr} 
NUMBER OF RESIDUALS INCLUDED: & \multicolumn{1}{c}{13} \\
$-0.297 \mathrm{E}-01$ & $-0.241 \mathrm{E}-01$ & $-0.212 \mathrm{E}-01$ & $-0.176 \mathrm{E}-01$ & $-0.141 \mathrm{E}-01$ & $-0.905 \mathrm{E}-02$ \\
$0.141 \mathrm{E}-02$ & $0.156 \mathrm{E}-01$ & $0.262 \mathrm{E}-01$ & $0.269 \mathrm{E}-01$ & $0.298 \mathrm{E}-01$ & $0.354 \mathrm{E}-01$
\end{tabular}
NUMBER OF RESIDUALS INCLUDED:
$\begin{array}{rrrrrr}-0.297 \mathrm{E}-01 & -0.241 \mathrm{E}-01 & -0.212 \mathrm{E}-01 & -0.176 \mathrm{E}-01 & -0.141 \mathrm{E}-01 & -0.905 \mathrm{E}-02 \\ 0.141 \mathrm{E}-02 & 0.156 \mathrm{E}-01 & 0.262 \mathrm{E}-01 & 0.269 \mathrm{E}-01 & 0.298 \mathrm{E}-01 & 0.354 \mathrm{E}-01\end{array}$
$0.156 \mathrm{E}-01 \quad 0.262 \mathrm{E}-01$
$0.269 E-01$
$0.298 \mathrm{E}-01$
$0.354 \mathrm{E}-01$

$0.456 \mathrm{E}-01$

CORRELATION BETWEEN ORDERED WEIGHTED RESIDUALS

AND NORMAI ORDER STATISTICS $=0.929$

(CALCULATED USING EQ.38 OF HILL, 1992 OR EQ.23 OF HILL, 1998)

COMMENTS ON THE INTERPRETATION OF THE CORRELATION BETWEEN

WEIGHTED RESIDUALS AND NORMAL ORDER STATISTICS:

Generally, IF the reported CORRELATION is LESS than the critical value, at the selected significance level (usually 5 or $10 \%$ ), the hypothesis that the weighted residuals are INDEPENDENT AND NORMALLY DISTRIBUTED would be REJECTED. HOWEVER, in this case, conditions are outside of the range of published critical values as discussed below.

The sum of the number of observations and prior information items is 13 which is less than 35 , the minimum value for which critical values are published. Therefore, the critical values for the 5 and 108 significance levels are less than 0.943 and 0.952 , respectively.

CORRELATIONS GREATER than these critical values indicate that, probably, the weighted residuals ARE INDEPENDENT AND NORMALLY DISTRIBUTED.

Correlations IESS than these critical values MAY BE ACCEPTABLE, and rejection of the hypothesis is not necessarily warranted.

The Kolmogorov-Smirnov test can be used to further evaluate the residuals. The Kolmogorov-Smi rnov test can be used to further evaluate the residuals.

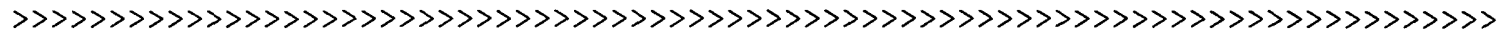

PARAMETER VALUES AND STATISTICS FOR ALL ITERATIONS

PARAMETER NAMES

K1 KC KrB $\quad$ rch1

$\mathrm{RCH} 2$

INITIAL PARAMETER VALUES
$0.300 \mathrm{E}-01$
$0.500 \mathrm{E}-07$
2.00
0.500

$$
2.00
$$

\author{
LEAST SQUARES \\ OBJ OBJ FNC \\ FUNC W/PRIOR MAX-CHG PARAM MARQRDT \\ $\begin{array}{llllr}.42 \mathrm{E}+03.42 \mathrm{E}+03 & 1.0 & \text { rch } 1 & 0.00\end{array}$
}




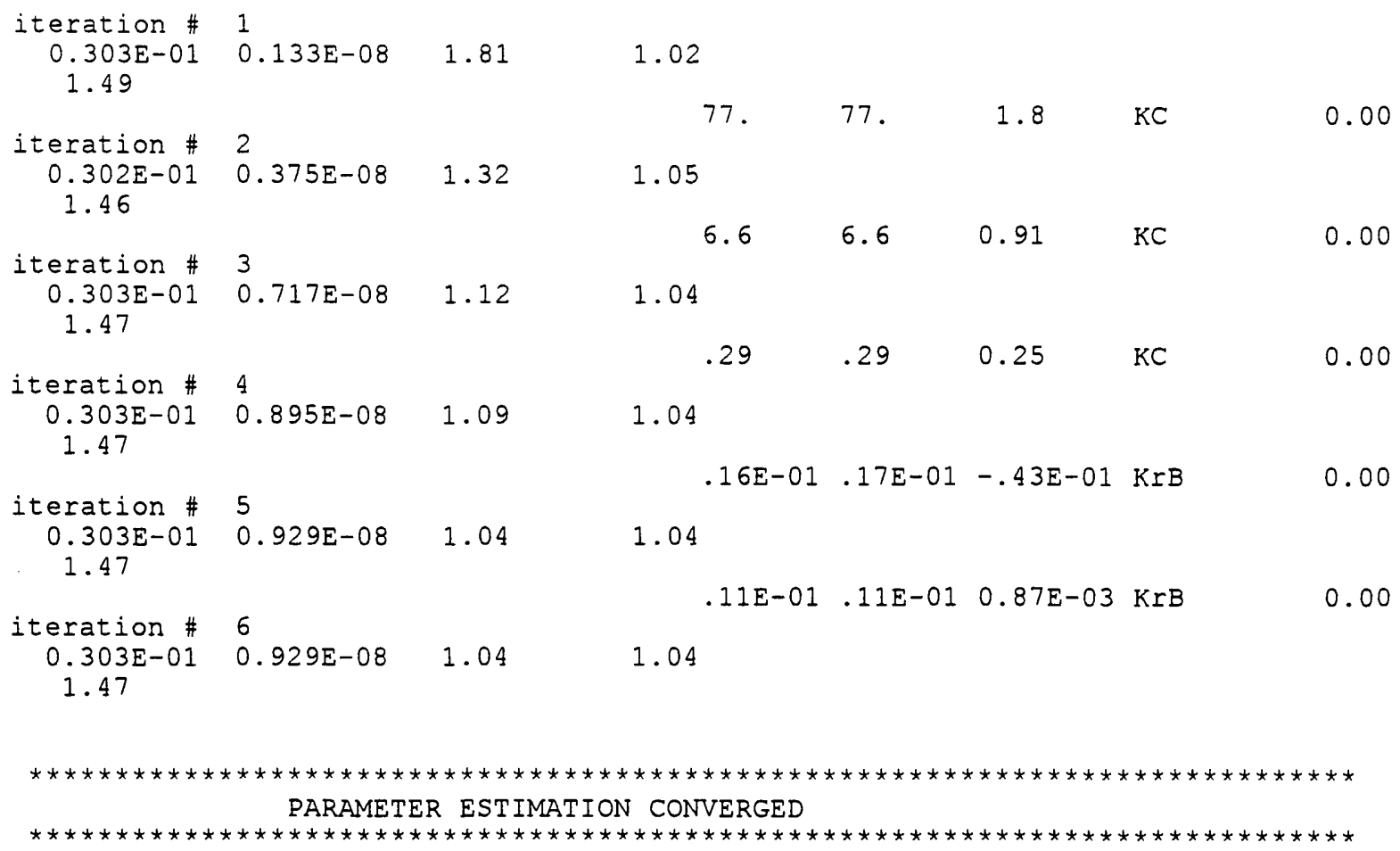

\section{Check File--fn._ck}

test._ck

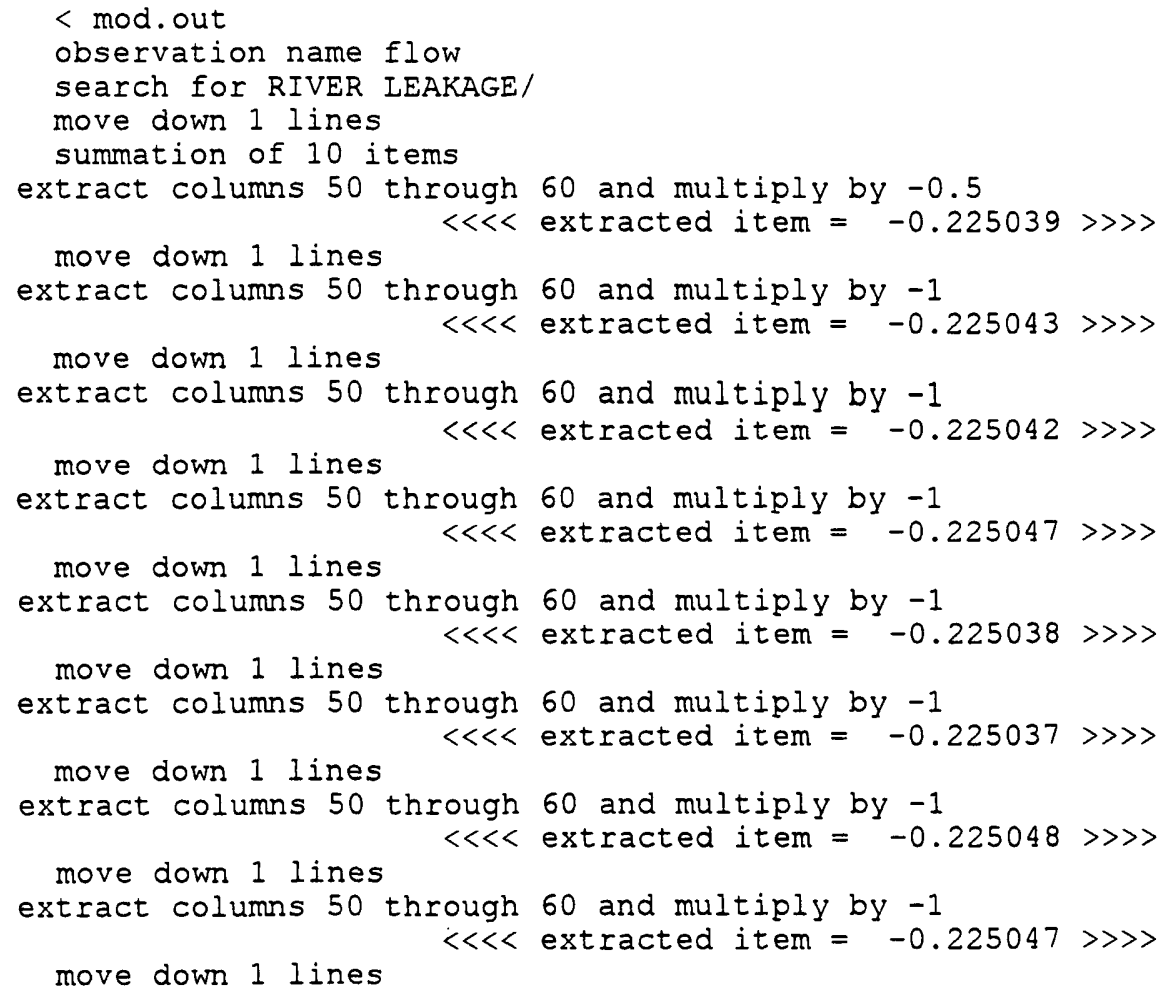




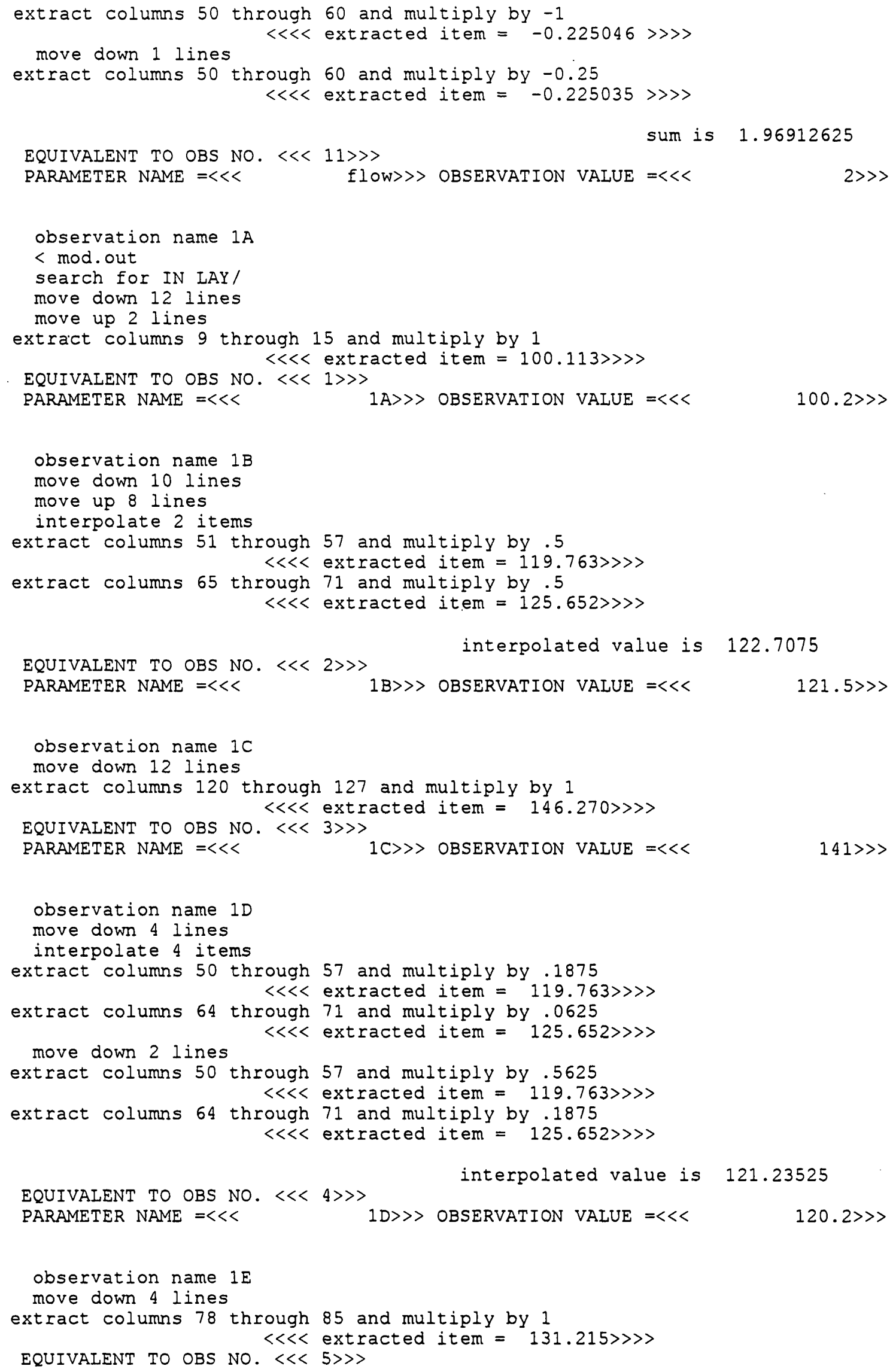




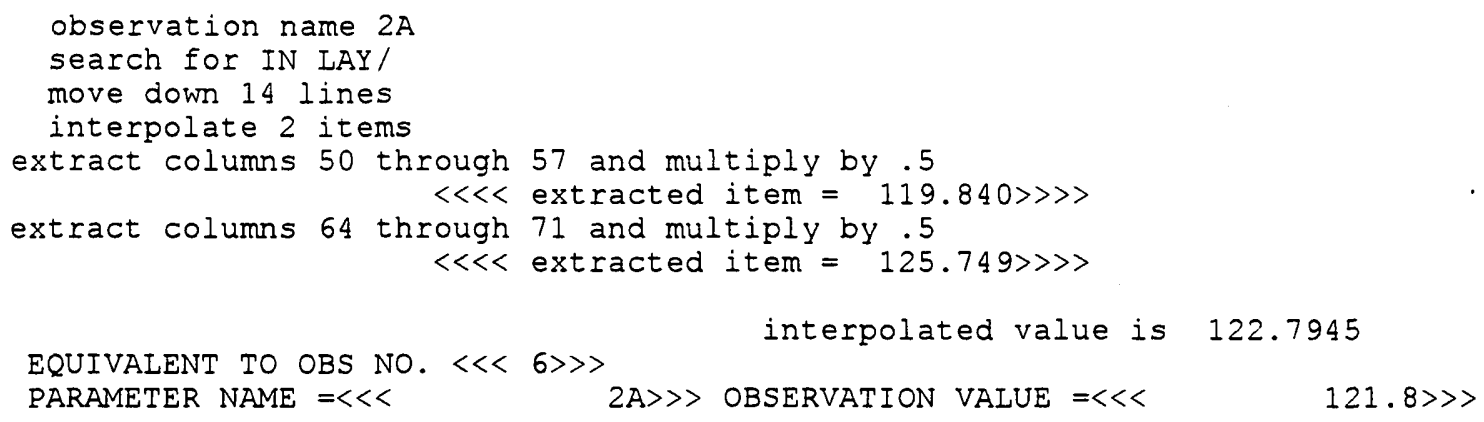




\section{Residual Analysis Files}

\begin{tabular}{|c|c|c|c|c|c|c|c|c|c|}
\hline \multicolumn{5}{|c|}{ test._os } & \multicolumn{5}{|c|}{ test._ww } \\
\hline \multicolumn{2}{|c|}{ unweighted } & \multirow{2}{*}{$\begin{array}{c}\text { plot } \\
\text { variable }\end{array}$} & \multirow{2}{*}{\multicolumn{2}{|c|}{$\begin{array}{l}\text { observation } \\
\text { name }\end{array}$}} & \multicolumn{2}{|c|}{ weighted } & \multirow{2}{*}{$\begin{array}{c}\text { plot } \\
\text { variable }\end{array}$} & \multirow{2}{*}{\multicolumn{2}{|c|}{$\begin{array}{l}\text { observation } \\
\text { name }\end{array}$}} \\
\hline $\begin{array}{l}\text { simulated } \\
\text { value }\end{array}$ & observation & & & & $\begin{array}{l}\text { simulated } \\
\text { value }\end{array}$ & observation & & & \\
\hline 100.2170 & 100.2000 & & & $1 A$ & 141.7282 & 141.7042 & & & $1 \mathrm{~A}$ \\
\hline 121.4815 & 121.5000 & & & $1 \mathrm{~B}$ & 171.8008 & 171.8270 & & 1 & IB \\
\hline 141.0100 & 141.0000 & & & $1 \mathrm{C}$ & 199.4182 & 199.4041 & & 1 & $1 \mathrm{C}$ \\
\hline 120.1677 & 120.2000 & & 1 & $1 D$ & 169.9429 & 169.9885 & & 1 & 10 \\
\hline 128.9210 & 128.9000 & & 1 & $1 \mathrm{E}$ & 182.3218 & 182.2921 & & 1 & $1 E$ \\
\hline 121.8150 & 121.8000 & & 2 & $2 \mathrm{~A}$ & 172.2724 & 172.2512 & & 2 & $2 \mathrm{~A}$ \\
\hline 126.7750 & 126.8000 & & 2 & $2 \mathrm{~B}$ & 179.2869 & 179.3223 & & 2 & $2 \mathrm{~B}$ \\
\hline 101.4990 & 101.5000 & & 2 & $2 \mathrm{C}$ & 143.5413 & 143.5427 & & 2 & $2 \mathrm{C}$ \\
\hline 144.1890 & 144.2000 & & 2 & $2 \mathrm{D}$ & 203.9140 & 203.9296 & & 2 & 2D \\
\hline 156.0810 & 156.1000 & & 2 & $2 E$ & 220.7319 & 220.7587 & & 2 & $2 \mathrm{E}$ \\
\hline 1.976168 & 2.000000 & & 0 & flow & 2.470210 & 2.500000 & & 0 & flow \\
\hline-1.518489 & -1.522879 & & 3 & PRIORI & -6.073955 & -6.091515 & & 3 & PRIOR1 \\
\hline 1.254525 & 1.250000 & & 3 & PRIOR2 & 2.509050 & 2.500000 & & 3 & PRIOR2 \\
\hline
\end{tabular}

\begin{tabular}{|c|c|c|c|c|c|c|}
\hline \multicolumn{4}{|c|}{ test._ws } & \multicolumn{3}{|c|}{ test._r } \\
\hline \multicolumn{2}{|c|}{ weighted } & \multirow{2}{*}{$\begin{array}{c}\text { plot } \\
\text { variable }\end{array}$} & \multirow{2}{*}{$\begin{array}{l}\text { observation } \\
\text { name }\end{array}$} & \multirow{2}{*}{$\begin{array}{l}\text { unweighted } \\
\text { residual }\end{array}$} & \multirow{2}{*}{$\begin{array}{c}\text { plot } \\
\text { variable }\end{array}$} & \multirow{2}{*}{$\begin{array}{l}\text { observation } \\
\text { name }\end{array}$} \\
\hline $\begin{array}{l}\text { simulated } \\
\text { value }\end{array}$ & residual & & & & & \\
\hline 141.7282 & $-0.2405000 \mathrm{E}-01$ & 1 & $\overline{1 A}$ & $-0.1700592 \mathrm{E}-01$ & 1 & $1 \mathrm{~A}$ \\
\hline 171.8008 & $0.2616476 \mathrm{E}-01$ & 1 & $1 \mathrm{~B}$ & $0.1850128 \mathrm{E}-01$ & 1 & $\mathrm{IB}$ \\
\hline 199.4182 & $-0.1413437 \mathrm{E}-01$ & 1 & $1 \mathrm{C}$ & $-0.9994507 \mathrm{E}-02$ & 1 & $1 \mathrm{C}$ \\
\hline 169.9429 & $0.4560761 \mathrm{E}-01$ & 1 & ID & $0.3224945 \mathrm{E}-01$ & $\overline{1}$ & $1 \mathrm{D}$ \\
\hline 182.3218 & $-0.2971454 \mathrm{E}-01$ & 1 & $1 E$ & $-0.2101135 E-01$ & 1 & $1 \mathrm{E}$ \\
\hline 172.2724 & $-0.2121234 \mathrm{E}-01$ & 2 & $2 A$ & $-0.1499939 \mathrm{E}-01$ & 2 & $2 \mathrm{~A}$ \\
\hline 179.2869 & $0.3535750 \mathrm{E}-01$ & 2 & $2 \mathrm{~B}$ & $0.2500153 \mathrm{E}-01$ & 2 & $2 \mathrm{~B}$ \\
\hline 143.5413 & $0.1413437 E-02$ & 2 & $2 \mathrm{C}$ & $0.9994507 \mathrm{E}-03$ & 2 & $2 \mathrm{C}$ \\
\hline 203.9140 & $0.1555859 \mathrm{E}-01$ & 2 & 2D & $0.1100159 \mathrm{E}-01$ & 2 & 2D \\
\hline 220.7319 & $0.2688767 \mathrm{E}-01$ & 2 & $2 \mathrm{E}$ & $0.1901245 \mathrm{E}-01$ & 2 & $2 \mathrm{E}$ \\
\hline 2.470210 & $0.2979025 E-01$ & 0 & flow & $0.2383220 E-01$ & 0 & flow \\
\hline-6.073955 & $-0.1756039 E-01$ & 3 & PRIOR1 & $-0.4390098 E-02$ & 3 & PRIORI \\
\hline 2.509050 & $-0.9049892 \mathrm{E}-02$ & 3 & PRIOR2 & $-0.4524946 \mathrm{E}-02$ & 3 & PRIOR2 \\
\hline
\end{tabular}




\begin{tabular}{|c|c|c|c|c|c|c|}
\hline \multicolumn{3}{|c|}{ test._w } & \multicolumn{4}{|c|}{ test._nm } \\
\hline $\begin{array}{l}\text { weighted } \\
\text { residual }\end{array}$ & $\begin{array}{c}\text { plot } \\
\text { variable }\end{array}$ & $\begin{array}{l}\text { observation } \\
\text { name }\end{array}$ & $\begin{array}{l}\text { weighted } \\
\text { residual }\end{array}$ & $\begin{array}{c}\text { probability } \\
\text { plotting position }\end{array}$ & $\begin{array}{c}\text { plot } \\
\text { variable }\end{array}$ & $\begin{array}{c}\text { observation } \\
\text { name }\end{array}$ \\
\hline$-0.2405000 \mathrm{E}-01$ & 1 & $1 \mathrm{~A}$ & $-0.297145 \mathrm{E}-01$ & -1.76935 & 1 & IE \\
\hline $0.2616476 \mathrm{E}-01$ & 1 & $1 \mathrm{~B}$ & $-0.240500 \mathrm{E}-01$ & -1.19858 & 1 & $1 \mathrm{~A}$ \\
\hline$-0.1413437 \mathrm{E}-01$ & 1 & 1C & $-0.212123 E-01$ & -0.869825 & 2 & $2 A$ \\
\hline $0.4560761 \mathrm{E}-01$ & 1 & 1D & $-0.175604 \mathrm{E}-01$ & -0.615361 & 3 & PRIORI \\
\hline$-0.2971454 \mathrm{E}-01$ & 1 & $1 \mathrm{E}$ & $-0.141344 E-01$ & -0.395823 & 1 & $1 \mathrm{C}$ \\
\hline$-0.2121234 \mathrm{E}-01$ & 2 & $2 A$ & $-0.904989 E-02$ & -0.193967 & 3 & PRIOR2 \\
\hline $0.3535750 E-01$ & 2 & $2 \mathrm{~B}$ & $0.141344 \mathrm{E}-02$ & 0.000000 & 2 & $2 \mathrm{C}$ \\
\hline $0.1413437 \mathrm{E}-02$ & 2 & $2 \mathrm{C}$ & $0.155586 \mathrm{E}-01$ & 0.193967 & 2 & 2D \\
\hline $0.1555859 \mathrm{E}-01$ & 2 & $2 \mathrm{D}$ & $0.261648 \mathrm{E}-01$ & 0.395823 & 1 & $1 \mathrm{~B}$ \\
\hline $0.2688767 \mathrm{E}-01$ & 2 & $2 E$ & $0.268877 \mathrm{E}-01$ & 0.615361 & 2 & $2 \mathrm{E}$ \\
\hline $0.2979025 \mathrm{E}-01$ & 0 & flow & $0.297903 E-01$ & 0.869825 & 0 & flow \\
\hline$-0.1756039 \mathrm{E}-01$ & 3 & PRIORI & $0.353575 \mathrm{E}-01$ & 1.19858 & 2 & $2 \mathrm{~B}$ \\
\hline$-0.9049892 \mathrm{E}-02$ & 3 & PRIOR2 & $0.456076 \mathrm{E}-01$ & 1.76935 & 1 & $1 \mathrm{D}$ \\
\hline
\end{tabular}

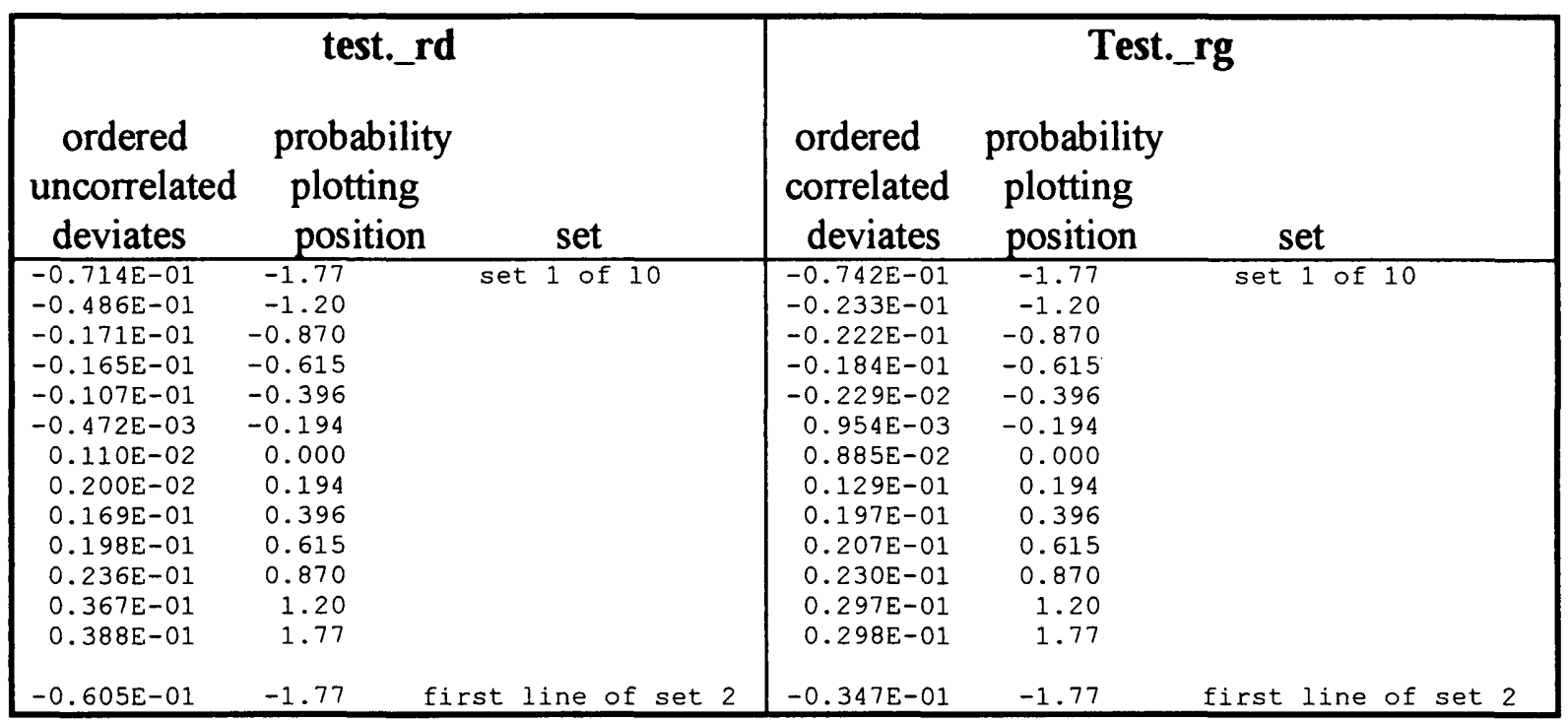


in

ก * * *

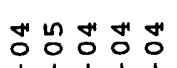

111

in

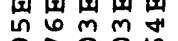

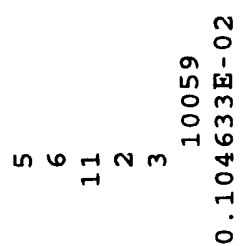

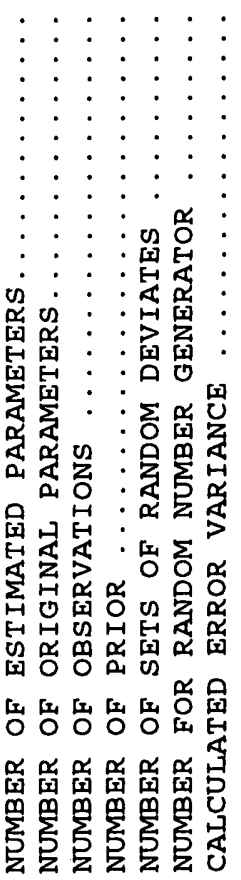
$m$ o o in 0

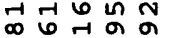
$\dot{0} i$ i $0 \dot{0}$ ธํํㅇํㅇ요유 自闰间 Ұु

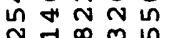
สసี่ - i 000

西 농ํํํํํํํํ 四国国 m O승 Nㅜ을 นกำ ט ? ยn $m$ N $n$ n

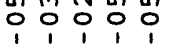

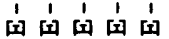
政 Niro 우ㅇㅝㅛ o: 1 i

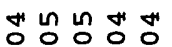

11 1

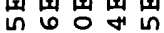
उ० 6 出

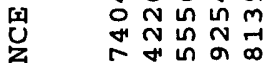

*

नन न

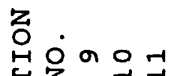

茛行

$\rightarrow$

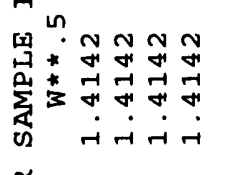

영

空

o nor 鼠

悹

约

* F स

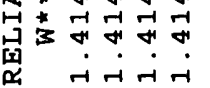$$
\text { O० : i } 0
$$

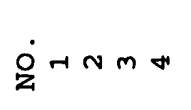

6

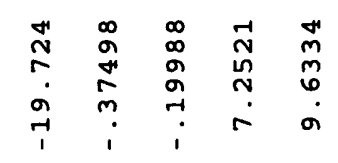

in

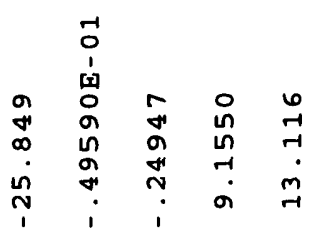

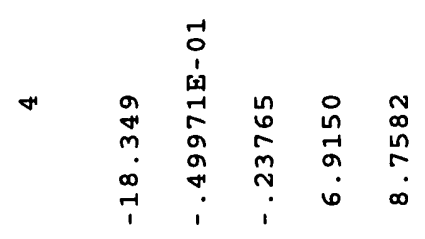

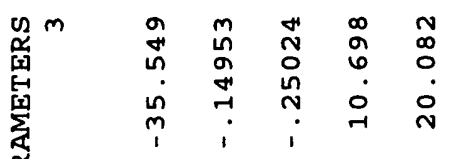

$$
\begin{aligned}
& \text { 愛 }
\end{aligned}
$$

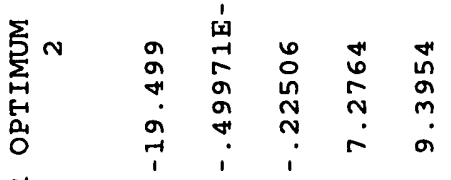




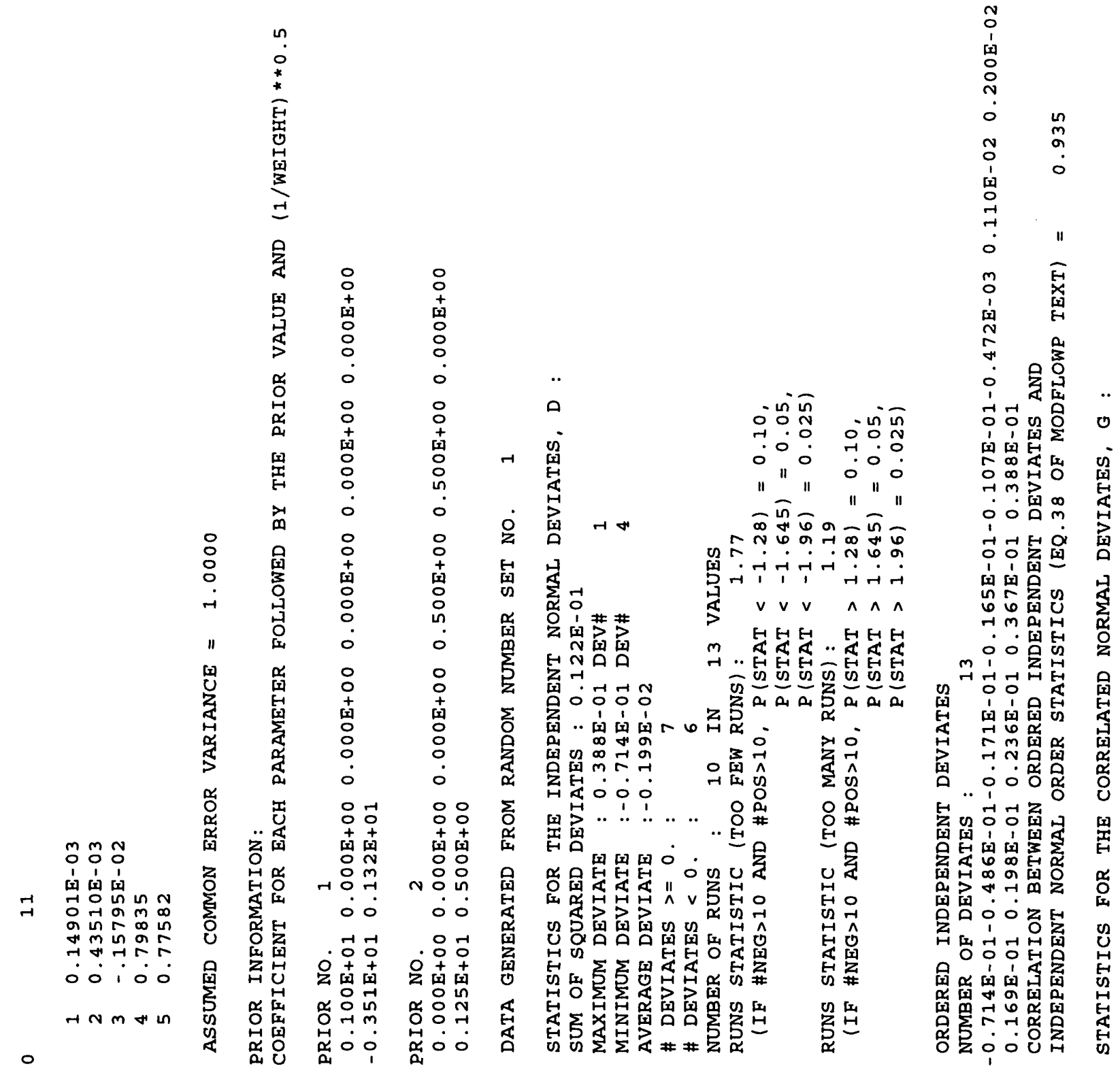




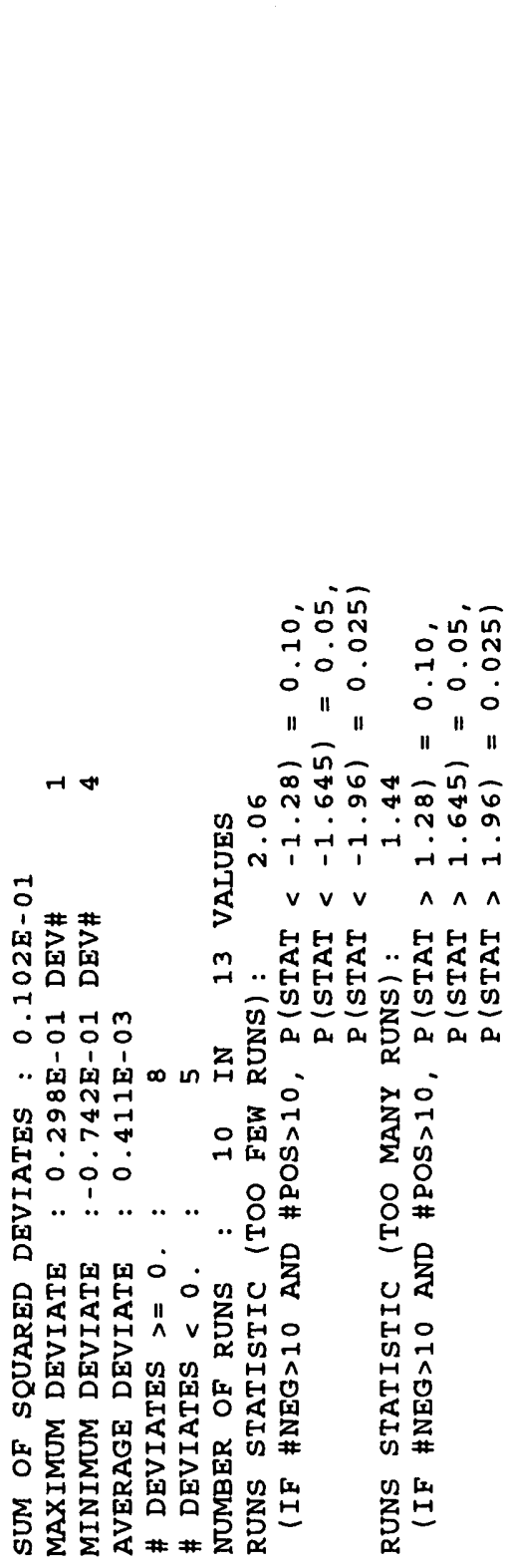

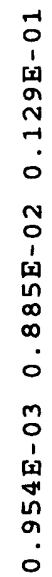

$\infty$
$\infty$
$\infty$
0

-1ㅜㄷㅇ

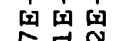

D $\hat{m}=\mathbb{N}$

궁

ก ก

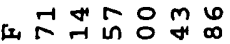

nก⿻上丨

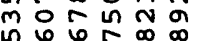

000000

\%ำ

1' 1' 1'

ง ถูก

\$ㄷำ

D.

तै

001

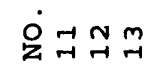

跔

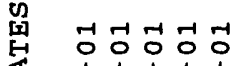

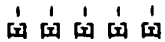

年

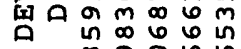

กับ

00 国

न-10

1'国

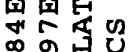

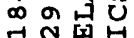

웁

$m$
-1

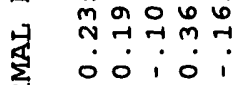

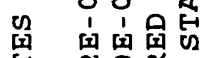

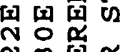

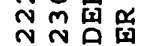

思. 웅영

..

国国圆国罗

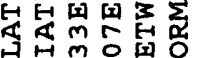

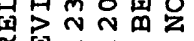

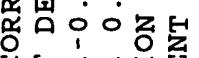

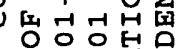

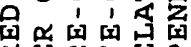

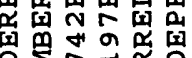

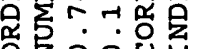

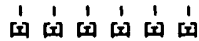

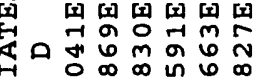

잉

运 $\underset{n}{\sim} \underset{-1}{m}$

啇

崖

.

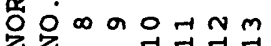

obrao

员

留

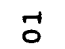

i

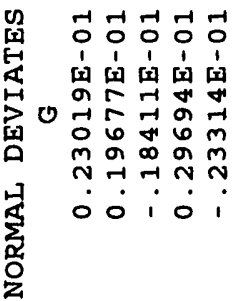

요부

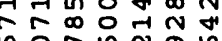
in or in

(1)

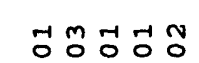

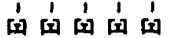

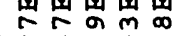

口 $N 6000$

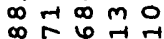

0
0

0 i0 0

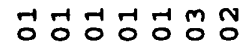

1' 1 ' 1 ' 1

mN nN

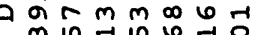

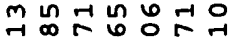

$0: 0 ; 0$

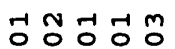

111

N

ช N6ชึ:

冓恋

กัก

$\therefore \because \because \because \therefore$

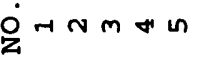

造-nmangr

Dूandun 


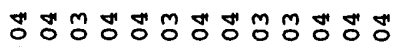

건

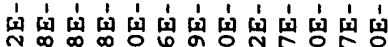
N N त̂̃. io io o o o i i i i :

ガず

a

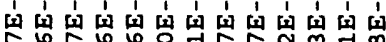
in

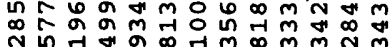
$0 ; i i i i i i_{0} i 00$

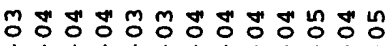

$\infty$

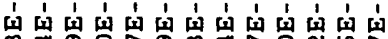

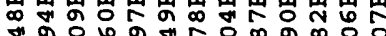
* ㄷํㅇㄱำ

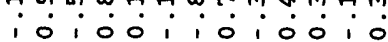

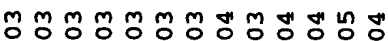

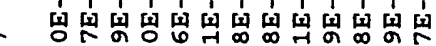

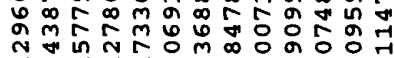
N

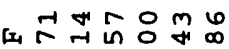
$\ln 2000$ กิ ○ं 0 0 0000

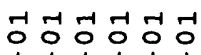
四四四四回自 (5) $\infty \begin{gathered}\infty \\ 0\end{gathered}$ 要

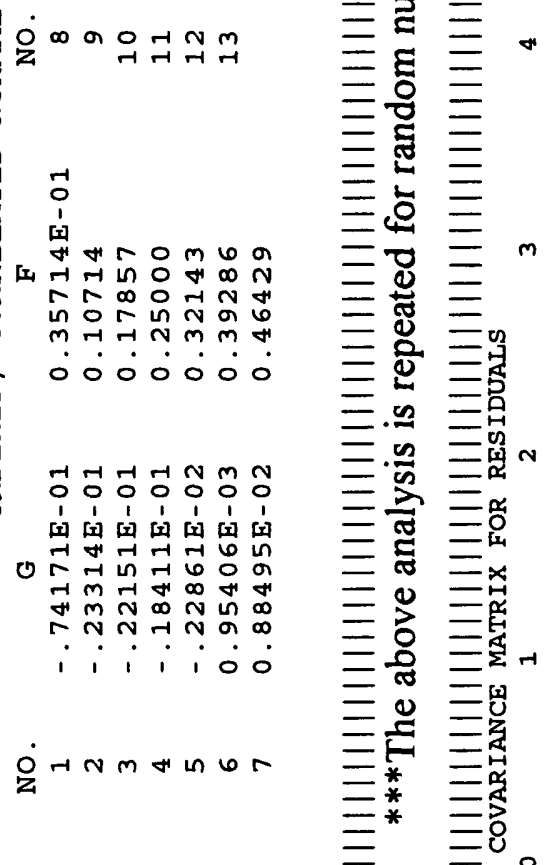

$\dot{0} i i_{i} i \dot{0} i$ i $\dot{0}^{\prime} \dot{0}$

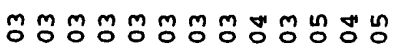

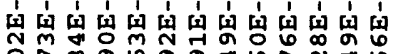

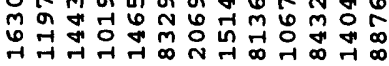
oi i i i i i i i i i

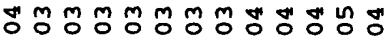

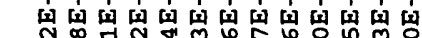
궁규

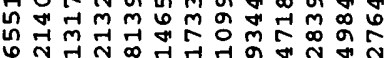

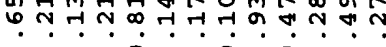

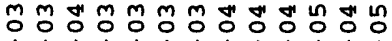

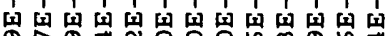

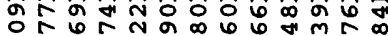

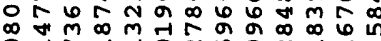
ก $i$ ioi i ioiojo:

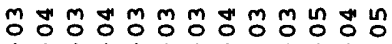

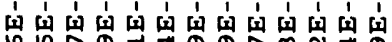
수의

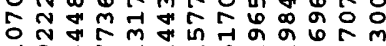

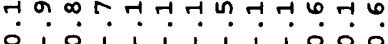

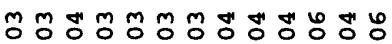

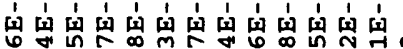

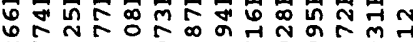

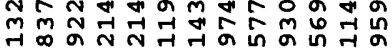
ioi i i io io i o

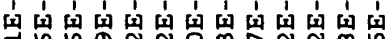

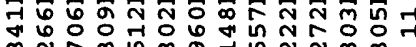
Mำ

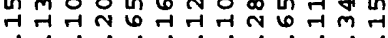
0 i 1 io 0 io i 0 io

HNm

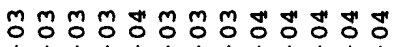

$\infty$<smiles>O=CI</smiles>

r<smiles>O=C=C=CC=O</smiles>

$\omega$<smiles>O=C=O</smiles>
우

in

$$
\begin{gathered}
a \\
m \\
n \\
\infty \\
\hdashline \\
i
\end{gathered}
$$

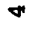

$$
\begin{gathered}
0 \\
\multirow{1}{1}{} \\
0 \\
0 \\
1
\end{gathered}
$$

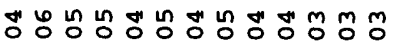

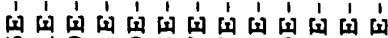

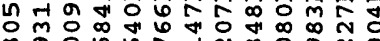

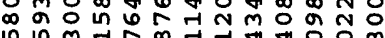

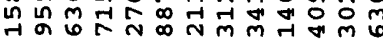
0 $000 i$ i i 001 i

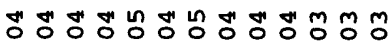

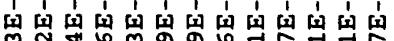

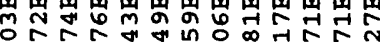

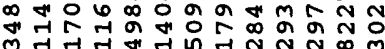

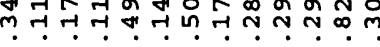

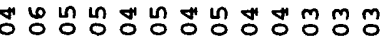
1 । 1 । 1 国国国国国国国国 N

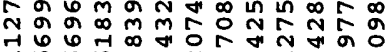

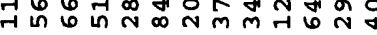
- ió i i io io i HNM⿻上丨冂

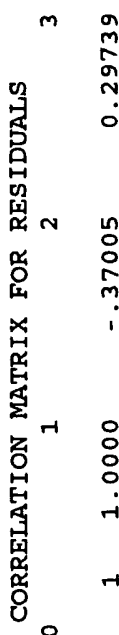



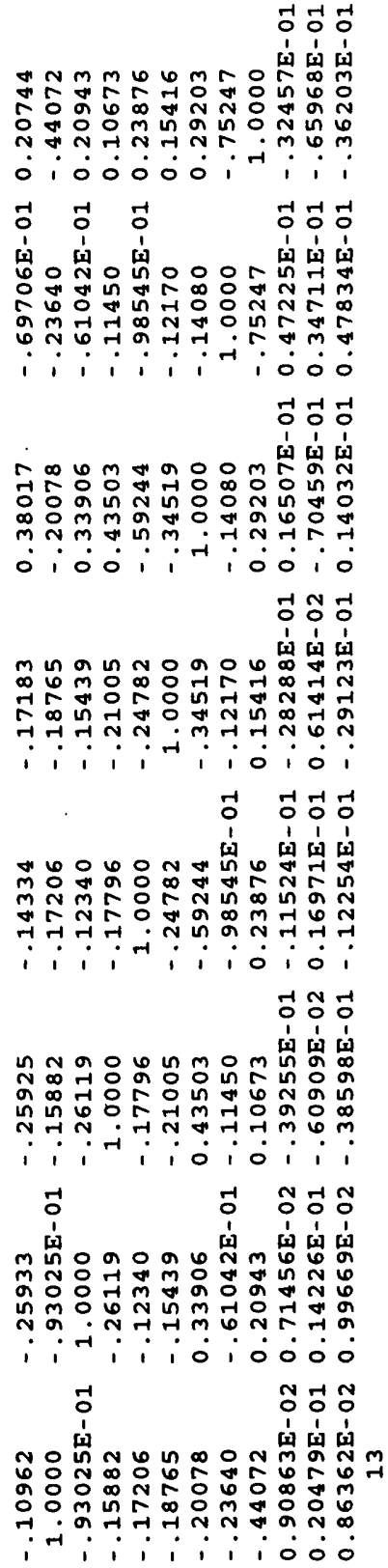

-1 m용

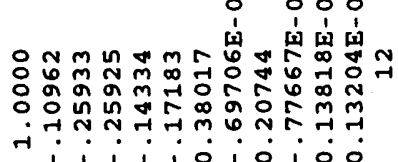

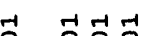

i 잉

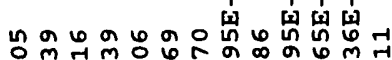

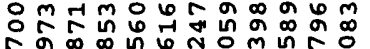

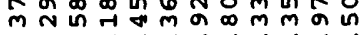

$i 0 i i 0 ; 0 i 0 ; 0$

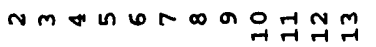

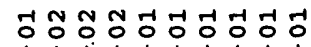

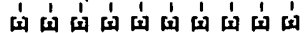

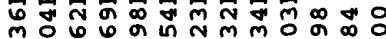

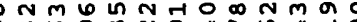

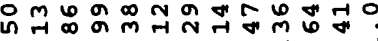
ó $0 \dot{0} i$ i ió i i

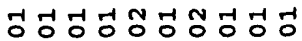

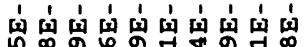

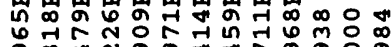
ด皮

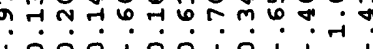

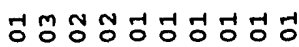

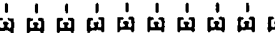

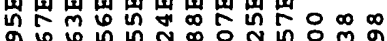

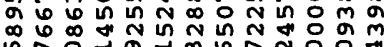

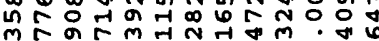

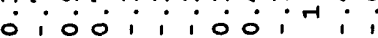

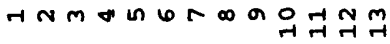




\section{Modified Beale's Measure of Model Linearity--fn._33}

\section{test._33}

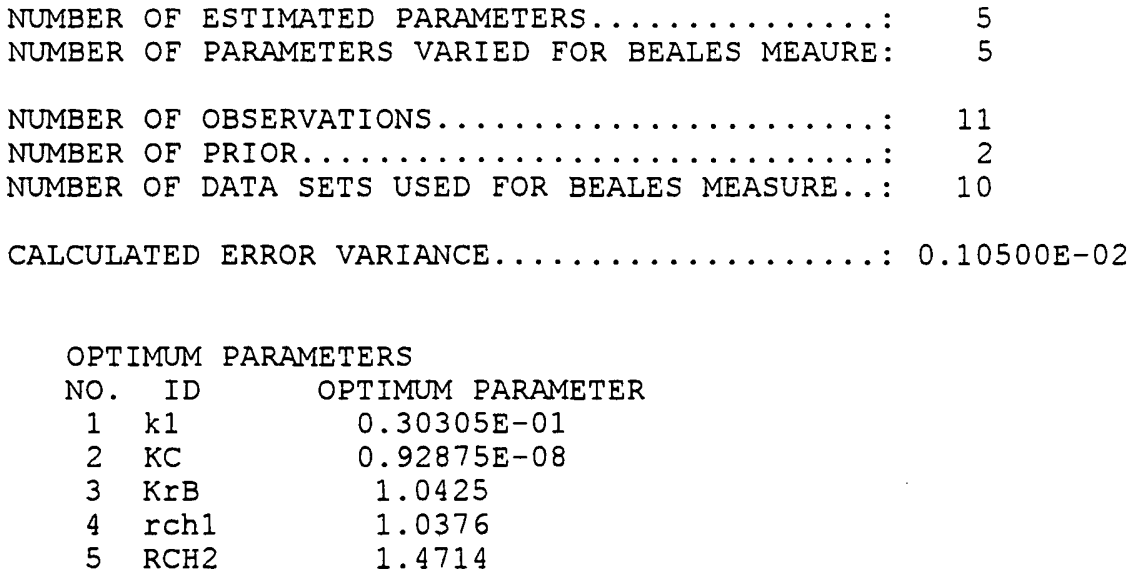




$$
\begin{aligned}
& \text { SENSITIVITIES FOR OPTIMUM PARAMETERS } \\
& \begin{array}{lrrr}
0 & 1 & 2 & 3
\end{array} \\
& \begin{array}{llll}
3 & 4 & 5 & 6
\end{array} \\
& \begin{array}{rlrrrrr}
1 & 0.00000 & -19.499 & -35.549 & -18.349 & -25.849 & -19.724 \\
2 & 0.00000 & -.49971 \mathrm{E}-01 & -.14953 & -.49971 \mathrm{E}-01 & -.49590 \mathrm{E}-01 & -.37498 \\
3 & -.25024 & -.22506 & -.25024 & -.23765 & -.24947 & -.19988 \\
4 & 0.48161 \mathrm{E}-01 & 7.2764 & 10.698 & 6.9150 & 9.1550 & 7.2521 \\
5 & 0.10214 & 9.3954 & 20.082 & 8.7582 & 13.116 & 9.6334 \\
& 7 & 8 & 9 & 10 & 11 &
\end{array} \\
& \begin{array}{rrrccl}
1 & -23.974 & -1.2500 & -37.948 & -46.448 & 0.14901 \mathrm{E}-03 \\
2 & -.29983 & -1.1501 & -.50353 \mathrm{E}-01 & 0.29983 & 0.43510 \mathrm{E}-03 \\
3 & -.22468 & -.24985 & -.25024 & -.19988 & -.15795 \mathrm{E}-02 \\
4 & 8.5050 & 0.57830 & 10.649 & 10.698 & 0.79835 \\
5 & 12.114 & 0.61183 & 22.257 & 30.209 & 0.77582
\end{array}
\end{aligned}
$$

PRIOR NUMBER 1 ESTIMATE(LOG IF LN>0) $=-3.51$, WEIGHT $=16.0$

$\begin{array}{llr}1 & \mathrm{k} 1 & 1.0000 \\ 2 & \mathrm{KC} & 0.00000 \\ 3 & \text { KrB } & 0.00000 \\ 4 & \text { rCh1 } & 0.00000 \\ 5 & \text { RCH2 } & 0.00000 \\ 6 & \text { noestimate } & 0.00000\end{array}$

PRIOR NUMBER 2 ESTIMATE(LOG IF LN>0) $=1.25$, WEIGHT $=4.00$

$\begin{array}{lll}1 & \mathrm{k1} & 0.00000 \\ 2 & \mathrm{KC} & 0.00000 \\ 3 & \text { KrB } & 0.00000 \\ 4 & \text { rCh1 } & 0.50000 \\ 5 & \text { RCH2 } & 0.50000 \\ 6 & \text { noestimate } & 0.00000\end{array}$

PARAMETER

NUMBER LN

$\begin{array}{ll}1 & 1 \\ 2 & 1 \\ 3 & 1 \\ 4 & 0 \\ 5 & 0 \\ 6 & 1\end{array}$

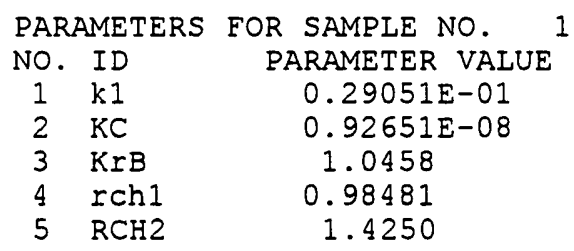

DEPENDENT VARIABLES COMPUTED FOR SAMPLE NO. 1

$\begin{array}{rlr}\text { NO. } & \text { ID } & \text { "SIMULATED" } \\ 1 & 1 \mathrm{~A} & 100.21 \\ 2 & 1 \mathrm{~B} & 121.46 \\ 3 & 1 \mathrm{C} & 140.96 \\ 4 & 1 \mathrm{D} & 120.15 \\ 5 & 1 \mathrm{E} & 128.89 \\ 6 & 2 \mathrm{~A} & 121.79 \\ 7 & 2 \mathrm{~B} & 126.75 \\ 8 & 2 \mathrm{C} & 101.49 \\ 9 & 2 \mathrm{D} & 144.14 \\ 10 & 2 \mathrm{E} & 156.01 \\ 11 & \text { flOW } & 1.8981\end{array}$

IINEARIZED DEPENDENT VARIABLES COMPUTED FOR SAMPLE NO. 1 NO. ID "IINEARIZED" DEPENDENT VARIABLES

1 IA 100.21 


$\begin{array}{rll}2 & 1 B & 121.48 \\ 3 & 1 C & 141.01 \\ 4 & 1 D & 120.17 \\ 5 & 1 \mathrm{E} & 128.92 \\ 6 & 2 \mathrm{~A} & 121.82 \\ 7 & 2 \mathrm{~B} & 126.78 \\ 8 & 2 \mathrm{C} & 101.49 \\ 9 & 2 \mathrm{D} & 144.20 \\ 10 & 2 \mathrm{E} & 156.07 \\ 11 & \text { flow } & 1.8980\end{array}$

PARAMETERS FOR SAMPLE NO.

2

$\star \star \star * *$ SIMILAR ANALYSES ARE PRESENTED FOR SAMPLES 2 THROUGH $10 * \star \star \star * *$

USING FSTAT $=4.8200 \quad$ BEALES MEASURE $=0.78238 \mathrm{E}-01$

IF BEALES MEASURE IS GREATER THAN 0.21 , THE MODEL IS NONLINEAR.

IF BEALES MEASURE IS LESS THAN 0.19E-01, THE MODEL IS EFFECTIVELY LINEAR,

AND LINEAR CONFIDENCE INTERVALS ARE FAIRLY ACCURATE IF THE RESIDUALS ARE NORMALLY DISTRIBUTED.

THE FOLLOWING TABLE SHOWS VALUES OF THE STATISTIC DESCRIBED BY COOLEY AND NAFF (1990, P.174, TOP OF RIGHT COLUMN). THE STATISTIC EQUALS THE NONLINEAR SUM OF SQUARED ERRORS EVALUATED FOR EACH DATA SET (NSSE) MINUS THE SUM OF SQUARED ERRORS FOR THE OPTIMUM PARAMETER VALUES ( $0.840 E-02)$.

IF THE MODEI IS LINEAR, THE STATISTIC SHOULD BE CLOSE TO $0.253 E-01$.

IF THE CORRELATIONS BETWEEN PARAMETERS IS SMALI, THE TABLE SHOWS WHICH INDIVIDUAL PARAMETERS ARE MOST NONLINEAR. THE FIRST PAIR OF PARAMETER SETS ARE RELATED TO THE FIRST PARAMETER, THE SECOND PAIR ARE RELATED TO THE SECOND PARAMTER, AND SO ON.

\begin{tabular}{cccrr}
$\begin{array}{c}\text { PARAMETER } \\
\text { SET }\end{array}$ & NSSE & STATISTIC & \multicolumn{1}{c}{$\begin{array}{l}\text { STATISTIC } \\
-0.253 \mathrm{E}-01\end{array}$} & \multicolumn{1}{c}{$\begin{array}{c}\text { PERCENT } \\
\text { DIFFERENCE }\end{array}$} \\
1 & $0.679 \mathrm{E}-01$ & $0.595 \mathrm{E}-01$ & $0.342 \mathrm{E}-01$ & 135.21 \\
2 & $0.386 \mathrm{E}-01$ & $0.302 \mathrm{E}-01$ & $0.492 \mathrm{E}-02$ & 19.43 \\
3 & $0.395 \mathrm{E}-01$ & $0.311 \mathrm{E}-01$ & $0.575 \mathrm{E}-02$ & 22.73 \\
4 & $0.319 \mathrm{E}-01$ & $0.235 \mathrm{E}-01$ & $-0.176 \mathrm{E}-02$ & -6.94 \\
5 & $0.398 \mathrm{E}-01$ & $0.314 \mathrm{E}-01$ & $0.613 \mathrm{E}-02$ & 24.23 \\
6 & $0.231 \mathrm{E}-01$ & $0.147 \mathrm{E}-01$ & $-0.106 \mathrm{E}-01$ & -41.82 \\
7 & $0.549 \mathrm{E}-01$ & $0.465 \mathrm{E}-01$ & $0.212 \mathrm{E}-01$ & 83.82 \\
8 & $0.354 \mathrm{E}-01$ & $0.270 \mathrm{E}-01$ & $0.171 \mathrm{E}-02$ & 6.77 \\
9 & $0.727 \mathrm{E}-01$ & $0.643 \mathrm{E}-01$ & $0.390 \mathrm{E}-01$ & 154.22 \\
10 & $0.381 \mathrm{E}-01$ & $0.297 \mathrm{E}-01$ & $0.441 \mathrm{E}-02$ & 17.44
\end{tabular}

\title{
Output File for Predictions and Their Linear Confidence and Prediction Intervals-fn._44
}

\author{
test._44 \\ UCODE PHASE .............. $=44$ \\ NUMBER OF ESTIMATED PARAMETERS = 5 \\ NUMBER OF OBSERVATIONS ...... = 11 \\ NUMBER OF PRIOR INFORMATION... = 2 \\ DEGREES OF FREEDOM.......... $=8$ \\ VARIANCE-COVARIANCE MATRIX FOR ESTIMATED PARAMETERS \\ 0 \\ 1 \\ 3 \\ 4 \\ 5 \\ $\begin{array}{lllllll}1 & 0.74045 \mathrm{E}-04 & 0.42267 \mathrm{E}-05 & -.55560 \mathrm{E}-05 & 0.92544 \mathrm{E}-04 & 0.81395 \mathrm{E}-04 \\ 2 & 0.42267 \mathrm{E}-05 & 0.60744 \mathrm{E}-03 & -.12922 \mathrm{E}-02 & -.21461 \mathrm{E}-05 & -.61076 \mathrm{E}-05 \\ 3 & -.55560 \mathrm{E}-05 & -.12922 \mathrm{E}-02 & 0.71509 \mathrm{E}-02 & 0.18228 \mathrm{E}-03 & -.16903 \mathrm{E}-04 \\ 4 & 0.92544 \mathrm{E}-04 & -.21461 \mathrm{E}-05 & 0.18228 \mathrm{E}-03 & 0.13262 \mathrm{E}-03 & 0.95503 \mathrm{E}-04 \\ 5 & 0.81395 \mathrm{E}-04 & -.61076 \mathrm{E}-05 & -.16903 \mathrm{E}-04 & 0.95503 \mathrm{E}-04 & 0.92664 \mathrm{E}-04\end{array}$
}




\begin{tabular}{|c|c|c|c|c|c|}
\hline 0 . & ID & VALUE & DEV. & CONFIDENCE & INTERVAL \\
\hline 1 & head stream & 100.135 & $0.119112 \mathrm{E}-01$ & 100.099 & 100.171 \\
\hline 2 & head_center & 136.783 & $0.577290 E-01$ & 136.607 & 136.959 \\
\hline 3 & upper_flow & 0.762555 & $0.914431 E-02$ & 0.734726 & $; 0.79038$ \\
\hline
\end{tabular}

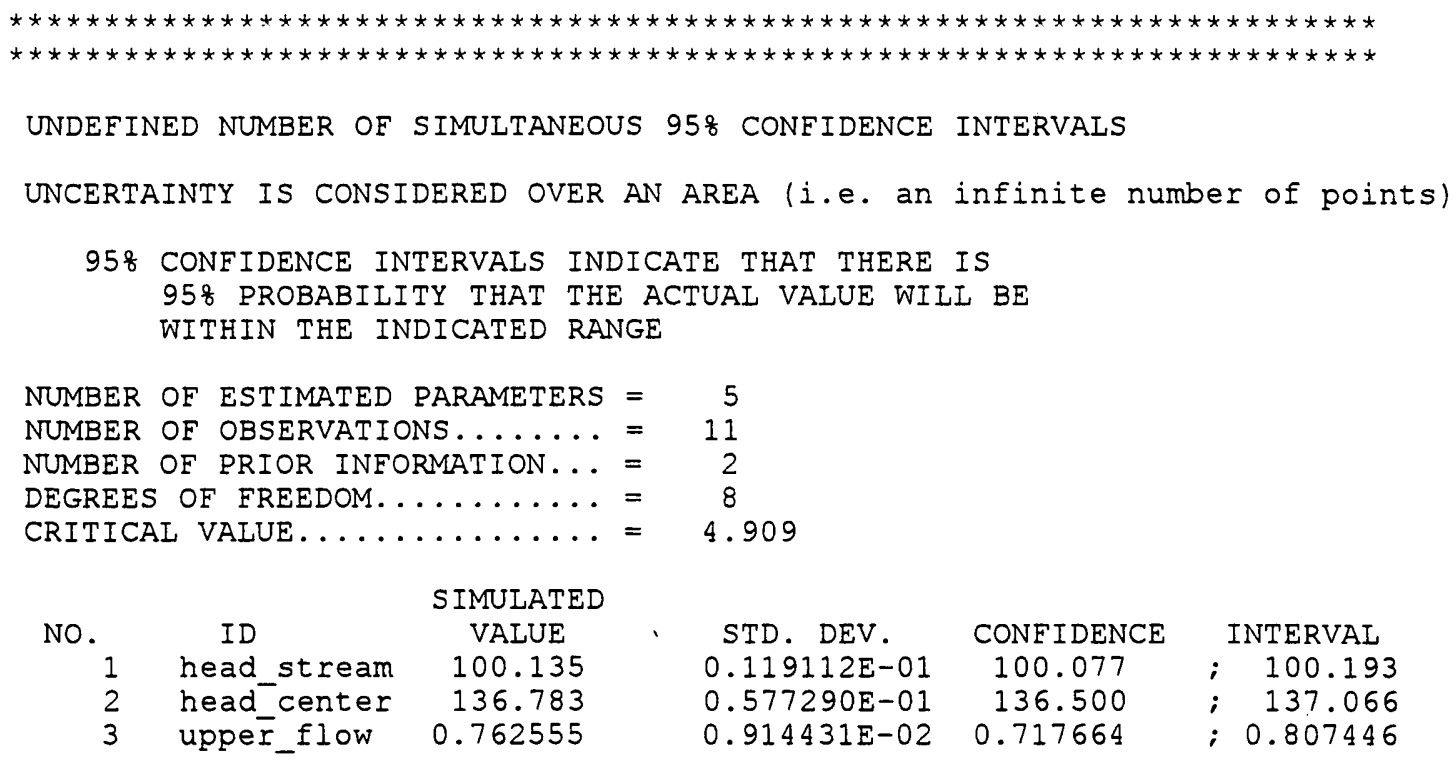


PREDICTION INTERVALS INCLUDE MEASUREMENT ERROR,

I.E. GIVEN THE VARIANCE NOTED IN fn. U44,

THERE IS A $95 \%$ PROBABILITY THAT THE MEASUREMENT

WILL FALL WITHIN THE INDICATED RANGE

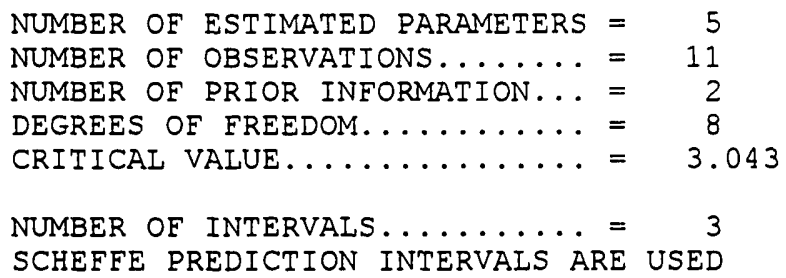

STD. DEV.

$0.257884 \mathrm{E}-01$

$0.620951 \mathrm{E}-01$

$0.274458 \mathrm{E}-01$
PREDICTION INTERVAI

$100.057 ; 100.213$

$136.594 ; 136.972$

$0.679028 ; 0.846082$

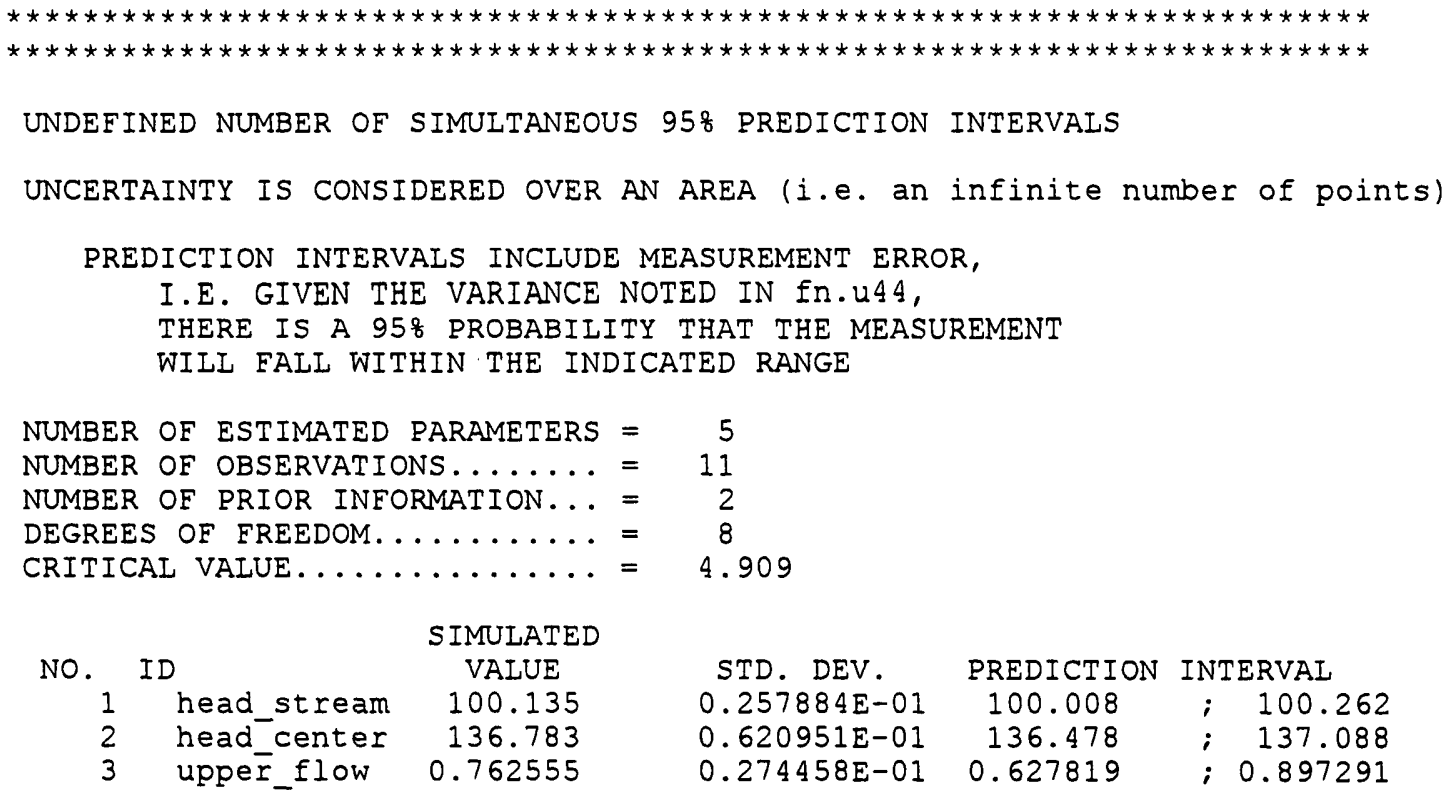

$$
0.620951 \mathrm{E}-01
$$$$
\text { STD. DEV. }
$$$$
0.257884 \mathrm{E}-01
$$$$
0.274458 \mathrm{E}-01
$$

PREDICTION INTERVAI

$\begin{array}{rlr}100.008 & ; & 100.262 \\ 136.478 & ; & 137.088 \\ 0.627819 & ; & 0.897291\end{array}$

\section{Output File for Differences and Their Linear Confidence and Prediction Intervals--fn._45}

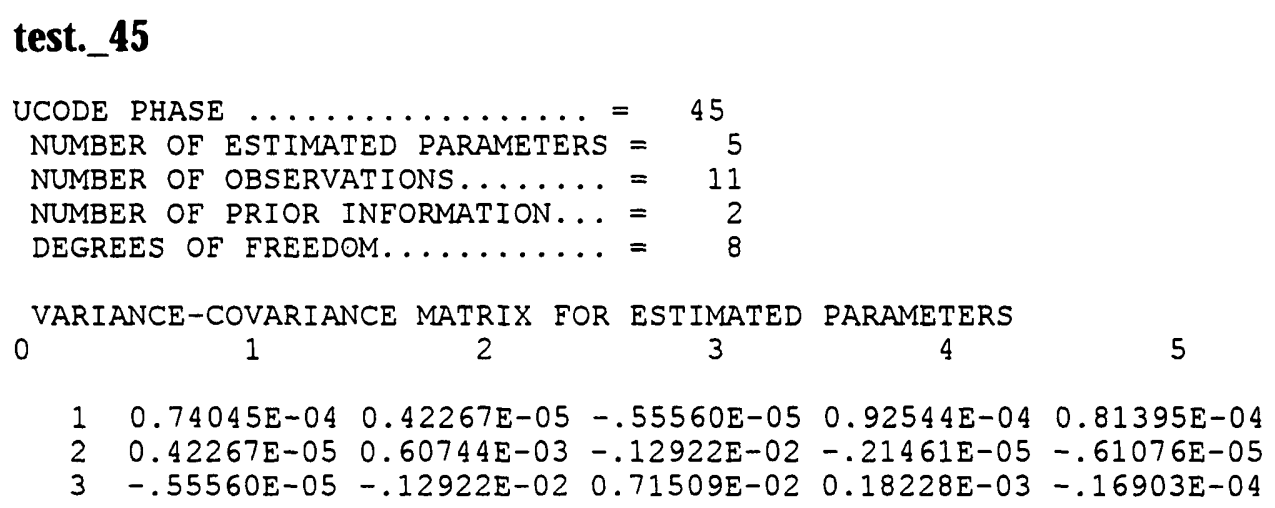




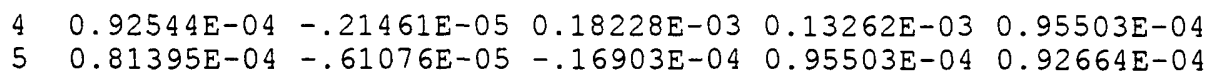

VALUES COMPUTED WITH OPTIMUM PARAMETERS FOR PREDICTIVE CONDITIONS AND ASSOCIATED IDS

\begin{tabular}{|c|c|c|}
\hline $\begin{array}{c}\text { NO. } \\
1 \\
2 \\
3\end{array}$ & $\begin{array}{l}\text { ID } \\
\text { head_stream } \\
\text { head_center } \\
\text { upper flow }\end{array}$ & $\begin{array}{l}\text { VAIUE } \\
100.14 \\
136.78 \\
0.76256\end{array}$ \\
\hline
\end{tabular}

SENSITIVITIES FOR OPTIMUM PARAMETERS FOR PREDICTIVE CONDITIONS

\begin{tabular}{llrl}
0 & \multicolumn{1}{c}{1} & 2 & \multicolumn{1}{c}{3} \\
1 & $-.49971 \mathrm{E}-01$ & -31.399 & $-.36000 \mathrm{E}-02$ \\
2 & $-.49971 \mathrm{E}-01$ & 0.00000 & $-.27507 \mathrm{E}-02$ \\
3 & -.14991 & -.15029 & $-.23990 \mathrm{E}-02$ \\
4 & $0.48161 \mathrm{E}-01$ & 10.698 & 0.45634 \\
5 & 0.10188 & 22.325 & 0.44348
\end{tabular}

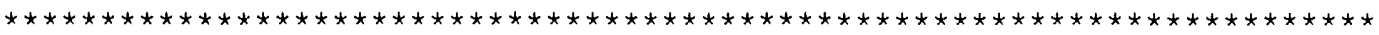

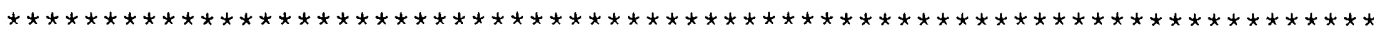

INDIVIDUAL 95\% CONEIDENCE INTERVALS ON DIFFERENCES BETWEEN PREDICTIVE AND BASE CASES

UNCERTAINTY ON EACH DIFFERENCE IS CONSIDERED SEPARATELY IF SIMULTANEOUS UNCERTAINTY IS DESIRED, GO TO NEXT TABLE

95\% CONFIDENCE INTERVALS INDICATE THAT THERE IS $95 \%$ PROBABILITY THAT THE ACTUAL VALUE WILI BE WITHIN THE INDICATED RANGE

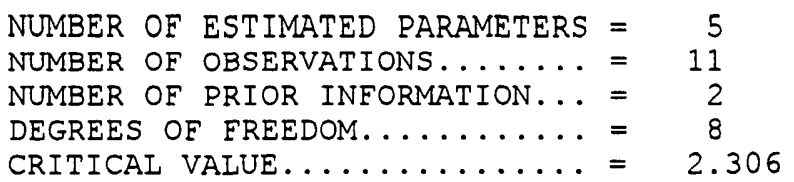

\begin{tabular}{clcccc}
\multicolumn{9}{c}{ SIMULATED } & & \\
No. ID & DIFFERENCE & STD. DEV. & CONFIDENCE & INTERVAL \\
1 & head_stream & $-0.820007 \mathrm{E}-01$ & $0.931183 \mathrm{E}-02$ & -0.103474 & $;-0.605276 \mathrm{E}-01$ \\
2 & head_center & -7.54599 & $0.580505 \mathrm{E}-01$ & -7.67985 & $;-7.41213$ \\
3 & upper_flow & -0.366685 & $0.946575 \mathrm{E}-04$ & -0.366903 & $;-0.366467$
\end{tabular}

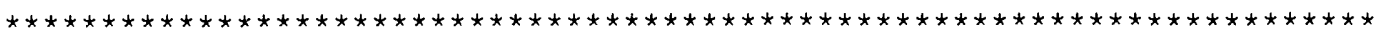

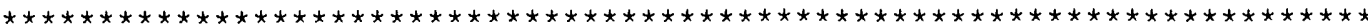

3 SIMULTANEOUS 95\% CONFIDENCE INTERVALS ON DIFFERENCES 
BETWEEN PREDICTIVE AND BASE CASES

UNCERTAINTY ON EACH DIFFERENCE IS CONSIDERED JOINTLY

IF UNCERTAINTY OVER AN AREA IS DESIRED, GO TO NEXT TABLE

$95 \%$ CONFIDENCE INTERVALS INDICATE THAT THERE IS

95\% PROBABILITY THAT THE ACTUAL VALUE WILL BE WITHIN THE INDICATED RANGE

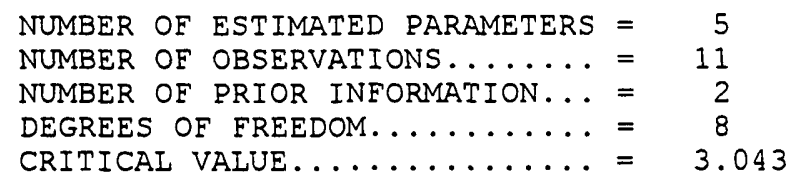

\begin{tabular}{|c|c|c|c|c|c|}
\hline & & SIMULATED & & & \\
\hline $\begin{array}{c}\text { No. } \\
1 \\
2 \\
3\end{array}$ & $\begin{array}{l}\text { ID } \\
\text { head_stream } \\
\text { head_center } \\
\text { upper flow }\end{array}$ & $\begin{array}{l}\text { DIFFERENCE } \\
-0.820007 \mathrm{E}-01 \\
-7.54599 \\
-0.366685\end{array}$ & $\begin{array}{c}\text { STD. DEV. } \\
0.931183 \mathrm{E}-02 \\
0.580505 \mathrm{E}-01 \\
0.946575 \mathrm{E}-04\end{array}$ & $\begin{array}{c}\text { CONFIDENCE } \\
-0.110340 \\
-7.72266 \\
-0.366973\end{array}$ & $\begin{array}{l}\text { INTERVAL } \\
\quad ;-0.536617 \mathrm{E}-01 \\
\quad ;-7.36932 \\
;-0.366397\end{array}$ \\
\hline
\end{tabular}

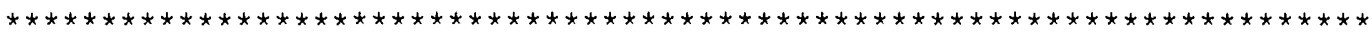

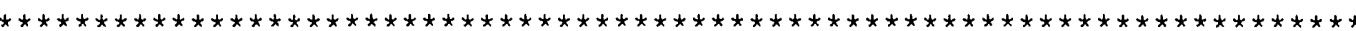

UNCERTAINTY IS CONSIDERED OVER AN AREA (i.e. an infinite number of points)

$95 \%$ CONFIDENCE INTERVALS INDICATE THAT THERE IS 95\% PROBABIIITY THAT THE ACTUAL VALUE WILL BE WITHIN THE INDICATED RANGE

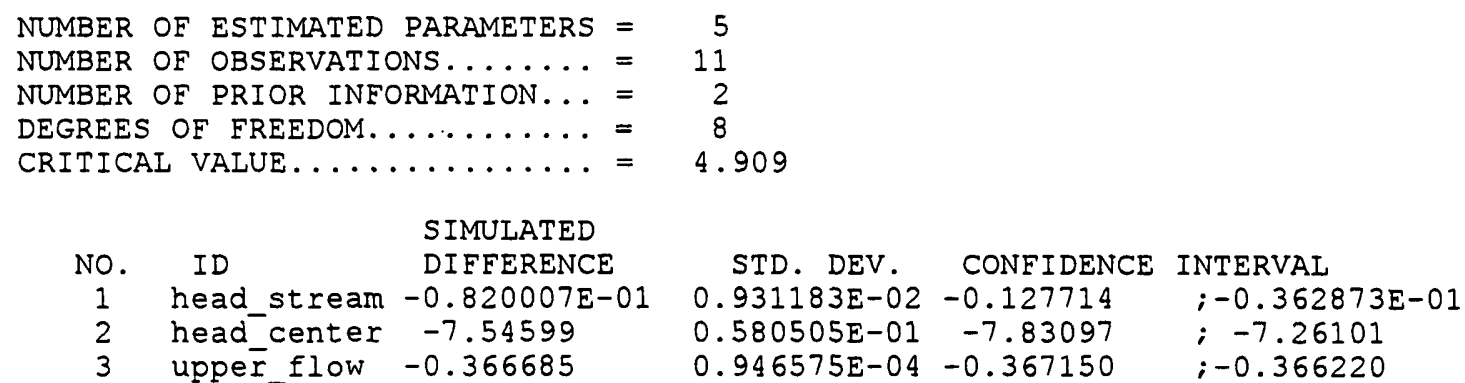

NUMBER OF ESTIMATED PARAMETERS $=5$ 


$$
\begin{aligned}
& \text { NUMBER OF OBSERVATIONS....... = } 11 \\
& \text { NUMBER OF PRIOR INFORMATION... = } 2 \\
& \text { DEGREES OF FREEDOM......... }=8 \\
& \text { CRITICAL VALUE............. = } 2.306
\end{aligned}
$$

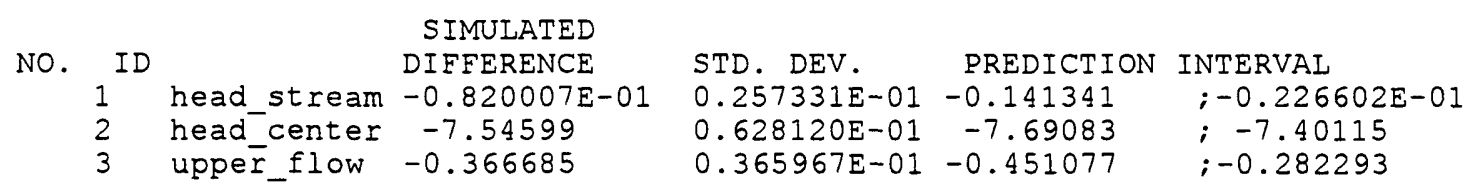

$\begin{array}{lllll}\text { head_center } & -7.54599 & 0.628120 \mathrm{E}-01 & -7.69083 & ;-7.40115 \\ \text { upper_flow }-0.366685 & 0.365967 \mathrm{E}-01-0.451077 & ;-0.282293\end{array}$

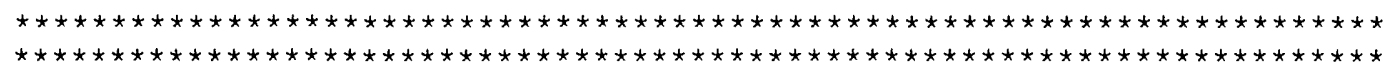

3 SIMULTANEOUS $95 \%$ PREDICTION INTERVALS ON DIFFERENCES BETWEEN PREDICTIVE AND BASE CASES

UNCERTAINTY ON EACH DIFFERENCE IS CONSIDERED JOINTLY IF UNCERTAINTY OVER AN AREA IS DESIRED, GO TO NEXT TABLE

PREDICTION INTERVALS INCLUDE MEASUREMENT ERROR,

I.E. GIVEN THE VARIANCE NOTED IN fn.u45,

THERE IS A 95\% PROBABILITY THAT THE MEASUREMENT

WILL FAIL WITHIN THE INDICATED RANGE

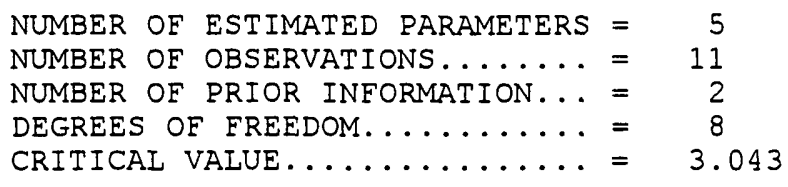

NUMBER OF INTERVALS ......... $=3$ SCHEFFE PREDICTION INTERVALS ARE USED

\begin{tabular}{lllll} 
NO. ID & \multicolumn{1}{c}{ SIMULATED } \\
DIFFERENCE & STD. DEV. & PREDICTION INTERVAL \\
1 & head_stream $-0.820007 \mathrm{E}-01$ & $0.257331 \mathrm{E}-01$ & -0.160315 & $;-0.368632 \mathrm{E}-02$ \\
2 & head_center -7.54599 & $0.628120 \mathrm{E}-01$ & -7.73715 & -7.35483 \\
3 & upper_flow -0.366685 & $0.365967 \mathrm{E}-01$ & -0.478061 & $;-0.255309$
\end{tabular}

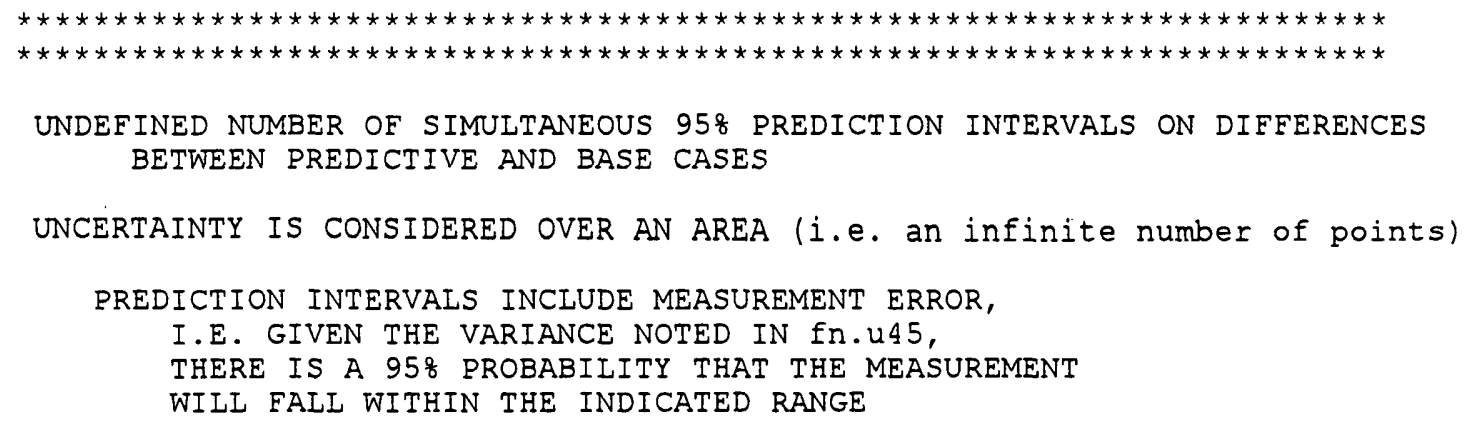

\begin{tabular}{|c|c|c|}
\hline NUMBER OF & ESTIMATED PARAMETERS & $=$ \\
\hline NUMBER OF & OBSERVATIONS. & $=$ \\
\hline NUMBER OF & PRIOR INFORMATIOI & $=$ \\
\hline DEGREES O & EREEDOM. & $=$ \\
\hline CRITICAI & LUE & $=$ \\
\hline
\end{tabular}

UNCERTAINTY IS CONSIDERED OVER AN AREA (i.e. an infinite number of points)

PREDICTION INTERVALS INCLUDE MEASUREMENT ERROR, I.E. GIVEN THE VARIANCE NOTED IN fn. U45, THERE IS A 95\% PROBABILITY THAT THE MEASUREMENT WILI FALL WITHIN THE INDICATED RANGE

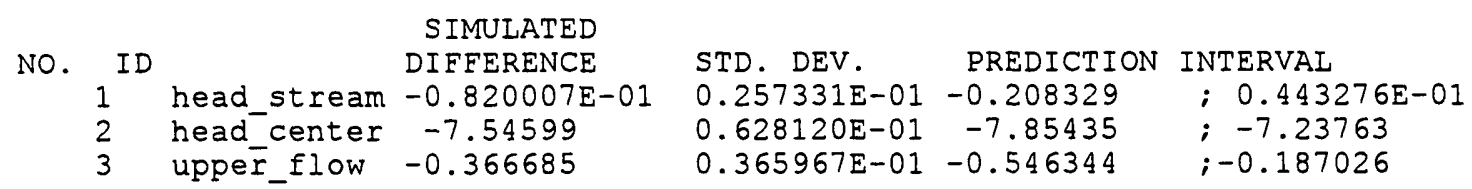


Output Files for PHASE=11 -fn._11

\section{test._11}

$3 . e-03-2.52297198276396 \quad 0.2-0.698995836019153 .25397 .765417 .00$

$\begin{array}{llllllll}0.03 & -1.52293502598045 & 0.2 & -0.698995836019153 & .2 & 15769.4 & 15772.6\end{array}$

$\begin{array}{lllllll}0.3 & -0.522898069196932 & 0.2 & -0.698995836019153 & .2 & 22481.2 & 22500.4\end{array}$

3.e-03 $-2.52297198276396 \quad 2 \quad 0.301041120764363 \quad .25343 .60 \quad 5362.84$

$0.03-1.5229350259804520 .301041120764363 \quad .2 \quad 15997.0 \quad 16000.2$

$0.3-0.52289806919693220 .301041120764363 .222769 .822789 .0$

$3 . e-03-2.5229719827639620 \quad 1.30107807754788 .2 \quad 5337.45 \quad 5356.69$

$0.03-1.5229350259804520 \quad 1.30107807754788 \quad .2 \quad 16016.0 \quad 16019.2$

$0.3-0.52289806919693220 \quad 1.30107807754788 \quad .222798 .822818 .1$

$3 . e-03-2.52297198276396 \quad 0.2 \quad-0.698995836019153 \quad 20 \quad 0.403955 \mathrm{E}+08 \quad 0.403958 \mathrm{E}+08$

$\begin{array}{lllllllll}0.03 & -1.52293502598045 & 0.2 & -0.698995836019153 & 20 & 0.174002 \mathrm{E}+07 & 0.174034 \mathrm{E}+07\end{array}$

$\begin{array}{lllllllll}0.3 & -0.522898069196932 & 0.2 & -0.698995836019153 & 20 & 4403.67 & 4743.67\end{array}$

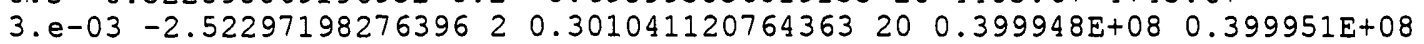

$\begin{array}{lllllllll}0.03 & -1.52293502598045 & 2 & 0.301041120764363 & 20 & 0.166118 \mathrm{E}+07 & 0.166151 \mathrm{E}+07\end{array}$

$0.3-0.52289806919693220 .30104112076436320 \quad 1551.31 \quad 1891.31$

test._lb

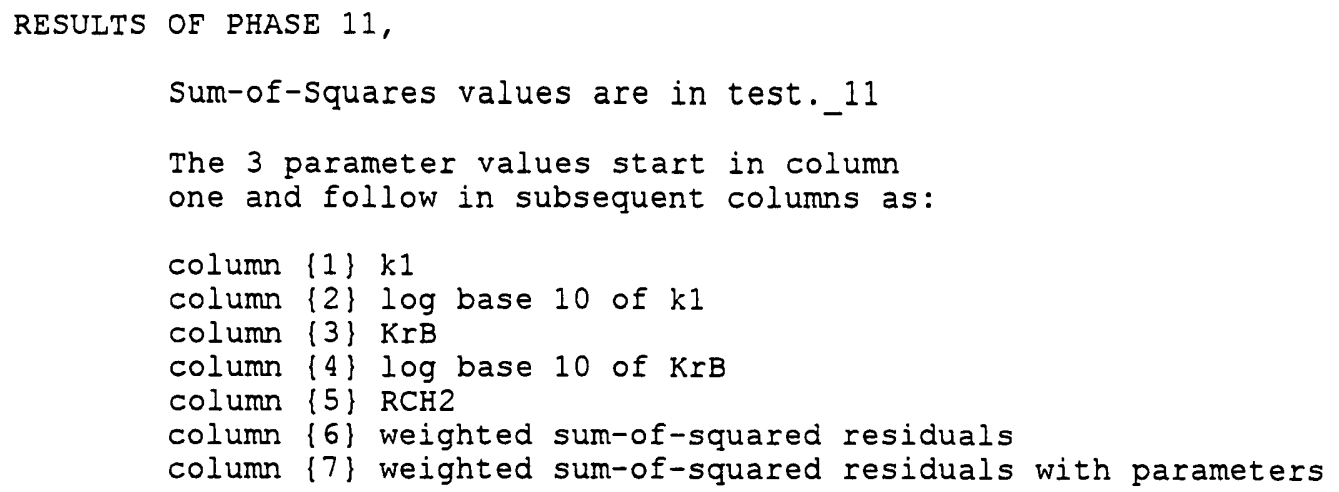




\section{APPENDIX B: DISTRIBUTION, COMPILING, PORTABILITY, AND SPACE ISSUES}

\section{Distributed Files and Directories}

UCODE can be downloaded from the internet site listed in the preface. To use UCODE, the paths for ucode and perl need to be specified in the run command, or the paths need to be specified in the autoexec.bat file for a DOS or Windows operating system, in the profile file for a UNIX operating system, or in an analogous file for other operating systems.

\section{Compiling and Loading}

1. If needed, compile and load the application model(s).

2. The executable for MRDRIVE distributed with UCODE was compiled either on a PC using or an RS6000. If this executable cannot be used, compile and link the ten files for mrdrive, which are: mrdrive.f, mrcall.f, sns.f, prm.f, spr.f, sjz.f, resanp.f, beale.f, ut.f, and ycint.f

3. perl may already be on your computer. If not, either use the copy provided with UCODE or download the appropriate version. Copies can be retrieved from http://www.perl:com/perl/ and are available for most operating systems (UNIX, DOS, SUNOS, and so on).

\section{Portability}

MRDRIVE is written in Fortran90, so is highly portable. MRDRIVE is nearly compatible with Fortran77, and could be converted if needed.

UCODE is written in perl. Perl is designed to be highly portable provided the appropriate perl executable for your platform is anywhere on the computer. The command line needed to run UCODE depends on the location of the perl executable.

\section{Space Requirements}

Approximately $4 \mathrm{Mb}$ is required to load version 1.0 of UCODE including source, executable, interpreter, example files and documentation in the form of PDF files. Additional disk 
space is needed for the user's application code(s), associated input files, and the UCODE template files.

\section{APPENDIX C: PROGRAM DESCRIPTION}

\section{UCODE Programs and Subroutines and Their Tasks}

UCODE (written in perl; named as Universal inverse CODE)

*substitutes base parameter values using model input file templates

*executes application code(s) (in any language) for starting parameter values

*extracts model calculated values and combines them to obtain equivalent simulated values corresponding to observations in the regression

* perturbs parameter values; generates and substitutes parameter values into template files for model runs needed to calculate sensitivities

*extracts model calculated values and combines them to obtain equivalent simulated values corresponding to observations in the regression

*executes MRDRIVE

*reads regression results from MRDRIVE output, writes them to UCODE output, *performs convergence testing; if not converged, continues to iterate until convergence or maximum number of iterations; if converged, calls MRDRIVE for final parameter value statistics.

*closes files and stops

MRDRIVE (written in Fortran90; named as Multiple Regression DRIVEr):

mrdrive.f reads universal data, sets up variable dimensions and calls mrcall.f

mrcall.f reads UCODE scratch files, and calls subroutines in sns.f, prm.f, spr.f, and/or sjz.f, as appropriate

sns.f calculates sensitivities by forward or central finite-difference

prm.f performs regression by modified Gauss-Newton method; nearly identical to subroutine PAR1AP of MODFLOWP (Hill, 1992) 
sjz.f calculates and prints residual statistics; nearly identical to subroutine SSEN1O of MODFLOWP (Hill, 1992)

spr.f subroutines called by prm.f for calculation and printing of final statistics

ut.f controls printing and calculates statistics

resanp.f produces sample sets of residuals for testing the possibility that residuals are correlated due to the fitting process of the regression

bealep.f calculates measures of model linearity

ycint.f calculates confidence and prediction intervals on predictions

\section{Scratch Files}

Scratch files created by UCODE include u9_zscr.1 through u9_zscr.19, and u9_zscr.44 and $u 9$ zscr.45. If the scratch file names used by UCODE exist in the directory where UCODE is executed, these files could be overwritten when UCODE is executed. The scratch files are deleted at the end of the main perl program, UCODE. To retain these files in the directory, pound signs can be added in UCODE at the beginning of the lines in which scratch files are deleted.

u9_zscr.1 parameter information for backward difference sensitivity calculation: unperturbed parameters, prior information, perturbed parameters, iteration number.

u9_zscr.2 parameter information for forward difference sensitivity calculation: unperturbed parameters, prior information, perturbed parameters, iteration number.

u9_zscr.3 perturbed heads for forward difference sensitivities.

u9_zscr.4 temporary holding file for extracted heads.

u9_zscr.5 unperturbed heads.

u9_zscr.6 temporary holding file for regression output.

u9_zscr.7 parameter values and regression restarting information.

u9_zscr.8 updated parameter values.

u9_zscr.9 maximum fractional change of parameter value during last iteration.

u9_zscr.10 jmax, ap, dmx values needed to start subsequent iteration.

u9_zscr.11 perturbed heads for backward difference sensitivities.

u9_zscr.12 flag for final convergence to indicate need for central difference sensitivities at final parameter values. 
u9_zscr.13 modified fn.uni information for input to MRDRIVE

u9_zscr.14 temporary holding file for regression output

u9_zscr.15 temporary holding file for regression history information

u9_zscr.16 temporary holding file for sum-of-squared weighted residuals

u9_zscr.17 temporary holding file for $\mathrm{R}, \mathrm{G}$, and $\mathrm{X}$ matrices for quasi-Newton updating

u9_zscr.18 temporary holding file for DD matrix for quasi-Newton updating

u9_zscr.19 temporary holding file for summary information from each parameter iteration

u9_zscr.44 holding file for regression output that is not needed for phase 44

u9_zscr.45 holding file for regression output that is not needed for phase 45 